\title{
Assessment of Proposed Calibration Support for the Analog Instrumentation Functions in the Integirated Family of Test Equipment (IFTE) Systems
}

B. A. Bell

N. M. Oldham

P. S. Hetrick

U.S. DEPARTMENT OF COMMERCE Technology Administration National Institute of Standards and Technology

Gaithersburg, MD 20899

Prepared for: U.S. Army TMDE Support Activity Redstone Arsenal, AL 358985400 



\section{Assessment of Proposed Calibration Support for the Analog Instrumentation Functions in the Integrated Family of Test Equipment (IFTE) Systems}

\section{B. A. Bell \\ N. M. Oldham \\ P. S. Hetrick}

U.S. DEPARTMENT OF COMMERCE Technology Administration

National Institute of Standards and Technology

Gaithersburg, MD 20899

Prepared for.

U.S. Army TMDE Support Activity Redstone Arsenal, AL 35898-5400

November 1992

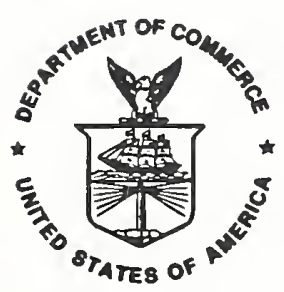

U.S. DEPARTMENT OF COMMERCE Barbara Hackman Frankilin, Secretary

TECHNOLOGY ADMINISTRATION

Robert M. White, Under Secretary for Technology

NATIONAL INSTITUTE OF STANDARDS

AND TECHNOLOOY

John W. Lyons, Diractor 

Table of Contents

page

List of Figures . . . . . . . . . . . . . . . . . . . . . . iii

List of Tables . . . . . . . . . . . . . . . . . . . . . v v

Executive Summary . . . . . . . . . . . . . . . . . . . . . . vi

Abstract . . . . . . . . . . . . . . . . . . . . . . 1

1. Introduction . . . . . . . . . . . . . . . . . . . . . 1

2. List of Commonly Used Acronyms . . . . . . . . . . . . . . . 5

3. Assessment of the Self-Alignment Interconnect Device . . . . . . . 6

4. Assessment of the Digital Multimeter . . . . . . . . . . . . . . 10

5. Assessment of the Three-Function Board Instruments . . . . . . . . . 21

6. Test Results and Analysis . . . . . . . . . . . . . . . . . . . 45

7. Summary and Recommendations . . . . . . . . . . . . . . . 67

8. Acknowledgements . . . . . . . . . . . . . . . . . 67

9. References . . . . . . . . . . . . . . . . . . . . 68

Appendix A - Tolerance Analysis of the DC Reference Voltages in the
Self-Alignment ICD . . . . . . . . . . . . . . . . . 70

Appendix B - RMS Value vs. Waveform Parameters . . . . . . . . . . . . . 74

Appendix C - Harmonic Analysis . . . . . . . . . . . . . . . . . . 77

Appendix D - Tables of Test Data . . . . . . . . . . . . . . . 81

Appendix E - Specification Sheets . . . . . . . . . . . . . . . . 87 

Figure 1. Interconnect device (ICD) used for self-alignment

standards . . . . . . . . . . . . . . . . . .

Figure 2. Interconnections between self-alignment ICD and the IFTE analog instrument functions via the "Gold Dot" panel and the Switching Distribution System (SDS) . . . . . . . . . . 11

Figure 3. Errors caused by two-point ( 0 and $18 \mathrm{~V}$ ) alignment procedure of the DMM on the $100 \mathrm{~V}$ range . . . . . . . . . . . . 14

Figure 4. Measured error of IFTE counter-timer vs. period . . . . . . 48

Figure 5. Measured error of IFTE counter-timer vs. pulse-width . . . 48

Figure 6. Measured error of IFTE counter-timer vs. phase angle at $1 \mathrm{kHz}$................. . . 51

Figure 7. Measured error of IFTE counter-timer vs. phase angle at $100 \mathrm{kHz}$. . . . . . . . . . . . . . . . 51

Figure 8. Measured error of IFTE digitizer vs. frequency for

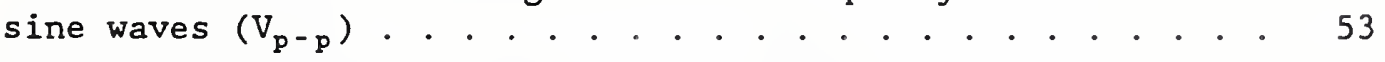

Figure 9. Measured error of IFTE digitizer vs. frequency for

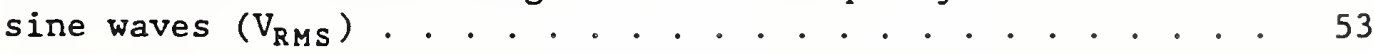

Figure 10. Measured error of IFTE digitizer vs. frequency for

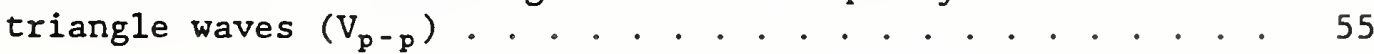

Figure 11. Measured error of IFTE digitizer vs. frequency for

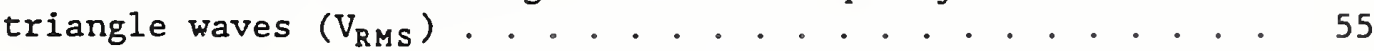

Figure 12. Measured error of IFTE digitizer vs. frequency for square waves $\left(\mathrm{V}_{\mathrm{p}-\mathrm{p}}\right) . . . . . . . . . .456$

Figure 13. Measured error of IFTE arbitrary function generator vs. frequency for pulsed dc $\left(3.5 \mathrm{v}_{\mathrm{p}-\mathrm{p}}\right)$. . . . . . . . . . 56

Figure 14. Measured error of IFTE arbitrary function generator vs. frequency for pulsed dc $\left(350 \mathrm{mV}_{\mathrm{p}-\mathrm{p}}\right)$. . . . . . . . 58

Figure 15. Measured error of IFTE arbitrary function generator vs. frequency for pulsed dc $\left(35 \mathrm{mV}_{\mathrm{p}-\mathrm{p}}\right)$. . . . . . . . 58

Figure 16. Measured error of IFTE arbitrary function generator vs. frequency for square waves $\left(7.0 \mathrm{v}_{\mathrm{p}-\mathrm{p}}\right)$ 
List of Figures (continued)

page

Figure 17. Measured error of IFTE arbitrary function generator vs. frequency for square waves $\left(700 \mathrm{mV}_{\mathrm{p}-\mathrm{p}}\right)$. . . . . . .

Figure 18. Measured error of IFTE arbitrary function generator vs. frequency for square waves $\left(70 \mathrm{mV}_{\mathrm{p}-\mathrm{p}}\right) . . . . . .$. . .

Figure 19. Measured error of IFTE arbitrary function generator

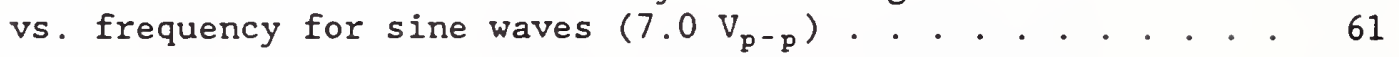

Figure 20. Measured error of IFTE arbitrary function generator vs. frequency for sine waves $\left(700 \mathrm{mV}_{\mathrm{p}-\mathrm{p}}\right)$. . . . . . . . .

Figure 21. Measured error of IFTE arbitrary function generator vs. frequency for sine waves $\left(70 \mathrm{mV}_{\mathrm{p}-\mathrm{p}}\right)$. . . . . . . . . 62

Figure 22. Measured error of IFTE arbitrary function generator vs. frequency for triangle waves $\left(700 \mathrm{mV}_{\mathrm{p}-\mathrm{p}}\right)$. . . . . . . . 64

Figure 23. Measured error of IFTE arbitrary function generator vs. frequency for triangle waves $\left(70 \mathrm{mV}_{\mathrm{p}-\mathrm{p}}\right)$. . . . . . . 64

Figure 24. Ideal, periodic, bipolar, pulsed-dc waveform and its associated time and amplitude parameters . . . . . . . . . 


\section{List of Tables}

page

Table 1. Error data obtained on the IFTE (SN 017) DMM . . . . . . 45

Table 2. Test data obtained on the self-alignment ICD (SN 009). . . 65

Table 3. Test data obtained on the self-alignment ICD (SN 015) . . . 66 


\section{EXECUTIVE SUMMARY}

This document was prepared as a final report for work carried out by staff in the Electricity Division of NIST, under contract (number A1-0-FQM01-JF-JF) with the U.S. Army Test, Measurement, and Diagnostic Equipment (TMDE) Support Activity, Redstone, AL. It contains an analysis and assessment of the calibration support scheme proposed by the vendor for selected instrumentation functions contained in an automatic test-equipment (ATE) system being procured by the Army.

The introduction (section 1) of this report explains the background for doing the project and an overview of the calibration support approach proposed by the vendor, as determined from engineering literature obtained through the Army. Section 2 lists the commonly used acronyms contained in the report.

Sections 3, 4, and 5 of this report describe an assessment of the calibration support scheme proposed by the vendor for the self-alignment interconnect device, digital multimeter, and three-function board instruments, respectively. Each section of the Calibration/Measurement Requirements Summary (CMRS) associated with each of these instruments is reviewed in detail. Section 6 provides the results of some performance verification tests that were run on a specific ATE system located at the Tobyhanna Army Depot in Tobyhanna, PA.

In general, it was found that the proposed calibration support procedures are not adequate and need to be improved. Shown in bold face type throughout the document are the various key assessment findings and recommended actions. 


\title{
ASSESSMENT OF PROPOSED CALIBRATION SUPPORT FOR THE ANALOG
} INSTRUMENTATION FUNCTIONS IN THE IFTE TEST SYSTEMS

\author{
B.A. Bell, N.M. Oldham, and P.S. Hetrick \\ Final Report \\ Automated Electronic Test Equipment Calibration \\ and Support Strategies Project \\ Electricity Division of NIST \\ for the \\ U.S. Army TMDE Support Activity \\ Redstone Arsenal, AL
}

\begin{abstract}
An assessment is made of the vendor's proposed calibration support for the dc and low frequency analog instrumentation functions in the Integrated Family of Test Equipment (IFTE) systems being procured by the U.S. Army. The report provides a detailed analysis of the calibration support scheme described in the vendor's proposed calibration/measurement requirements summary and related documents for the digital multimeter, counter-timer, high-speed digitizer, and arbitrary function generator instrument functions contained in the commercial equipment equivalent (CEE) version of an IFTE test system. The results of onsite tests made on a CEE IFTE station (SN 017) located at Tobyhanna Army Depot are also given in this report.
\end{abstract}

Keywords: accuracy, calibration, measurement error, performance, selfalignment, software, specification, tolerance

\section{Introduction}

In general, this report addresses the metrology issues associated with various automatic test equipment (ATE) systems, such as the Integrated Family of Test Equipment (IFTE) system, being procured by the U.S. Army. ${ }^{1}$ Under consideration were the calibration requirements, testing methods and strategies, interface devices, accuracy ratios, curve fitting software, impact on Mil stds, and other concerns faced by the Army in attempting to field these types of automatic test systems with adequate metrology support. Funding to perform this task was provided by the U.S. Army Test, Measurement, and Diagnostic Equipment (TMDE) Support Group (now, Activity), Redstone, AL under contract number Al-0-FQM01JF-JF.

${ }^{1}$ In order to describe adequately the systems and tests discussed in this report, commercial equipment and instruments are identified by manufacturer's name and/or model number. In no case does such identification imply recommendation or endorsement by the National Institute of Standards and Technology, nor does it imply that the material or equipment identified is necessarily the best available for the purpose. 
In particular, the effort described in this report concentrates on an analysis of the calibration/measurement requirements summary (CMRS) for the digital multimeter (DMM), counter-timer, high-speed digitizer, and arbitrary function generator instrument functions contained in most versions of the IFTE systems. The adequacy of the proposed calibration procedures and standards needed to assure that these particular functions meet the CMRS are reviewed. Data obtained from on-site performance tests by NIST are provided on the "self-alignment" interconnect devices, and the four instrument functions from CEE IFTE station (SN 017), located at Tobyhanna Army Depot (TOAD), Tobyhanna, PA. The test data are analyzed relative to the CMRS and the system performance specifications. The issue of "self-alignment" software procedures is addressed, vis-a-vis system calibration at the interconnect device (ICD) interface panel. Present NIST research on test methods for DMMs, waveform recorders, and high-speed analogto-digital converters is referenced where appropriate, as well as the work on developing techniques to characterize the performance of counter-timers and programmable arbitrary waveform sources.

\subsection{Background}

NIST staff were minimally involved with the initial development of this system and the associated calibration requirements support back in 1985 [1]. T. F. Leedy had held discussions at that time with the vendor's Vice President for Test Equipment Products, Electronic Systems, who said that "...he would be interested in cooperating with NBS to assure that their systems are 'traceable' and incorporate good metrology practices." A letter dated July 24, 1986, from Lt. Col. L. E. Crapse, Jr., System Manager for Test, Measurement, and Diagnostic Systems in the Training Readiness and Doctrine Command (TRADOC) to C. K. Miller, Chief, Electromagnetic Fields Division of (then) NBS stated that "...The purpose of this letter is to establish a dialog with NBS and solicit your support in resolving user concerns regarding traceability of the IFTE automatic test equipment back to NBS as required by US Code" [2]. Clearly, there was interest in addressing the IFTE calibration issues at that time with staff at (now) NIST. However, the opportunity to accomplish this effort was never realized, probably because of the unavailability of funding to carry out the task.

However, since that time, the Program Manager (PM) for the IFTE system (until 1990 located at the U.S. Army Communication Electronics Command (CECOM) in Fort Monmouth, NJ) has gone ahead with the procurement process for IFTE. Now that prototypes of the IFTE system are being fielded at selected sites for checkout and the development of Test Program Sets (TPSs), the PM is anxious for the U.S. Army TMDE Support Group (USATSG) to give its approval to the calibration support plan proposed by the vendor.

NIST staff visited with the sponsor at the USATSG, Redstone Arsenal, AL in March, 1990, to review the activities and accomplishments expected for the project. Discussions with staff in the Engineering Directorate at USATSG involved the calibration support issues that are of concern regarding the IFTE system. The Army IFTE ATE system is more or less equivalent to the Air Force Modular Automatic Test Equipment (MATE) and the Navy Consolidated Automatic Support System (CASS) systems, i.e., a modular, integrated type of general-purpose tester that can be used for numerous test applications and environments. Initially, the IFTE system was used by the Army for test support of the electronic devices, 
modules, and subassemblies used in the Hawk missile.

The analog and digital measurement functions of the IFTE systems are implemented with "virtual instrument cards" (VICs) that are housed in a chassis and are functionally similar to the requirements of the VXIbus (an extension of the VMEbus, IEEE Std 1014). The VXIbus "instrument-on-a-card" architecture has created a revolution in the packaging of electronic instruments and test equipment. However, this new instrument architecture is having an impact on the way measurement data provided by such modules can be made "traceable" to higher accuracy standards, in the conventional way that benchtop instruments (packaged in a stand-alone chassis) have been. Along with this new architecture, the use of microcomputer technology has allowed the possibility of having the instrument run internal checks and use built-in circuitry (such as zener diode-based dc voltage references) to provide an internal or "self-calibration, "thereby helping to minimize the number of external standards needed to calibrate fully the various measurement functions of the instrument. The question is, however, just how well do these new approaches actually work?

NIST was asked to review the calibration support that has been proposed by the vendor for the IFTE system, and to assess the adequacy of their "self-alignment" approach. In particular, it was agreed that the DMM card and the "threefunction" card (counter-timer, high-speed digitizer, and arbitrary function generator on one board) would be the two VICs on which to focus attention initially. Typically, a rigorous calibration support approach for measurement and stimulus functions like these would require a multifunction calibrator, a spectrum analyzer, and perhaps precision pulse and signal generators, in order to provide a full calibration of the various instrument accuracy specifications. However, a major operational constraint is the need to keep the size of the necessary external standards as small as possible; hence, the concept of incorporating electrical standards in a self-alignment interconnect device (SAICD). The SA-ICD should be as compact as possible in order to accommodate the usage of IFTE in an Army $S 280 \mathrm{C} / \mathrm{G}$ shelter; $i . e$. , the SA-ICD is supposed to have a "small footprint." Also, the cost of the SA-ICD is important since the Army already has a more complete calibration support package, available in the field via the USATSG calibration vans.

During the March, 1990 trip, a brief visit was made to the Maintenance and Testing TPS Development area under the U.S. Army Missile Command (MICOM). A Commercial Equivalent Equipment (CEE) version of an IFTE system (serial number 008) is being used there by MICOM to develop TPSs for the Hawk missile. The system consists of three bays of 19-inch racks with a bench containing a color cathode ray tube (CRT) console and power supplies. Next to the console is the bay with (from top to bottom) the analog VICs, the ICD interface, and the digital VICs. Ancillary equipment is in the next bay, and the $\mathrm{rf} / \mu \mathrm{W}$ bay is on the end, containing a Hewlett Packard microwave signal generator and spectrum analyzer as well as a unit-under-test (UUT) interface for signals up to $22 \mathrm{GHz}$.

In discussions with the Army operators and TPS developers the following comments were obtained:

The $100 \mathrm{MHz}$ bandwidth of the CEE version of the IFTE system is a big advantage over earlier general-purpose testers; 
- The performance of the DMM and the three-function VICs depends to some degree on the slot position in the multicard chassis;

- The IFTE software was difficult to use at first - it just wouldn't do what was claimed; the present version 5.2 is much better;

- Much better testing consistency is obtained with the IFTE than with earlier general-purpose testers.

The Army personnel gave a short demonstration of the self-alignment software that uses color-enhanced, menu-driven screens for easy function identification and diagnosis. When the purpose of the visit was explained to these people, they made it clear that they wanted the "calibration" ICD to have enough in it to allow the soldier to do a "maintenance calibration" on-site. They were adamant that the calibration support should not require any hardware assets of the test station to be removed, even temporarily.

1.2 Calibration Support Approach Proposed by the Vendor for the Analog/Digital Functions

The vendor proposes to provide a special unit-under-test (UUT) self-alignment interconnect device (SA-ICD) that contains the following electrical standards [3]:

1. An $18.000 \pm 0.001$ volt dc reference (10 ppm stability for 30 days).

2. A $1.0000 \pm 0.0005$ volt RMS and $10.000 \pm 0.005$ volt RMS, $20 \mathrm{kHz}$, ac reference ( $100 \mathrm{ppm}$ stability for $1 \mathrm{yr}$. ).

3. Resistance standards of $100 \pm 0.05 \mathrm{ohm}, 1000 \pm 0.05 \mathrm{ohm}, 10 \mathrm{k} \pm 1$ $\mathrm{ohm}, 100 \mathrm{k} \pm 10 \mathrm{ohm}$, and $1 \mathrm{M} \pm 100 \mathrm{ohm}$ (30 ppm stability for $1 \mathrm{yr}$. ).

4. A $9.000 \pm 0.001$ volt, $0.9000 \pm 0.0001$ volt, and $0.09000 \pm 0.00001$ volt dc resistive voltage divider (unspecified ratio accuracy and/or stability), and

5. A 0.6 to 3.0 volt ac RMS thermal voltage converter ( $3 \mathrm{mV}$ dc output for $2.5 \mathrm{~V}$ ac RMS input) with \pm 200 to $\pm 600 \mathrm{ppm}$ accuracy over a $20 \mathrm{~Hz}$ to $1 \mathrm{MHz}$ frequency range.

This particular ICD for providing calibration support is one of many ICDs that are used with the IFTE system to provide a high-reliability ("gold dot" connectors), quick disconnect to a UUT, and to house any needed interfacing electronics (see figure 1).

There is also provided in the IFTE system a $10 \mathrm{MHz}$ rubidium frequency standard mounted in the bottom of the rack of equipment that can be connected via cable to the counter-timer in the three-function card. This standard has a frequency of $10 \mathrm{MHz} \pm 1 \times 10^{-11}$ ( 1 volt RMS output into $50 \mathrm{ohms}$ ) with $4 \times 10^{-11}$ /month stability. 


\section{SELF-ALIGNMENT ICD STANDARDS}

- $18.000 \pm 0.001 \vee \propto$ reference $( \pm 10$ ppm for 30 cays $)$

- $9.000 \pm 0.001 \mathrm{~V}, 0.9000 \pm 0.0001 \mathrm{~V}$, and $0.090000 \pm 0.00001 \mathrm{v}$ oc divider

- $1.0000 \pm 0.0005 \mathrm{~V}$ and $10.000 \pm 0.005 \mathrm{~V} \mathrm{~ms}, 20 \mathrm{kHz}$ ac reference $( \pm 100 \mathrm{pom} / \mathrm{yr}$.)

- 0.6 to $3.0 \mathrm{~V} \mathrm{rms}$ ac thermal voltage corverter $( \pm 200$ to $\pm 600 \mathrm{ppm}, 20$ tr to $1 \mathrm{Mr}$ )

- $100 \pm 0.05 \Omega, 1 k \pm 0.05 \Omega, 10 k \pm 1 \Omega, 100 k \pm 10 \Omega$, and $1 \mathrm{M} \pm 100 \Omega$

standard resistors ( $\$ 30 \mathrm{ppm}$ for 1 year)

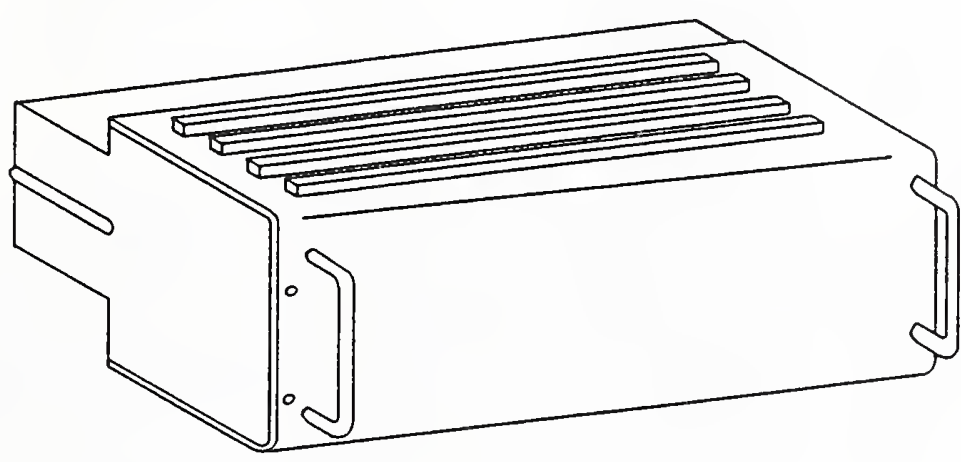

Figure 1. Interconnect device (ICD) used for self-alignment standards

\section{List of Commonly Used Acronyms}

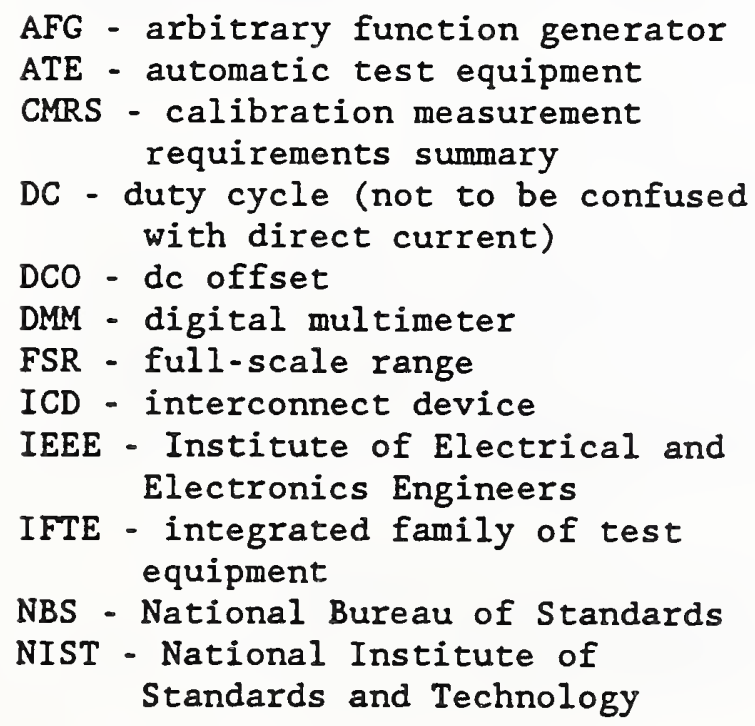

PLI - phase locked loop

PV - programmed value

RMS - root mean square

SA-ICD - self-alignment ICD

SDS - switching distribution system

TAR - test accuracy ratio

TMDE - test, measurement, and diagnostic equipment

TOAD - Tobyhanna Army Depot

TPS - test program set

TVC - thermal voltage converter

USATSG - U.S. Army TMDE Support Group

UUT - unit under test

VIC - virtual instrument card 
3. Assessment of the Self-Alignment Interconnect Device (SA-ICD)

\subsection{Voltage}

In category II of the Calibration/Measurement Requirements Summary $[5,6]$ are shown the dc standards contained in the SA-ICD that are used to support the dc voltage ranges of the DMM. These consist of the $18 \mathrm{~V}$ zener-based dc voltage reference and the $9.0 \mathrm{~V}, 0.9 \mathrm{~V}$, and $0.09 \mathrm{~V}$ levels obtained from the precision resistive divider used in conjunction with the $18 \mathrm{~V}$ reference. The specified tolerances for these voltages are (see $[5,6])$ :

$$
\begin{gathered}
18.00 \mathrm{~V} \pm 0.0056 \% / \mathrm{yr} \\
9.00 \mathrm{~V} \pm 0.0076 \% / \mathrm{yr} \\
0.900 \mathrm{~V} \pm 0.0076 \% / \mathrm{yr} \\
0.0900 \mathrm{v} \pm 0.0076 \% / \mathrm{yr}
\end{gathered}
$$

As discussed above, [3] indicates that the $18 \mathrm{~V}$ reference has a tolerance of $\pm 1 \mathrm{mV}$ with a stability of $50 \mathrm{ppm} / \mathrm{yr}$., which translates into a total possible error of $\pm 1.9 \mathrm{mV}$, or $\pm 0.0106 \%$. Similarly, an analysis of the tolerances allowed for the divider resistors, together with the errors in the zener reference (see Appendix A), shows that errors in the divider output voltages can be on the order of $\pm 0.02 \%$. This analysis assumes that the $18 \mathrm{~V}$ reference can hold its specification with the $18 \mathrm{k} \Omega$ load of the resistive divider, even though [3] indicates that this reference must have a minimum load impedance of $1 \mathrm{M} \Omega$. Consequently, meeting the tolerance specifications given in the category II tables of $[5,6]$ is rather doubtful, unless these can be supported by measurements made by the voltmeter standard given in category III.

The category III instrument in $[5,6]$ is indicated as the HP $3490 \mathrm{~A} 5$ digit integrating-type digital voltmeter that has a 30 day accuracy specification (23 $\left.\pm 5^{\circ} \mathrm{C}\right)$ of $\pm(0.01 \%$ reading $+0.005 \%$ range $)$ on the $0.1 \mathrm{~V}$ range, and $\pm(0.008 \%$ reading $+0.002 \%$ range) on the $1 \mathrm{~V}$ to $1000 \mathrm{~V}$ ranges (see specification sheets in Appendix E). Consequently, in measuring the four dc voltage standards of the SA-ICD, the following error bands are possible:

$$
\begin{aligned}
18 \mathrm{~V}: \text { Error } & = \pm[0.008 \%(18 \mathrm{~V})+0.002 \%(100 \mathrm{~V})] \\
& = \pm[1.44 \mathrm{mV}+2 \mathrm{mV}]= \pm 3.44 \mathrm{mV}
\end{aligned}
$$

Thus, calibrating the $18 \mathrm{~V}$ dc output of the ICD to $\pm 0.0056 \%$ is not possible when the HP 3490 A can have more than 3 times this error.

$$
\begin{aligned}
9 \mathrm{~V}: \text { Error } & = \pm[0.008 \%(9 \mathrm{~V})+0.002 \%(10 \mathrm{~V})] \\
& = \pm[0.72 \mathrm{mV}+0.2 \mathrm{mV}]= \pm 0.92 \mathrm{mV}
\end{aligned}
$$

Thus, calibrating the $9 \mathrm{~V}$ dc output of the ICD to $\pm 0.0076 \mathrm{z}$ is not possible when the HP 3490 A can have nearly $50 \%$ more error. 


$$
\begin{aligned}
0.9 \mathrm{~V}: \text { Error } & = \pm[0.008 \%(0.9 \mathrm{~V})+0.002 \%(1 \mathrm{~V})] \\
& = \pm(0.072 \mathrm{mV}+0.02 \mathrm{mV})= \pm 0.092 \mathrm{mV} \\
\text { or, Relative Error }= \pm 0.092 \mathrm{mV} / 0.9 \mathrm{~V}(100 \%)= \pm 0.0102 \% &
\end{aligned}
$$

Thus, calibrating the $0.9 \mathrm{~V}$ dc output of the ICD to $\pm 0.0076 \%$ is not possible when the HP 3490 A can have nearly $50 \%$ more error.

$$
\text { 0.09V: Error }= \pm \begin{aligned}
& = \pm 0.01 \%(0.09 \mathrm{~V})+0.005 \%(0.1 \mathrm{~V})] \\
& = \pm(0.009 \mathrm{mV}+0.005 \mathrm{mV})= \pm 0.014 \mathrm{mV}
\end{aligned}
$$

Thus, calibrating the $0.09 \mathrm{~V}$ dc output of the ICD to $\pm 0.0076 \%$ is not possible when the HP $3490 \mathrm{~A}$ can have 2 times more error.

It should also be noted that the category III instrument will have significantly more calibration error than calculated above, particularly on the range that reads the $9 \mathrm{~V}$ output from the ICD, if the input resistance of the voltmeter standard on that range is not on the order of $100 \mathrm{M} \Omega$ or larger. This requirement is due, of course, to the rather large (approximately $5 \mathrm{k} \Omega$ ) effective source resistance of the resistive divider on the $9 \mathrm{~V}$ output. There are now several $7 \frac{1}{2}$ and $8 \frac{1}{2}$ digit DMMs commercially available that have $>1$ G input impedance and better than $0.001 \%$ dc voltage accuracy specifications, which would be quite adequate for providing category III calibration support.

\subsection{AC Voltage}

So long as the error limits for the DMM readings in the ac voltage selfalignment software are allowed to be as large as indicated in [7], then the $\pm 0.06 \%$ tolerance specification of the $1 \mathrm{~V}$ and $10 \mathrm{~V}, 20 \mathrm{kHz}$ ac voltage reference source contained in the SA-ICD is probably adequate for calibration purposes, although it only provides a TAR of 1.29 on the $1 \mathrm{~V}$ range of the DMM at $20 \mathrm{kHz}$. Actually, this TAR can probably be improved with further analysis of the errors given in table 1 of the Calibration/Measurement Requirements Summary [5,6] (see section 4.2$)$.

The category III instrument for supporting the $1 \mathrm{~V}$ and $10 \mathrm{~V}, 20 \mathrm{kHz}$ ac voltage reference in the SA-ICD is indicated as the Ballantine 1600A thermal transfer standard. This instrument has been superseded by the Model $1605 \mathrm{~B}$ that has a specification $\left(10^{\circ} \mathrm{C}\right.$ to $\left.40^{\circ} \mathrm{C}\right)$ of $\pm(0.0016 \% \mathrm{~F} . \mathrm{S}$. range $+10 \mu \mathrm{V}) \pm 0.0023 \% \mathrm{dc}$ output on the $1-2 \mathrm{~V}$ range $(20 \mathrm{~Hz}$ to $20 \mathrm{kHz})$, and $\pm(0.0015 \% \mathrm{~F}$.S . range $+15 \mu \mathrm{V}) \pm 0.0020 \%$ dc output on the $8-16 \mathrm{~V}$ range $(20 \mathrm{~Hz}$ to $20 \mathrm{kHz})$, per the Ballantine specification sheet shown in Appendix $\mathrm{E}$. Thus, in measuring the $1 \mathrm{~V}$ and $10 \mathrm{~V}$, $20 \mathrm{kHz}$ ac voltage reference levels from the SA-ICD, the following error bands are possible:

$$
\begin{aligned}
1 \mathrm{~V} \text { : Error } & = \pm[0.0016 \%(2 \mathrm{~V})+10 \mu \mathrm{V}+0.0023 \%(1 \mathrm{~V})] \\
& = \pm[32 \mu \mathrm{V}+10 \mu \mathrm{V}+23 \mu \mathrm{V}] \\
& = \pm 65 \mu \mathrm{V}
\end{aligned}
$$


The TAR is then calculated as

$$
\mathrm{TAR}=\frac{0.06 \%(1 \mathrm{~V})}{65 \mu \mathrm{V}}=\frac{600 \mu \mathrm{V}}{65 \mu \mathrm{V}}
$$

$=9.23$

$$
\begin{aligned}
10 \mathrm{~V} \text { : Error } & = \pm[0.0015 \%(16 \mathrm{~V})+15 \mu \mathrm{V}+0.002 \%(10 \mathrm{~V})] \\
& = \pm[240 \mu \mathrm{V}+15 \mu \mathrm{V}+200 \mu \mathrm{V}] \\
& = \pm 455 \mu \mathrm{V}
\end{aligned}
$$

Again, the TAR is then calculated as

$$
\mathrm{TAR}=\frac{0.06 \%(10 \mathrm{~V})}{455 \mu \mathrm{V}}=\frac{6000 \mu \mathrm{V}}{455 \mu \mathrm{V}}
$$

$$
-13.2
$$

Hence, it appears that the Ballantine 1605B has at least an order of magnitude better accuracy to support the calibration of the $1 \mathrm{~V}$ and $10 \mathrm{~V}, 20 \mathrm{kHz}$ ac voltage reference in the SA-ICD. The major flaw in this analysis, however, is that of neglecting the loading effect of the low input impedance of an ac-dc transfer instrument such as the Ballantine 1605B. Typically, the impedance is low for such instruments because of the low-value heater resistance in the internal thermal voltage converter. The input impedance specification for the Ballantine $1605 \mathrm{~B}$ is $200 \Omega /$ volt, or $200 \Omega$ and $2000 \Omega$, respectively, for the $1 \mathrm{~V}$ and $10 \mathrm{~V}$ levels from the $20 \mathrm{kHz}$ ac voltage reference, orders of magnitude less than the $2 \mathrm{M} \Omega$ load specified. Because of the high accuracy ratio, however, it may be possible to provide a precision impedance matching network between the output of the ac voltage reference and the input of the Ballantine 1605B, without too large a loss in accuracy. Alternatively, there are now several $7 \frac{6}{2}$ and $8 \frac{2}{2}$ digit DMMs commercially available that have $1 \mathrm{M} \Omega$ ac input impedance and $0.01 \%$ ac voltage accuracy specifications. These are probably adequate for providing category III calibration support. Therefore, to calibrate the $1 \mathrm{~V}$ and $10 \mathrm{~V}, 20 \mathrm{kHz}$ ac voltage reference in the SA-ICD to within $\pm 0.06 \%$, using only the Ballantine 1600A (now 1605B), is not a reasonable support approach, even though the potential TAR is very adequate.

\section{$\underline{3.3 \text { DC Resistance }}$}

In category II of the Calibration/Measurement Requirements Summary of $[5,6]$ are shown the dc resistance standards contained in the SA-ICD that are used to support the dc resistance ranges of the DMM. These consist of the five Julie Research precision resistance standards described in [3]. The tolerance specification given in $[5,6]$ for these resistors is $\pm 0.0055 \% / y r$. However, the accuracies of these resistors are described in [3] as:

$\begin{array}{ll}100 \Omega & \pm 0.05 \Omega, \text { or } \pm 500 \mathrm{ppm} \\ 1 \mathrm{k} \Omega & \pm 0.05 \Omega \text { or } \pm 50 \mathrm{ppm} \\ 10 \mathrm{k} \Omega & \pm 1 \Omega, \text { or } \pm 100 \mathrm{ppm} \\ 100 \mathrm{k} \Omega & \pm 10 \Omega \text { or } \pm 100 \mathrm{ppm} \\ 1 \mathrm{M} \Omega & \pm 100 \Omega, \text { or } \pm 100 \mathrm{ppm}\end{array}$


As indicated in [3], these resistors have a stability of $30 \mathrm{ppm} / \mathrm{yr}$, and a temperature coefficient of $1 \mathrm{ppm} /{ }^{\circ} \mathrm{C}$ so that the total range of uncertainty over a $\pm 20^{\circ} \mathrm{C}$ operating temperature would be:

$\begin{array}{ll}100 \Omega & \pm 550 \mathrm{ppm}( \pm 0.055 \%), \text { or } \pm 0.055 \Omega \\ 1 \mathrm{k} \Omega & \pm 100 \mathrm{ppm}( \pm 0.01 \%) \text {, or } \pm 0.1 \Omega \\ 10 \mathrm{k} \Omega & \pm 200 \mathrm{ppm}( \pm 0.02 \%), \text { or } \pm 2 \Omega \\ 100 \mathrm{k} \Omega & \pm 200 \mathrm{ppm}( \pm 0.02 \%), \text { or } \pm 20 \Omega \\ 1 \mathrm{M} \Omega & \pm 200 \mathrm{ppm}( \pm 0.02 \%), \text { or } \pm 200 \Omega\end{array}$

Consequently, meeting the $\pm 0.0055 \% / y r$. tolerance specification given in the category II tables of [5,6] for the ICD Resistance Standards is not possible, unless this specification can be supported by measurements made by the resistance measurement system given in category III.

The category III instrument for supporting the precision resistance standards in the SA-ICD is indicated in $[5,6]$ as the ESI 2980 Resistance Measurement System, having a tolerance specification of $\pm 0.001 \%$ (or, $\pm 10 \mathrm{ppm}$ ), and a range of $5 \Omega$ to $10 \mathrm{M} \Omega$. The ESI 2980 system is not listed in the available ESI literature, and is apparently now obsolete. However, ESI markets the Model 242D Resistance Measuring System that has a direct reading accuracy over a $5 \Omega$ to $100 \mathrm{M} \Omega$ range of $\pm 10 \mathrm{ppm}$ (see ESI specification sheet given in Appendix E). This system utilizes the ESI RS 925D Decade Resistance Standard that requires calibration conditions of $23^{\circ} \mathrm{C}$, four-terminal measurements, and $30 \%$ to $70 \% \mathrm{R} . \mathrm{H}$. In measuring the resistance standards in the SA-ICD with the ESI 242D system under specified laboratory conditions once per year, the following TAR is possible:

$$
\operatorname{TAR}=\frac{0.0055 \%}{0.0010 \%}=5.5
$$

Thus, the ESI 242D Resistance Measuring System has a factor of 5.5 greater accuracy, needed to support calibration of the five Julie Research precision resistance standards (to the $0.0055 \%$ level) in the SA-ICD. Calibration (annual) of the Julie resistors entails an uncertainty of $\pm 0.0010 \%$ of the assigned value and an additional uncertainty of $\pm 0.0030 \%$ per year due to drift. Subtracting these uncertainty percentages from the specification of $\pm 0.0055 \%$, and taking into account the $0.0001 \%$ per ${ }^{\circ} \mathrm{C}$ temperature coefficient of the resistors, leads to a permissible ambient temperature range of $\pm 15^{\circ} \mathrm{C}$ about $23^{\circ} \mathrm{C}\left(8^{\circ} \mathrm{C}\right.$ to $\left.38^{\circ} \mathrm{C}\right)$. Therefore, the proposed calibration support at the category III level for the resistance standards in the SA-ICD does appear to be adequate; consequently, the $\pm 0.0055 \% / y r$. tolerance specification given in the category II tables of $[5,6]$ for the ICD Resistance Standards is probably justifiable. 


\section{Assessment of the Digital Multimeter}

Using the specific information given in $[3,5,6$, and 7$]$, together with material from the other referenced documents, the details can be pieced together of how the measurement modes of the DMM in the IFTE system are to be supported. The following description is an attempt to summarize the apparent calibration support scheme.

\subsection{Voltage}

From the category I information contained in the Calibration/Measurement Requirements Summary $[5,6]$, the tolerance specifications on the various dc voltage ranges are given. Assuming these figures are correct (and are required), the calibration support can be assessed by analyzing whether the process for verifying the measurement errors of the 5 h digit DMM on these ranges is adequate.

\section{$4.1 .11 \mathrm{~V}$ Range}

According to the description given in [7], the DMM is a basic $1 \mathrm{~V}$ instrument with input scaling to attenuate or amplify higher or lower voltages. Offset (zero drift) errors are obtained by connecting the DMM HI and LO leads together in the IFTE Signal Distribution System (SDS), virtually at the user interface (see figure 2). One hundred readings are averaged, the average verified to be less than $1 \mathrm{mV}$, and this value stored as an offset correction. Although fine in principle, the fact that as much as $1 \mathrm{mV}$ of offset can be expected in making DMM measurements (with $10 \mu \mathrm{V}$ resolution on the $1 \mathrm{~V}$ range) implies an offset that could be nearly 5 times greater than the error tolerance, calculated as

$$
\begin{aligned}
\text { Error } & = \pm[0.012 \% \text { input }+10 \text { digits (counts) }] \\
& = \pm[0.00012(1 \mathrm{~V})+100 \mu \mathrm{V}] \\
& = \pm 220 \mu \mathrm{V}
\end{aligned}
$$

So that the expected measurement errors can be at the $220 \mu \mathrm{V}$ level, offset corrections using the DMM self-alignment program should be made whenever the zero drift changes by more than this amount.

Assuming that the $0.9 \mathrm{~V}$ reference in the ICD does have a tolerance of $\pm 0.0076 \%$ (per year), then it has an error band calculated as

$$
\text { Error }= \pm 0.0076 \%(0.90 \mathrm{~V})= \pm 68.4 \mu \mathrm{V} .
$$

The test accuracy ratio (TAR) for the measurement of the $0.9 \mathrm{~V}$ reference on the $1 \mathrm{~V}$ range of the DMM is then calculated as

$$
\begin{aligned}
\text { TAR } & =\frac{0.0012 \%(0.9 \mathrm{~V})+100 \mu \mathrm{V}}{68.4 \mu \mathrm{V}}=\frac{108 \mu \mathrm{V}+100 \mu \mathrm{V}}{68.4 \mu \mathrm{V}}=\frac{208 \mu \mathrm{V}}{68.4 \mu \mathrm{V}} \\
& =3.04
\end{aligned}
$$

The TAR for the $1 \mathrm{~V}$ range of the DMM using the $0.9 \mathrm{~V}$ reference is 3.04 , not 3.21 , as indicated in $[5,6]$. 


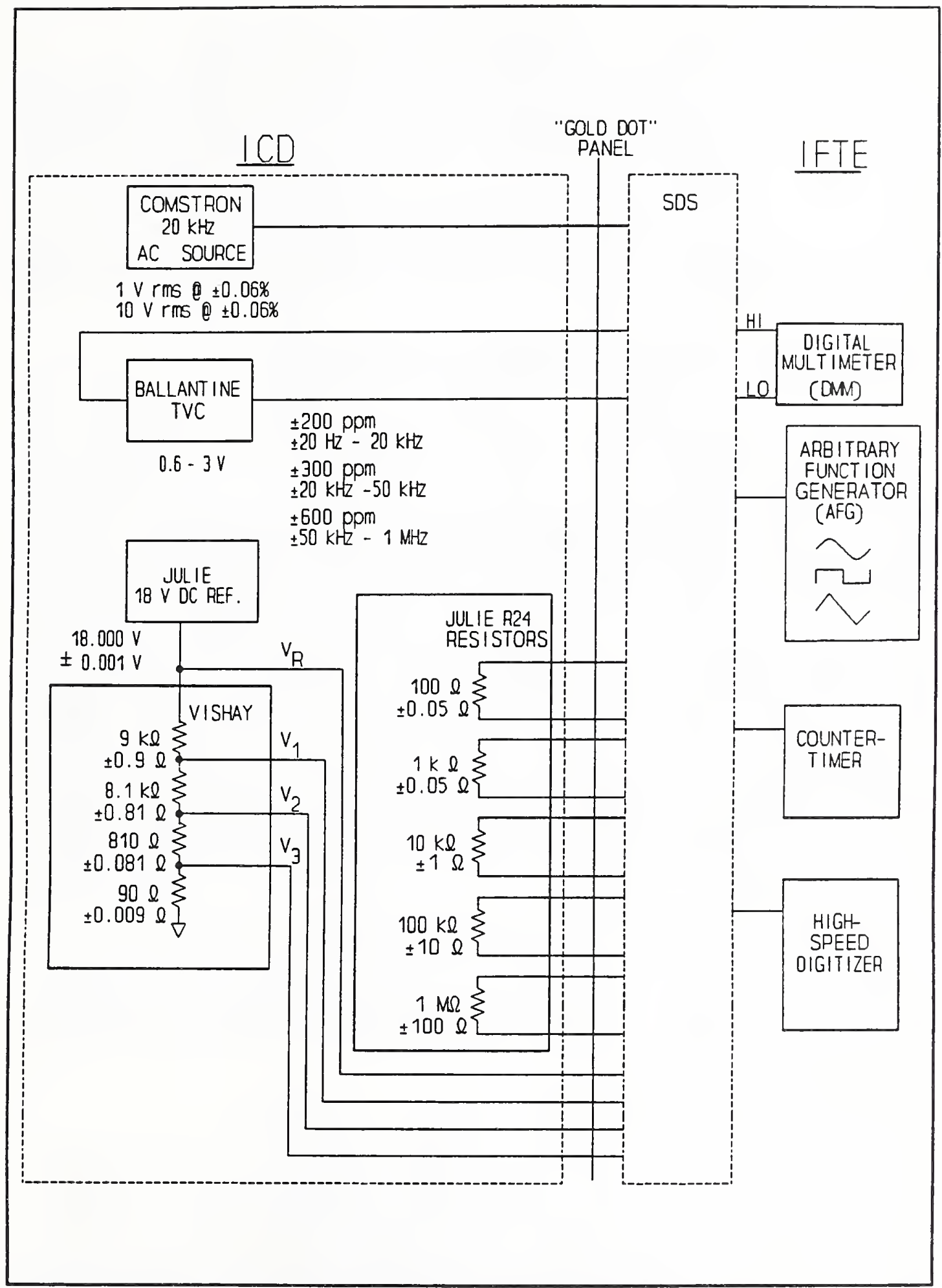

Figure 2. Interconnections between self-alignment ICD and the IFTE analog instrument functions via the "Gold Dot" panel and the Switching Distribution System (SDS) 
The gain error for this range is corrected by connecting the DMM to the $0.9 \mathrm{~V}$ dc standard in the SA-ICD, subtracting the offset correction, and then dividing the result into an exact value of 0.9 volts. Again, this is fine in principle except that this "multiplicative gain factor" is allowed to be in error by $\pm 5 \%$ in the self-alignment software, according to [7]. Even if the worse case sum of the offset, DMM tolerance, and $0.9 \mathrm{~V}$ reference tolerance (claimed to be $0.0076 \%$ ) is taken (equal to $0.01296 \%$ ), the allowed gain error is more than two orders of magnitude too large. The vendor should consider drastically reducing the allowed error in the calculation of the multiplicative gain factor on this range in the DMM self-alignment program.

Because of the large $\pm 5 \%$ tolerance allowed on the gain error in the selfalignment software, it is unlikely that the two-point alignment (zero and $90 \%$ points on the $1 \mathrm{~V}$ range) proposed by the vendor corrects the subsequent DMM readings to be within the allowed tolerance specification. A three-point alignment (at 10\%, 50\%, and $90 \%$ points) for each range now has been proposed in the Calibration TPS Statement of Work (see [10, 11, and 12])..."to validate range linearity and full-scale accuracy of the DMM and three-function virtual instrument cards." It is important that the modified self-alignment software be consistent with the additional reference voltage hardware, i.e., the allowed tolerance for these three test points should be consistent with the desired linearity specification of the DMM. Actually, a truer calibration of the DMM will result from averaging several readings at these three test points, and using the mean values (plus the offset correction), to provide a fit to a straight line "calibration curve." Then, for any subsequent dc voltage inputs, corrections can be made to the readings based on the predicted readings from the (stored) calibration curve (see [13]). The vendor should consider adding a relatively small amount of code to the self-alignment software that provides for the averaging of several readings (say 10 to 100) at the three test points, that fits a straight line to these points (including the offset) using a leastsquares error criterion, and that makes corrections to the DMM run-time readings based on this stored calibration curve.

All of the above alignment procedure hinges, of course, on having adequate reference voltages at the $10 \%, 50 \%$, and $90 \%$ points. At present the only reference voltage used is the $0.9 \mathrm{~V}$ output ( $90 \%$ point) from the resistive divider in the ICD (see discussion below regarding the category II and III standards and support equipment).

\section{$4.1 .2 \quad 0.1 \mathrm{~V}$ and $10 \mathrm{~V}$ Ranges}

For these two ranges, according to the description given in [7], the selfalignment procedure assumes the same offset correction as for the $1 \mathrm{~V}$ range, and gain errors are corrected by connecting the DMM to the $90 \%$ point dc voltage references in the ICD. Consequently, all of the comments made above for the 1 $\mathrm{V}$ range hold for these two ranges also. In addition, because there may be significantly different offset due the amplifier needed for the $0.1 \mathrm{~V}$ range, the self-alignment procedure for this range should include another offset error measurement that would correct for the amplifier. 


\section{$4.1 .3100 \mathrm{~V}$ and $300 \mathrm{~V}$ Ranges}

For these ranges the $18 \mathrm{~V}$ dc reference in the ICD is used for a gain factor correction in the self-alignment procedure described in [7]. Assuming that this reference does have a tolerance of $0.0056 \%$ (as indicated in $[5,6]$ ), then it has an error band calculated as

$$
\text { Error }= \pm 0.0056 \%(18.000 \mathrm{~V})= \pm 0.001008 \mathrm{~V}= \pm 1.008 \mathrm{mV}
$$

The TAR for the measurement of the $18 \mathrm{~V}$ reference on the $100 \mathrm{~V}$ range of the DMM is then calculated as

$$
\begin{aligned}
\text { TAR } & =\frac{0.024 \%(18.000 \mathrm{~V})+10(1 \mathrm{mV})}{1.008 \mathrm{mV}}=\frac{4.32 \mathrm{mV}+10 \mathrm{mV}}{1.008 \mathrm{mV}} \\
& =14.2
\end{aligned}
$$

(as given in $[5,6]$ ). On the $300 \mathrm{~V}$ range a similar TAR calculation gives 103.49.

However, in [3] the $18.000 \mathrm{~V}$ dc reference is given a $\pm 1 \mathrm{mV}$ tolerance with a 50 ppm/yr. stability figure. Taking both the tolerance and the 1 year drift into account, the $18 \mathrm{~V}$ dc reference has a possible worst-case error of

$$
\text { Error }=1 \mathrm{mV}+0.0050 \%(18 \mathrm{~V})=1.9 \mathrm{mV}
$$

The TAR for the 100 and $300 \mathrm{~V}$ ranges of the DMM is then 7.53 and 54.9 , respectively, not 14.2 and 103.49. Nevertheless, these are more than adequate TARs.

The bigger issue on these ranges is the use of an $18 \mathrm{~V}$ reference point as a means of correcting gain error, since 18 volts is only $18 \%$ and $6 \%$ of full scale, respectively, on the $100 \mathrm{~V}$ and $300 \mathrm{~V}$ ranges. As shown in figure 3 , using the $18 \mathrm{~V}$ reference, the worst-case measurement error on the $100 \mathrm{~V}$ range is approximately $14 \mathrm{mV}$ (neglecting the error in the $18 \mathrm{~V}$ reference):

$$
\text { Error }=0.024 \%(18 \mathrm{~V})+10 \mathrm{mV}=4.32 \mathrm{mV}+10 \mathrm{mV}=14.32 \mathrm{mV}
$$

Assuming that this error can be of either polarity, then a multiplicative gain factor will be calculated in the self-alignment program that is either too low $\left(b_{L}\right)$ or too high $\left(b_{B}\right)$ :

$$
\begin{aligned}
& b_{L}=\frac{18.000}{18.014}=0.999223 \\
& b_{B}=\frac{18.000}{17.986}=1.00078
\end{aligned}
$$

When using these factors in the self-alignment program to scale the reading for a $100 \mathrm{~V}$ input from the linear relationship, $\mathrm{Y}=\mathrm{a}+\mathrm{bX}$, and neglecting the offset, a, the "corrected" result would be

$$
\begin{aligned}
& Y_{L}=0.999223(100 \mathrm{~V})=99.9223 \mathrm{~V} \\
& Y_{B}=1.00078(100 \mathrm{~V})=100.078 \mathrm{~V} .
\end{aligned}
$$




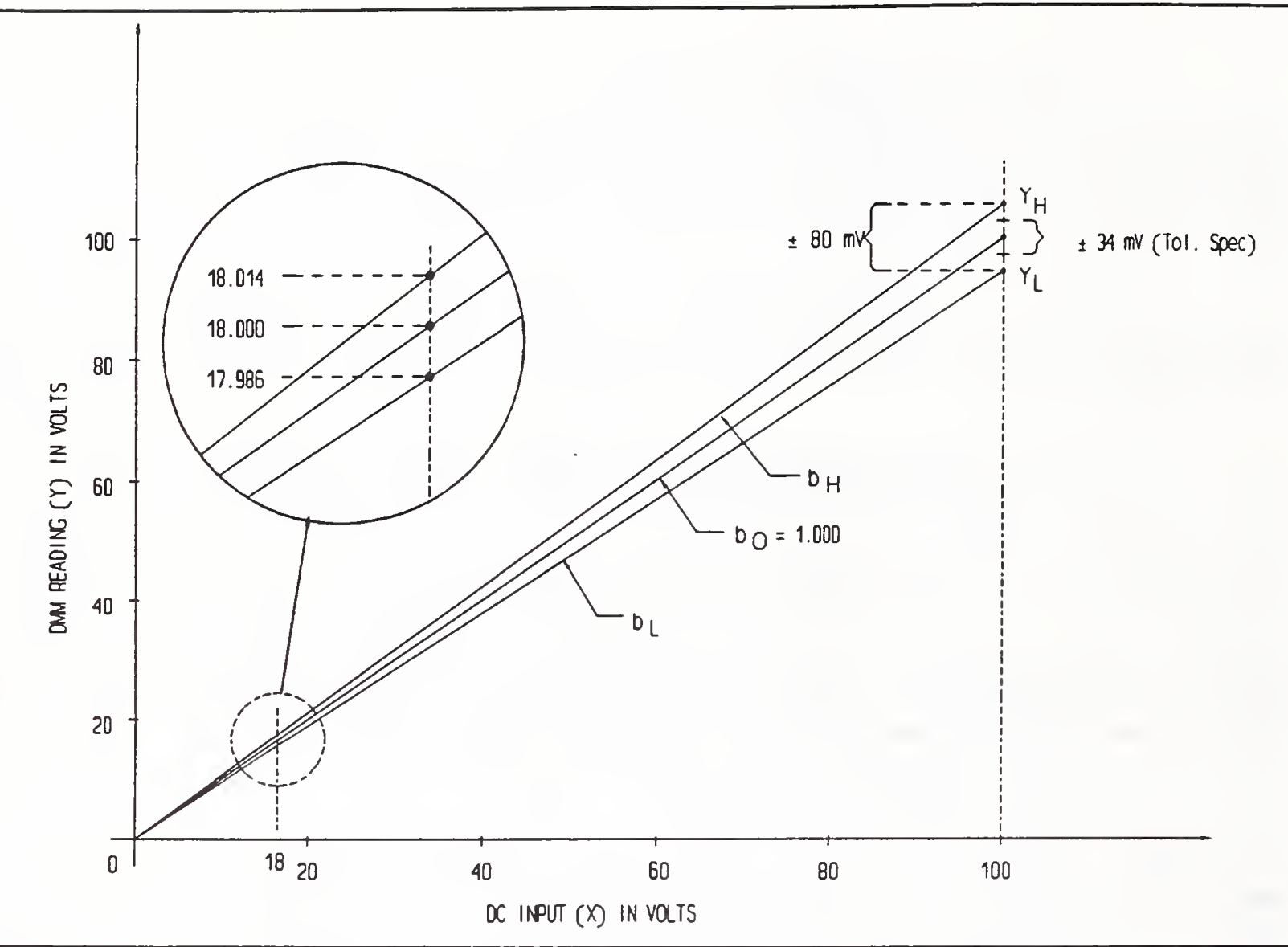

Figure 3. Errors caused by two-point ( 0 and $18 \mathrm{~V}$ ) alignment procedure of the DMM on the $100 \mathrm{~V}$ range

Thus, the DMM could have nearly a $\pm 80 \mathrm{mV}$ error band rather than the $\pm 34 \mathrm{mV}$ expected from the specification tolerance, calculated as

$$
\text { Tolerance }= \pm[0.024 \%(100 \mathrm{~V})+10 \mathrm{mV}]= \pm 34 \mathrm{mV}
$$

For the $300 \mathrm{~V}$ range, the full scale "corrected" result would be

$$
\begin{aligned}
& Y_{I}=0.999223(300 \mathrm{~V})=299.767 \mathrm{~V} \\
& Y_{B}=1.00078(300 \mathrm{~V})=300.234 \mathrm{~V} .
\end{aligned}
$$

Thus, the DMM could have a $\pm 234 \mathrm{mV}$ error band rather than the $\pm 82 \mathrm{mV}$ expected from the specification tolerance, calculated as

$$
\text { Tolerance }= \pm[0.024 \%(300 \mathrm{~V})+10 \mathrm{mV}]= \pm 82 \mathrm{mV} \text {. }
$$

of course, the alignment errors become much worse if the $b_{L}$ and $b_{B}$ factors are allowed to be off by $\pm 5 \%$ as indicated in [7]. The two-point (18 $v$ and zero) alignment procedure, as proposed for these ranges, is probably worse than no self alignment at all. 


\subsection{AC Voltage}

From the category I information contained in the Calibration/Measurement Requirements Summary $[5,6]$, the tolerance specifications on the various ac voltage ranges are given. Assuming these figures are correct (and are required), the calibration support can be assessed by analyzing whether the process for verifying the measurement errors of the $5 \frac{1}{2}$ digit DMM on these ranges is adequate. According to the description given in [7], the DMM ac voltage alignment is performed in two parts: 1) a range alignment using the SA-ICD dc and ac voltage standards, and 2) a frequency response using the thermal voltage converter standard in the ICD.

\section{$4.2 .10 .1 \mathrm{~V}$ Range}

The gain error for this ac voltage range is supposedly corrected by connecting the DMM to the $0.09 \mathrm{~V}$ dc reference level from the SA-ICD. Although the $0.09 \mathrm{~V} d c$ reference is certainly accurate enough for calibrating the DMM in reading the RMS value of a dc input, this is not a recommended technique for determining the gain error of an ac voltmeter since it does not take into account the additional possible errors in the measurement due to reactive components in the signal path. This reason is probably why the gain error is corrected on the remaining ranges using the $1 \mathrm{~V}$ and $10 \mathrm{~V}, 20 \mathrm{kHz}$ ac reference voltage levels from the SA-ICD (see discussion below). Even so, according to [7] the measurement of the $0.09 \mathrm{~V}$ reference (with a claimed specification tolerance of $\pm 0.0076 \%$, or $\pm 6.84 \mu \mathrm{V}$ ) is allowed by the self-alignment software to have a limit of $\pm 20 \mathrm{mV}$, almost 3000 times worse! The vendor should consider drastically reducing the allowed error for the gain measurement in the calculation of the multiplicative dc gain factor for this range. Moreover, a true ac voltage gain error correction should be implemented by using an accurate ac reference source.

\section{$4.2 .21 \mathrm{~V}$ and $10 \mathrm{~V}$ ranges}

Gain error correction for these ranges is accomplished by connecting the DMM to the $1 \mathrm{~V}$ and $10 \mathrm{~V}, 20 \mathrm{kHz}$ ac reference voltages from the SA-ICD. Thus, on these two ranges a full-scale signal is provided for a two-point (zero and full scale) alignment. Assuming that these reference voltages have a tolerance of $\pm 0.06 \%$ [3], then for the 1 and $10 \mathrm{~V}$ ranges, the error bands are, respectively

and

$$
\text { Error }_{1}= \pm 0.06 \%(1 \mathrm{~V})= \pm 0.0006 \mathrm{~V}= \pm 0.6 \mathrm{mV}
$$

$$
\text { Error }_{10}= \pm 0.06 \%(10 \mathrm{~V})= \pm 0.006 \mathrm{~V}= \pm 6 \mathrm{mV} \text {. }
$$

These errors could be worse if the input impedance of the DMM at $20 \mathrm{kHz}$ on the 1 and $10 \mathrm{~V}$ ranges is less than $2 \mathrm{M} \Omega$, since [3] specifies a load impedance for the ac voltage reference of $2 \mathrm{M} \Omega$.

Taking the $20 \mathrm{kHz}$ specification of the DMM $[5,6]$, the TAR for both the 1 and 10 volt ranges is then

$$
\mathrm{TAR}_{1}=\frac{0.12 \%(1 \mathrm{~V})+50(10 \mu \mathrm{V})}{0.6 \mathrm{mV}}=\frac{0.0012 \mathrm{~V}+500 \mu \mathrm{V}}{0.6 \mathrm{mV}}=\frac{1.7 \mathrm{mV}}{0.6 \mathrm{mV}}
$$




$$
\begin{aligned}
\text { TAR }_{1} & =2.83 \\
\text { TAR }_{10} & =\frac{0.12 \%(10 \mathrm{~V})+50(100 \mu \mathrm{V})}{6 \mathrm{mV}}=\frac{0.012 \mathrm{~V}+5 \mathrm{mV}}{6 \mathrm{mV}}=\frac{17 \mathrm{mV}}{6 \mathrm{mV}}
\end{aligned}
$$

Table 1 in $[5,6]$ indicates a TAR of 10.33, but that is because of reading the $1 \mathrm{~V}, 20 \mathrm{kHz}$ ac voltage reference source on the $10 \mathrm{~V}$ range of the DMM:

$$
\operatorname{TAR}_{[5.6]}=\frac{0.12 \%(1 \mathrm{~V})+50(100 \mu \mathrm{V})}{0.6 \mathrm{mV}}=\frac{0.0012 \mathrm{~V}+5 \mathrm{mV}}{0.6 \mathrm{mV}}=\frac{6.2 \mathrm{mV}}{0.6 \mathrm{mV}}
$$$$
=10.33
$$

Calculating TARs for the various frequency ranges indicated in table 1 in $[5,6]$ by using the DMM specification of the $10 \mathrm{~V}$ range is overly optimistic when applying the $1 \mathrm{~V}, 20 \mathrm{kHz}$ ac voltage reference source. (See further discussion below under Frequency Response).

Thus, whereas the DMM tolerance specification is $\pm 0.17 \%$ and $\pm 0.62 \%$ for the 1 and $10 \mathrm{~V}$ ranges, respectively, the self-alignment software allows a $\pm 5 \% 1$ imit in calculating the multiplicative gain factor for these ranges, per [7]. With the $\pm 0.06 \%$ tolerance in the 1 and $10 \mathrm{~V}, 20 \mathrm{kHz}$ ac reference source added to the DMM tolerances, this total tolerance of $\pm 0.23 \%$ gives an allowable error factor in the limits for these ranges of

$$
\begin{aligned}
& \text { Error Factor } 1=\frac{5 \%}{0.23 \%}=21.74 \\
& \text { Error Factor } 10_{10}=\frac{5 \%}{0.68 \%}=7.35
\end{aligned}
$$

As indicated previously, the vendor should consider drastically reducing the allowed error in the calculation of the multiplicative gain factor in the DMM self-alignment program for these ranges.

\section{$4.2 .3100 \mathrm{~V}$ and $200 \mathrm{~V}$ Ranges}

For these ranges the $10 \mathrm{~V}, 20 \mathrm{kHz}$ ac voltage reference source in the SA-ICD is used for a gain correction in the self-alignment procedure described in [7]. Thus, the TAR for these ranges is the same as calculated above, assuming that the error in the DMM is a function of frequency and not range, as indicated in $[5,6]$. However, for these ranges the bigger issue is the use of a $10 \mathrm{~V}$ reference point as a means of correcting gain error, since 10 volts is only $10 \%$ and $5 \%$ of full scale, respectively, on the $100 \mathrm{~V}$ and $200 \mathrm{~V}$ ranges. In this case, the error band in reading the $10 \mathrm{~V}, 20 \mathrm{kHz}$ ac reference will be

$$
\begin{aligned}
\text { Error } & = \pm[0.12 \%(10.017)+50(1 \mathrm{mV})]= \pm(12.02 \mathrm{mV}+50 \mathrm{mV}) \\
& = \pm 62.02 \mathrm{mV} .
\end{aligned}
$$


Thus, the allowed error limit of $1.0 \mathrm{~V}$ in the self-alignment software when reading the $10 \mathrm{~V}, 20 \mathrm{kHz}$ ac reference [7] is an error factor of

$$
\text { Error factor }=\frac{1.00000 \mathrm{~V}}{0.06202 \mathrm{~V}}=16.13
$$

The vendor should seriously reconsider the large limit allowed on these ranges in reading the $10 \mathrm{~V}, 20 \mathrm{kHz}$ ac voltage reference source as the basis for accepting the subsequent calculation of the multiplicative gain factor.

The $62.02 \mathrm{mV}$ error in reading the $10 \mathrm{~V}, 20 \mathrm{kHz}$ ac voltage reference is then propagated further in calculating the multiplicative gain factors, as described above for the $100 \mathrm{~V}$ and $300 \mathrm{~V}$ dc ranges (see Figure 3):

$$
\begin{aligned}
& b_{L}=\frac{10.000}{10.062}=0.99384 \\
& b_{H}=\frac{10.000}{9.93798}=1.0062
\end{aligned}
$$

Then, for a $100 \mathrm{~V}$ input, the "corrected" result would be

$$
\begin{aligned}
& Y_{L}=0.99384(100 \mathrm{~V})=99.384 \mathrm{~V} \\
& Y_{B}=1.0062(100 \mathrm{~V})=100.62 \mathrm{~V} .
\end{aligned}
$$

Thus, the DMM would have a $\pm 620 \mathrm{mV}$ error band rather than the $\pm 170 \mathrm{mV}$ expected from the tolerance specification, calculated as

$$
\text { Tolerance }= \pm[0.12 \%(100 \mathrm{~V})+50 \mathrm{mV}]= \pm 170 \mathrm{mV}
$$

For the $200 \mathrm{~V}$ range, the full scale "corrected" result would be

$$
\begin{aligned}
& Y_{L}=0.99384(200 \mathrm{~V})=198.768 \mathrm{~V} \\
& Y_{B}=1.0062(200 \mathrm{~V})=201.24 \mathrm{~V} .
\end{aligned}
$$

Thus, the DMM would have a $\pm 1.24 \mathrm{~V}$ error band rather than the $\pm 290 \mathrm{mV}$ expected from the tolerance specification, calculated as

$$
\text { Tolerance }= \pm[0.12 \%(200 \mathrm{~V})+50 \mathrm{mV}]= \pm 290 \mathrm{mV}
$$

Hence, the two-point (zero and $10 \mathrm{~V}$ ) alignment procedure, as proposed for these ranges, is probably worse than no self alignment at all. 


\subsubsection{Frequency Response}

The frequency response of the DMM is determined by comparing the readings made by the DMM at $25 \mathrm{~Hz}, 50 \mathrm{~Hz}, 60 \mathrm{kHz}, 175 \mathrm{kHz}$, and $750 \mathrm{kHz}$ relative to the reading by the DMM of the $1 \mathrm{~V}, 20 \mathrm{kHz}$ ac voltage reference contained in the SA-ICD. The source of the ac voltage at the various test frequencies is the arbitrary function generator (AFG) that is part of the three-function VIC in the IFTE system (Base Shop Test Set). According to [7], the AFG is capable of driving a $50 \Omega$ load impedance, so that the amplitude setting of the AFG at the various test frequencies can be adjusted, relative to the $1 \mathrm{~V}, 20 \mathrm{kHz}$ ac voltage reference, using the thermal voltage converter contained in the ICD. Table 1 in [5,6] gives the frequency response error of the DMM for different frequency ranges, showing the TAR calculated in conjunction with the $1 \mathrm{~V}, 20 \mathrm{kHz}$ ac voltage reference, $A F G$, and the thermal voltage converter.

Together with the procedure outlined in [7], there are several difficulties associated with this table. First, the column giving the DMM accuracy at $1 \mathrm{~V}$ RMS shows the accuracy obtained on the $10 \mathrm{~V}$ range rather than on the $1 \mathrm{~V}$ range. Normally, the $1 \mathrm{~V}$ range would be expected to be used for this purpose, taking into account the associated errors. Hence, rather than the accuracy figures given in the table, the following figures would hold for the DMM reading $1 \mathrm{~V}$ RMS on the $1 \mathrm{~V}$ range:

$$
\begin{aligned}
& 10 \mathrm{~Hz} \text { to } 30 \mathrm{~Hz} \\
& 30 \mathrm{~Hz} \text { to } 100 \mathrm{~Hz} \\
& 100 \mathrm{~Hz} \text { to } 20 \mathrm{kHz} \\
& 20 \mathrm{kHz} \text { to } 100 \mathrm{kHz} \\
& 100 \mathrm{kHz} \text { to } 300 \mathrm{kHz} \\
& 300 \mathrm{kHz} \text { to } 1 \mathrm{MHz}
\end{aligned}
$$

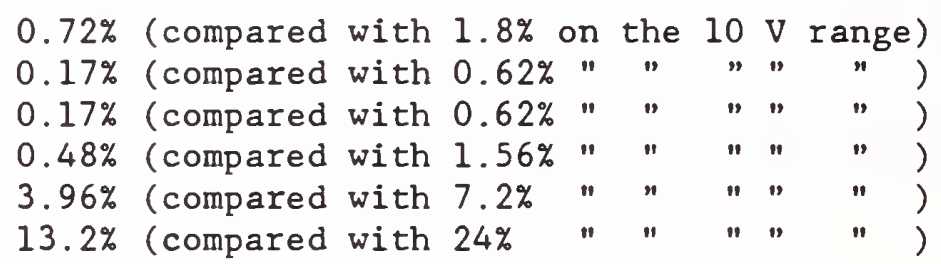

Consequently, the TARs shown in the last column would change accordingly:

$\begin{array}{ll}10 \mathrm{~Hz} \text { to } 30 \mathrm{~Hz} & 5.45 \text { (compared with } 13.36 \text { ) } \\ 30 \mathrm{~Hz} \text { to } 100 \mathrm{~Hz} & 1.29 \text { (compared with } 4.69 \text { ) } \\ 100 \mathrm{~Hz} \text { to } 20 \mathrm{kHz} & 1.29 \text { (compared with } 4.69 \text { ) } \\ 20 \mathrm{kHz} \text { to } 100 \mathrm{kHz} & 2.96 \text { (compared with } 9.62 \text { ) } \\ 100 \mathrm{kHz} \text { to } 300 \mathrm{kHz} & 24.4 \text { (compared with } 44.4 \text { ) } \\ 300 \mathrm{kHz} \text { to } 1 \mathrm{MHz} & 81.5 \text { (compared with } 148 \text { ) }\end{array}$

Simply for performing a frequency response check, these TARs are still probably adequate. In calculating the TAR, the denominator is determined by adding up the various errors of the DMM, thermal converter, and ac voltage reference, as given in the table. Since the DMM is used to compare dc voltage readings from the thermal converter that are the same within $\pm 20 \mu \mathrm{V}$ [7], the earlier discussion concerning offset corrections on both the $1 \mathrm{~V}$ dc and $0.1 \mathrm{~V}$ dc voltage ranges is even more critical. By making essentially the same reading from the output of the thermal voltage converter, the dc voltage accuracy specification $(0.012 \%+$ 10 digits) is really meaningless. Because of appreciable thermal drift possible in the thermal voltage converter, the transfer error of $0.01 \%$ given in the table may be optimistic; on the other hand, it should also be possible to realize better ac-dc difference uncertainties than the $0.03 \%(10 \mathrm{~Hz}$ to $20 \mathrm{kHz})$ and $0.06 \%$ 
(20 $\mathrm{kHz}$ to $1 \mathrm{MHz}$ ) specifications given for the thermal voltage converter. Another source of error that should be included in the table under "AC STD. ERROR" is the loading effect of the input impedance of the DMM. Typically, this impedance is $100 \mathrm{M} \Omega$ shunted by $100 \mathrm{pF}$, which at $20 \mathrm{kHz}$ is approximately $80 \mathrm{k} \Omega$, considerably less than the $2 \mathrm{M} \Omega$ load specified for the $1 \mathrm{~V}, 20 \mathrm{kHz}$ ac voltage reference. The vendor should reexamine the basis for the error analysis given in the "DMM AC Measurement Frequency Response" of table $1[5,6]$.

Nevertheless, assuming the DMM errors given on the $10 \mathrm{~V}$ range in reading the $1 \mathrm{~V}$ RMS level from the AFG at $25 \mathrm{~Hz}, 50 \mathrm{~Hz}, 60 \mathrm{kHz}, 175 \mathrm{kHz}$, and $750 \mathrm{kHz}$, the error limits given in [7] for the self-alignment software correspond as follows:

\begin{tabular}{|c|c|c|c|}
\hline Freq. Range & $\begin{array}{l}\text { DMM Error } \\
\text { (Table 1) }\end{array}$ & $\begin{array}{l}\text { Error Limits } \\
\text { from } 171\end{array}$ & DMM Error $/ 1$ \\
\hline $10-30 \mathrm{~Hz}$ & $1.8 \%$ & $4.18 \%$ @ $25 \mathrm{~Hz}$ & 2.32 \\
\hline $30-100 \mathrm{~Hz}$ & $0.62 \%$ & $3.56 \% @ 50 \mathrm{~Hz}$ & 5.74 \\
\hline $100 \mathrm{~Hz}-20 \mathrm{kHz}$ & $0.62 \%$ & & \\
\hline $20 \mathrm{kHz}-100 \mathrm{kHz}$ & $1.56 \%$ & $4.91 \% @ 60 \mathrm{kHz}$ & 3.15 \\
\hline $100 \mathrm{kHz}-300 \mathrm{kHz}$ & $7.2 \%$ & $8.15 \% @ 175 \mathrm{kHz}$ & 1.13 \\
\hline $300 \mathrm{kHz}-1 \mathrm{MHz}$ & $24 \%$ & $22.35 \% @ 750 \mathrm{kHz}$ & 0.93 \\
\hline
\end{tabular}

As would be expected, the software error limit nearly matches the expected DMM error for the $175 \mathrm{kHz}$ and $750 \mathrm{kHz}$ frequency points; however, the error limits are off by large factors at the lower frequencies. The vendor should reduce the error limits allowed for the $25 \mathrm{~Hz}, 50 \mathrm{~Hz}$, and $60 \mathrm{kHz}$ points in the DMM frequency response self-alignment software so that the DMM Error/Error Limit factor is near unity.

\subsection{Resistance}

From the category I information contained in the Calibration/Measurement Requirements Summary $[5,6]$, the tolerance specifications on the various dc resistance ranges are given. Assuming these figures are correct (and are required), the calibration support can be assessed by analyzing whether the process for verifying the measurement errors of the $5 \frac{1}{2}$ digit DMM on these ranges is adequate.

\section{$4.3 .1 \quad 100 \Omega$ Range}

According to the description given in [7], the DMM is aligned on the resistance function by compensating for lead resistances (path loss), connecting the DMM HI and LO leads through the IFTE Signal Distribution system (SDS) to the $100 \Omega$ resistance standard contained in the SA-ICD (see Figure 2). Since sense lines are also brought out to an unknown resistor when making four-wire resistance measurements, the lead compensation described obviously applies to making twowire resistance measurements. As described in [7], the measured value of the $100 \Omega$ standard (nominally $105 \Omega$ ) is then subtracted from $100 \Omega$, with the result being a negative number in the range of about $-5 \Omega$. However, in [7] it is stated that, "If the value is between $115 \mathrm{ohms}$ and $95 \mathrm{ohms,}$, it is stored as the system path loss additive correction factor for all ranges." There is some apparent confusion in this description! A better scheme, however, would be to connect 
the DMM HI and LO leads together right at the DMM input terminals to obtain a zero offset correction reading, and to connect a short circuit "virtually at the user interface" to obtain a measure of the lead resistances, taking into account the zero offset. Then a (full-scale) reading of the $100 \Omega$ resistance standard in the ICD can be corrected accurately for both errors. Subsequently dividing the corrected value into the nominal $100 \Omega$ value should generate an accurate full-scale "multiplicative gain factor." Unlike the limits (described in [7]) set for errors in the calculation of gain factors for the dc voltage and ac voltage ranges (see above discussions), there are no limits described for these errors under dc resistance measurements.

Assuming that the $100 \Omega$ resistance standard in the ICD does have a tolerance of $\pm 0.0055 \%$ (per year), it has an error band of

$$
\text { Error }= \pm 0.0055 \%(100 \Omega)= \pm 0.0055 \Omega .
$$

The TAR for the measurement of the $100 \Omega$ standard on the $100 \Omega$ range of the DMM is then calculated as

$$
\begin{aligned}
\text { TAR } & =\frac{0.02 \%(100 \Omega)+10 \text { digits }}{0.0055 \Omega}=\frac{0.02 \Omega+0.01 \Omega}{0.0055 \Omega} \\
& =5.45
\end{aligned}
$$

as shown in the category II tables $[5,6]$.

$$
4.3 .21 \mathrm{k} \Omega, 10 \mathrm{k} \Omega, 100 \mathrm{k} \Omega, 1 \mathrm{M} \Omega \text {, and } 10 \mathrm{M} \Omega \text { Ranges }
$$

For aligning each of the other resistance ranges, the DMM is connected to the corresponding (full-scale) resistance standard in the SA-ICD, and then the path loss measured on the $100 \Omega$ range is subtracted, as described in [7]. Although this procedure compensates for the lead resistances, it does not apply the proper offset correction since this value is very likely to be different on different ranges of the DMM. The multiplicative gain factor that is subsequently calculated is then in error. A better scheme, as described above, would be to connect the DMM HI and LO leads together right at the DMM to obtain a zerooffset correction. Then, together with the lead resistance compensation determined from the $100 \Omega$ range test, a reading of the full-scale resistance standard in the ICD can be corrected accurately for both errors. 
Using the specific information given in $[3,4,5,6,16$, and 17], together with material from the other referenced documents, the details can be pieced together of how the measurement and generation modes of the three-function board in the IFTE system are to be supported. The following description is an attempt to summarize the apparent calibration support scheme, and to recommend improvements that would assure better traceability to accurate electrical standards for the measurements by and signals from the three-function board.

\section{$\underline{5.1}$ Counter-Timer}

\subsubsection{Time-Base Aging Rate}

From the category I information given in the Calibration/Measurement Requirements Summary [5,6], the tolerance specification on the time-base aging rate is $\pm 2 \mathrm{ppm} / \mathrm{yr}$. A footnote on this item indicates that the "...rubidium standard is time base for counter-timer via timing generator card. PLL circuit will lose lock if rubidium standard drifts. If calibrated and in lock, rubidium standard can be used to provide guaranteed frequency of that accuracy."

There is confusion in this quoted description by relating the $\pm 2 \mathrm{ppm} / \mathrm{yr}$. aging (drift) rate (or stability) of the time base with the accuracy of the $10 \mathrm{MHz}$ frequency provided by the rubidium standard. The inference, apparently, is that the drift in the time base (timing-generator card) of the counter-timer can be maintained easily to within $\pm 2 \mathrm{ppm} / \mathrm{yr}$. by using the rubidium standard as the frequency reference of the phase-locked loop (PLL) circuit contained in the timing generator. From the engineering drawings of the IFTE station (SN 017) seen at the Tobyhanna Army Depot, the rubidium standard is, in fact, hard wired to the reference input of the counter-timer [15]. According to [5,6], the category II rubidium standard is claimed to have a frequency tolerance of only $\pm 0.0048 \mathrm{~Hz}$, or $\pm 0.00048 \mathrm{ppm}$. Since this is a rather tight specification, the amount of drift in the rubidium standard that is allowed before the PLL circuit in the timing-generator card will lose lock is unclear. As indicated in [3], the accuracy of the (category III) rubidium standard is $\pm\left(1 \times 10^{-11}\right.$ ) or 0.00001 $\mathrm{ppm}$, and the long term stability is $\pm 4 \times 10^{-11} / \mathrm{mo} .,( \pm 0.00004 \mathrm{ppm} / \mathrm{mo}$.), or \pm 0.00048 $\mathrm{ppm} / \mathrm{yr}$ (linear extrapolation). Most PLLs can tolerate at least several percent variation in the reference frequency without losing lock, so the issue of losing lock with the high accuracy and very small drift in the rubidium frequency standard appears not to be a problem. Without other information, it is unclear exactly how the $\pm 2 \mathrm{ppm} / \mathrm{yr}$. aging (drift) rate of the time base is maintained, beyond using the rubidium standard as the frequency reference, and why the very small drift in the rubidium standard would be a problem in maintaining lock. The vendor should clarify the supporting relationship between the rubidium standard shown in categories II and III, and the aging rate of the time base given in category $I$.

According to [6], the counter-timer has a time-base software alignment that is effected by using the $10 \mathrm{MHz}$ rubidium frequency standard, routed through the ICD and the Signal Distribution System (SDS) to channel A of the counter-timer. An "alignment factor" is then a multiplicative factor created by dividing the 
nominal $10 \mathrm{MHz}$ value of the rubidium standard by the measured frequency, i.e.,

$$
\text { time-base alignment factor }=\frac{10 \mathrm{MHz}}{10 \mathrm{MHz}_{\text {measured }}} \text {. }
$$

of course, this is equivalent to an alignment factor as the ratio of periods, i.e.,

$$
\text { time-base alignment factor }=\frac{10 \mathrm{MHz} \text { Period }_{\text {masured }}}{\text { Period }_{10 ~} \mathrm{MHz}_{2}} .
$$

The alignment factor is accepted, according to [6], if the measured frequency is within $\pm 120 \mathrm{~Hz}$ of $10 \mathrm{MHz}( \pm 12 \mathrm{ppm})$. However, the tolerance specification of the category II rubidium standard of $\pm 0.0048 \mathrm{~Hz}$ means that the ratio of acceptance tolerance for the counter-timer to the tolerance specification of the category II rubidium clock is $120 / 0.0048=25,000$ ! The large software allowance for a $\pm 120 \mathrm{~Hz}$ difference most likely takes into account the $\pm 2 \mathrm{ppm} / \mathrm{yr}$ $( \pm 20 \mathrm{~Hz} / \mathrm{yr})$ drift and other sources of error in the timing-generator card, as well as significant errors in the counter-timer measurement electronics. The most recent available specification [17, page 43] also indicates that the timebase error of the counter-timer is "less than 12 parts in million per year." The vendor should consider how to reduce the errors contributed by the timing generator, and the errors in the measurement electronics of the counter-timer, in order to take better advantage of the high accuracy and low, long-term drift of the rubidium standard.

\section{$\underline{5.1 .2}$ Impedance}

The specified $50 \Omega$ and $I M \Omega$ values for the input impedance of the counter are nominal "design parameters." However, for adequate performance in many applications, a tolerance on these impedance values over the "dc" to $100 \mathrm{MHz}$ frequency range of interest is an important consideration for time-interval and phase measurements of the counter-timer. Also, the impedance match between channels $A$ and $B$ is important. The vendor should consider setting a tolerance on the impedance specifications for channels A and B, over the full operating frequency range.

\subsubsection{Input Voltage}

Most specifications for the input voltage range of counter-timers spell out the units for the range, i.e., RMS, ave., peak-to-peak, etc. The vendor should clarify the ambiguity of the units for the input voltage given in $[4,5,16,17]$.

\subsubsection{Frequency Measurement}

With the input signal dc or ac coupled, the tolerance specification given $[4,5,16,17]$ for frequency measurements is \pm 1 count \pm time-base error. With the time-base alignment factor calculated as described above, the actual input frequency is then determined by [6]

actual frequency $=$ (measured frequency) (time-base alignment factor). 
Consequently, it would seem that any time-base errors are removed from the measurement of frequency. The time-base error term in the tolerance specification evidently includes further offsets and/or drifts that have occurred in the time base after doing an alignment with the $10 \mathrm{MHz}$ rubidium standard. Hopefully, these errors will be small, but the question is how small? Unless a year has elapsed since the last alignment, surely this error will be considerably less than the specified $\pm 12 \mathrm{ppm}$ [17]. With the use of a time-base alignment factor, the vendor should clarify the ambiguity of the remaining timebase error in the tolerance specification for frequency measurements, and this term should be quantified. Similarly, the \pm 1 count term in the tolerance specification (due to quantization error) means that the error for small input signal frequencies is large relative to a full-scale input frequency (unless the counter-timer can be used in an autoranging mode that would make the \pm 1 count be one digit out of the full-scale count on a given range). The vendor should clarify the meaning of the \pm 1 count term in the tolerance specification for frequency measurements.

Without clarifying either the \pm 1 count error or the time-base error terms, it is difficult to determine the expected accuracy of a frequency measurement. However, for a $10 \mathrm{MHz}$ input signal frequency (assumed read on a full-scale range of $10 \mathrm{MHz}$ ), and a time-base error of only $\pm 2 \mathrm{ppm}$ (the annual drift), the measurement error would be

$$
\begin{aligned}
\text { error }_{10 \mathrm{MHz}} & = \pm\left(1 \text { count in } 10^{7}+2 \mathrm{ppm}\right) 10 \mathrm{MHz} \\
& = \pm(2.1 \mathrm{ppm}) 10^{7} \mathrm{~Hz} \\
& = \pm\left(2.1 \times 10^{-6}\right) 10^{7} \mathrm{~Hz} \\
& = \pm 21 \mathrm{~Hz}
\end{aligned}
$$

Therefore, the test accuracy ratio (TAR) for this measurement, relative to the specified tolerance of $\pm 0.0048 \mathrm{~Hz}$ for the category II rubidium standard, would be

$$
\operatorname{TAR}=\frac{\text { error }_{10 \mathrm{MHz}}}{ \pm 0.0048 \mathrm{~Hz}}=\frac{ \pm 21 \mathrm{~Hz}}{ \pm 0.0048 \mathrm{~Hz}}=4375
$$

Hence, the TAR > 500, as indicated in [5,6], although so large a TAR is rather meaningless in terms of assuring the accuracy of the measurement relative to the rubidium standard.

\subsubsection{Time Measurement (Interval and Period)}

The time measurement range is given $[4,5,16,17]$ as 100 ns to $10,000 \mathrm{~s}$ with a tolerance specification of \pm 10 ns \pm 1 count \pm time-base error. With the timebase alignment factor calculated as described above, the actual input time interval (or period) is then determined by [6]

$$
\text { actual time parameter }=\text { (measured time }) \div(\text { time-base alignment factor }) \text {. }
$$

Consequently, as mentioned above under frequency measurement, it would seem that any time-base errors are removed from the measurement of time interval or period. 
Once again, the time-base error term in the tolerance specification is ambiguous, and evidently includes further offsets and/or drifts that have occurred in the time base after doing an alignment with the $10 \mathrm{MHz}$ rubidium standard (see section 1.4 above).

Most manufacturers of counter-timers include a term in the accuracy or tolerance specification for time interval or period that includes the effects of triggerlevel timing error, since this error can be significant. This timing error is due to the error in starting and stopping the gating of the signal to the internal counter when the input signal passes through a programmed trigger level. Noise on the input signal can also cause this error to increase.

The existing method for trigger-level alignment [6] is to set up a $1.2 \mathrm{~V}_{\text {peak }}$, $20 \mathrm{kHz}$ triangle wave from the Arbitrary Function Generator (AFG), as measured by the IFTE DMM, connect this signal to channel A of the counter-timer, and then increment or decrement the trigger level to find the highest setting on which channel A will trigger with the $1.2 \mathrm{~V}_{\mathrm{peak}}$ signal. Based on this single measurement, a multiplicative correction factor is then applied to all programmed trigger-level settings. Although this prescribed procedure may work in some cases, it contains several weaknesses:

1) The $1.2 \mathrm{~V}_{\text {peak }}$ amplitude is based on measurements made by the RMSresponding DMM. Any distortions in the triangle-wave output signal from the AFG, or in the input channel of the DMM, will cause the peak-to-RMS relationship to deviate from the ideal $\left(V_{p e a k}=\sqrt{ } 3 V_{R M S}\right)$.

2) Only the rising-edge trigger level is tested. However, hysteresis in the trigger circuitry will likely cause a difference in actual trigger levels between rising-edge and falling-edge measurements.

3) Only a positive polarity signal is tested, which may cause significant errors. With only a single point correction test, gain and offset errors are not taken into account in the multiplicative trigger-level alignment factor.

4) Only a single-frequency, triangle waveform is tested at its positive peak. This procedure will likely mask problems related to slew-rate limitations.

To overcome these weaknesses, the following changes in the trigger-level alignment are proposed, based on some preliminary trigger-level alignment tests performed at NIST:

1) Use a sine wave from the AFG instead of a triangle wave. Ideal sine waves are generally easier to approximate than ideal triangle waves. Also, this change will reduce the dependence of the alignment test on the exact linearity of the AFG and the DMM.

2) The trigger-level alignment test should be performed for both positive and negative peaks (on both rising and falling edges). Average readings are then taken and stored, which allows calculating a straight line correction curve based on a two-point measurement (with a likely corresponding offset correction). 
3) To account for slew-rate limitations, a test should be performed to see that positive pulse-width and negative pulse-width measurements agree. A simple test is to make pulse-width measurements for sinusoidal waves triggered at $0.0 \mathrm{~V}$ and compare these with corresponding (half) period measurements.

4) The above tests should be performed at several frequencies and amplitudes, and for both ac as well as dc coupling.

The $\pm 10 \mathrm{~ns}$ term in the tolerance specification appears to be a rather large error that could account for a variety of error sources, including the triggerlevel timing error just mentioned above. Another such source is the channel to channel delay difference, or offset, between channel A and channel B. By applying the same input signal to both $A$ and $B$, this offset $c a n$ be measured directly, and, if significant, subtracted out of the time-interval measurement. The vendor should consider adding to the counter-timer self-alignment software a small amount of code that would provide correcting for trigger-level timing and the channel to channel offset error, so that much of the large \pm 10 ns error could be eliminated, especially for time-interval measurements near $100 \mathrm{~ns}$.

\subsubsection{Phase Measurement}

The phase measurement capability in a counter-timer instrument is based on the more basic time interval and period measuring functions found in most countertimers. Phase angle(s) between two sinusoidal input signals, one applied to channel $A$ and the other to channel $B$, can be determined by measuring the frequency of both inputs, taking the ratio of these frequencies (to ensure that both are the same), and then measuring the time interval between corresponding trigger-level crossings (typically zero volts), as well as the period of the input signal, i.e.,

$$
\phi_{A-B}=\frac{\left(T_{A-B}\right) 360^{\circ}}{P} \text {, }
$$

where $\phi_{A-B}=$ phase angle of channel A relative to channel $B$ in degrees

$$
\begin{aligned}
T_{A-B} & =\text { measured time interval of } \mathrm{ch} \text {. A relative to } \mathrm{ch} . \mathrm{B} \\
\mathbf{P} & =\text { measured period of the sinusoidal input signals. }
\end{aligned}
$$

The error in determining $\phi$ is then dependent on the errors in measuring $T_{A-B}$ and $P$. Since the signal frequency, $f$, is simply the reciprocal of the period, $P$, then $\phi$ can also be expressed as

$$
\phi_{A-B}=\left(T_{A-B}\right) f\left(360^{\circ}\right) \text {. }
$$

Consequently, the error in $\phi$ (and, thus, the associated tolerance specification) is dependent on the sum of the errors in measuring $T_{A-B}$ and $f$ (errors add for multiplicative variables). As indicated in $[4,5,16,17]$, the tolerance in the 
measurement of phase is then \pm frequency measurement accuracy \pm time-interval measurement accuracy. Therefore, this tolerance can be expressed as

$$
\text { error } \phi_{A-B}= \pm 10 \text { ns } \pm 2 \text { counts } \pm 2 \text { (time-base error). }
$$

To express the phase angle error in degrees, all of the terms must be consistent in their units and converted to degrees, i.e.,

error $\phi_{A-B}($ deg. $)=\frac{ \pm(10 \mathrm{~ns}+2 \text { (counts in ns })+2(12 \mathrm{ppm}(\mathrm{P}[\text { in ns }]))) 360^{\circ}}{\mathrm{P}[\text { in } \mathrm{ns}]}$.

Again, the same comments about these error terms can be made, as were made above, concerning quantifying the time-base error and correcting for much of the large \pm 10 ns time offset. Also, as described in $[5,6]$, the range with dc coupling is indicated to be from "dc" to $100 \mathrm{MHz}$. Obviously, with $\mathrm{f}=0$ the measurement of a phase angle is meaningless. The vendor should revise the specified frequency range for phase measurements under category $I[5,6]$ at some low frequency cutoff.

\subsubsection{Category II and III Standards and Support Equipment}

Under category II of the Calibration/Measurement Requirements Summary [5,6] is shown the $10 \mathrm{MHz}$ rubidium standard (contained in the rf section of the station) having a frequency tolerance of $\pm 0.0048 \mathrm{~Hz}$, or $\pm 0.00048 \mathrm{ppm}$. This tolerance is then supported by the very same rubidium frequency standard, presumably located in an environmentally controlled standards laboratory. As indicated above in section 1.1, the accuracy of the category III rubidium standard is $\pm\left(1 \times 10^{-11}\right)$ or $0.00001 \mathrm{ppm}$, and the long-term stability is $\pm 4 \times 10^{-11} / \mathrm{mo} .,( \pm 0.00004 \mathrm{ppm} / \mathrm{mo}$.$) ,$ or $\pm 0.00048 \mathrm{ppm} / \mathrm{yr}$ (1inear extrapolation). Consequently, the category III standard could be in error in one year, due only to long-term stability, by as much as the $\pm 0.0048 \mathrm{~Hz}$ frequency tolerance specification for the category II standard. Therefore, the calibration interval for the category III rubidium standard should be set at less than one year (preferably six months) in order to support the calibration of the category II rubidium standard adequately.

The specified [3] temperature stability of $\pm 4 \times 10^{-10}$ from $-10^{\circ} \mathrm{C}$ to $50^{\circ} \mathrm{C}$ (corresponding to $0.66 \times 10^{-11} /{ }^{\circ} \mathrm{C}$ ) may also need to be taken into account, depending on the laboratory, in order to provide an adequate accuracy ratio to support the $\pm 0.0048 \mathrm{~Hz}$ tolerance of the category II rubidium standard. For example, if the laboratory has a temperature control of only $\pm 20^{\circ} \mathrm{C}$, then the rubidium standard could change by $\pm 1.32 \times 10^{-10}$, or $\pm 0.000132 \mathrm{ppm}(0.00132 \mathrm{~Hz})$. This is a factor of only 3.64 times the category II frequency tolerance specification. Of course, with the $\pm 2^{\circ} \mathrm{C}$ temperature control of a good standards lab, the temperature stability problem is essentially negligible.

\section{$\underline{5.2 \text { Digitizer }}$}

The analysis thus far of the calibration support for the three-function card has focused on the description of the specifications under category I of the Calibration/Measurement Requirements Summary $[5,6]$. However, with the availability of the most recent system specifications $[16,17]$, it is apparent that the design and specifications for the digitizer portion of this card have been changing. From [5,6] the specifications were for an 8-and 12-bit 
digitizer, having an input range of $\pm 100 \mathrm{mV}$ to $\pm 200 \mathrm{~V}$, an amplitude accuracy as good as $\pm 1.4 \%$ (dc to $500 \mathrm{kHz}$ ), and sampling storage of 2048 8-bit samples (4096 12-bit samples). The specifications from [16] were changed to 6 -bit resolution, input range of $\pm 100 \mathrm{mV}$ to $\pm 16 \mathrm{~V}$, best amplitude accuracy of $\pm 6 \%$ (dc to $1 \mathrm{MHz}$ ), and maximum storage depth of 1001 samples. The most recent specification [17] is now back to 8 - and 12-bits, input range of $\pm 100 \mathrm{mV}$ to $\pm 100 \mathrm{~V}$ ( $250 \mathrm{~V} \max . ?)$, best amplitude accuracy of $\pm 6 \%$ (dc to $1 \mathrm{MHz}$ ), and storage of 1001 samples, maximum. Therefore, the following discussion will address the description and support categories of $[5,6]$ with the latest specifications [17] in mind.

\subsubsection{Input Voltage Range}

Most specifications for the input voltage range of digitizers spell out the units for the range, i.e., RMS, ave., peak-to-peak, etc. The vendor should clarify the ambiguity of the units for the input voltage range given in $[4,5,16,17]$.

\section{2 .2 Impedance}

The specified $50 \Omega$ and $1 \mathrm{M} \Omega$ values for the input impedance of the digitizer are nominal "design parameters." However, for adequate performance in many applications, a tolerance on these impedance values over the "dc" to $50 \mathrm{MHz}$ frequency range of interest is an important consideration. The vendor should consider setting a tolerance on the impedance specifications over the full operating frequency range.

\subsubsection{Amplitude Accuracy}

In general, this is a specification for the dynamic performance of the digitizer. The principal use of a digitizer, in contrast with a DMM, is as a means of capturing a record of transient and repetitive pulse trains and arbitrary waveforms. Characterizing the performance of digitizers has been the subject of an IEEE technical committee (TC-10, Instrumentation and Measurement Society). After about five years of effort by this committee, a trial-use standard (IEEE Std 1057, Trial-Use Standard for Digitizing Waveform Recorders) has been published [9]. According to this document, to obtain a good measure of the amplitude accuracy of the digitizer, one can apply a variable-frequency, sinewave source with known amplitude (and dc component) to the precision desired for determining the gain and offset errors, which are the principal contributors to amplitude inaccuracy (Section 4.3.1.2 of 1057). In $[5,6]$ the tolerance specifications given are cryptic, e.g., $\pm 1.4 \%$ (dc to $500 \mathrm{kHz}$ ); however, in [16] the specification reads " $\pm 6 \%$ full scale, dc to $1 \mathrm{MHz}, "$ and in [17] the specification reads " $\pm 6 \%$ of full scale of input voltage range, dc to $1 \mathrm{MHz}$ input signal frequency." In any case, however, this performance specification cannot be supported simply by applying dc input voltages from the SA-ICD and making dc offset corrections, as indicated in $[3,4,5]$. Showing these dc standards in category II [5,6] with TARs of 184 and 250 is virtually meaningless in terms of supporting the amplitude accuracy performance of the digitizer as a function of frequency.

One possibility for calibrating the digitizer over the "dc" to $100 \mathrm{kHz}$ frequency range would be to connect the digitizer (50 $\Omega$ input) and DMM (already "self- 
aligned") in parallel to the output of the arbitrary function generator (AFG) via the Signal Distribution System (SDS). Up to $100 \mathrm{kHz}$, the RMS value of the DMM reading should be accurate to $\pm 0.48 \%$ [17]. Assuming the true RMS reading mode of the digitizer and a (low distortion) sine-wave output from the AFG, this comparison provides a TAR calculated as

$$
\operatorname{TAR}=\frac{6 \%\left(2 V_{p}\right)}{0.48 \%\left(V_{R M S}\right)}=\frac{6 \%\left(2 \sqrt{\left.2 V_{R M S}\right)}\right.}{0.48 \%\left(V_{R M S}\right)}=\frac{6 \%\left(2.83 V_{R M S}\right)}{0.48 \%\left(V_{R M S}\right)}=35.4,
$$

where $V_{p}$ is the peak value, and

$V_{R M S}$ is the root mean square value (of the applied sine wave).

This TAR is more than adequate in order to calibrate the digitizer on the lower voltage ranges ( $100 \mathrm{mV}$ to $10 \mathrm{~V}$ ) at frequencies up to $100 \mathrm{kHz}$. Alternatively, it should be noted that the use of section 4.3.1.2 of IEEE Std. 1057 to obtain gain and offset errors requires the implementation of a sine-wave curve fitting procedure of the recorded data from the digitizer; commercial curve fitting software packages may be adequate for this purpose. Simpler matrix versions of the three- and four-parameter, curve-fitting algorithms are planned for the next issue of IEEE Std. 1057.

Since the AFG can output sine waves up to $2 \mathrm{MHz}$, the above approach using the DMM as the reference could also work, in principle, for calibrating the digitizer up to $1 \mathrm{MHz}$. The problem in doing so is that the DMM frequency response (gain flatness) drops off rapidly above $100 \mathrm{kHz}$, so that the DMM accuracy goes to $\pm 3.96 \%$ from $100 \mathrm{kHz}$ to $300 \mathrm{kHz}$, and to $\pm 13.2 \%$ from $300 \mathrm{kHz}$ to $1 \mathrm{MHz}$. Therefore, to verify the $\pm 6 \%$ of full-scale range accuracy specification of the digitizer above $100 \mathrm{kHz}$, the 0.2 to $1.3 \mathrm{~V}_{\mathrm{R} M S}$ ac thermal voltage converter (TVC) in the SA-ICD could be employed. It has a specified transfer accuracy (ac-dc difference) of $\pm 0.05 \%$ (20 Hz to $1 \mathrm{MHz}$ ) [17]. The procedure would be similar to the frequency response test provided for the ac voltage mode of the DMM. The amplitude of the sine waves from the AFG would be corrected up to $1 \mathrm{MHz}$, relative to the amplitude at $100 \mathrm{kHz}$, for example, using the TVC to provide the same dc output voltage over the $100 \mathrm{kHz}$ to $1 \mathrm{MHz}$ range, as read by the DMM in the dc voltage mode. This leveled output from the AFG should be accurate to within the dc voltage tolerance specification of the DMM (approximately $\pm 0.012 \%$ ) plus the transfer accuracy of the TVC $( \pm 0.05 \%$ ), or about $\pm 0.062 \%$, giving a TAR (calculated as above) of $6 \%(2.83) / 0.062 \%=274$, which is much more than adequate. Unfortunately, this approach is only good for signal levels up to the $1.3 \mathrm{~V}_{\mathrm{RMS}}$ limit imposed by the TVC, which does not provide for testing the higher input ranges (up to 25 volts [17]).

For supporting the digitizer amplitude accuracy specifications between $1 \mathrm{MHz}$ and $50 \mathrm{MHz}$, the $25 \mathrm{MHz}$ square-wave output from the AFG could be used if its accuracy of $\pm(4 \%$ of the peak-to-peak programmed value $+15 \mathrm{mV}$ ) held up beyond the specified upper limit of $2 \mathrm{MHz}$ [17]. Since the digitizer accuracy goes to $\pm 15 \%$ ( $1 \mathrm{MHz}-25 \mathrm{MHz}$ ) and $\pm 25 \%$ (25 MHz - $50 \mathrm{MHz}$ ), the TAR would then be either about $15 \% / 4 \%=3.75$ or $25 \% / 4 \%=6.25$. However, the square-wave output from the AFG is bandwidth limited to $25 \mathrm{MHz}$. Therefore, an external rf RMS-responding voltmeter would be needed that has the necessary bandwidth and accuracy at $25 \mathrm{MHz}$ 
to measure the peak-to-peak amplitude of the square-wave output from the AFG. (See section 3.2 below and Appendix B where the RMS and peak-to-peak values of a square wave are discussed). The output of the AFG would be connected directly to the input channels of the digitizer, as well as to the external trigger input. In order to synchronize the sampling of the tops of the square wave, the triggermode delay capability of the digitizer would be utilized, down to 10 ns increments. This feature should readily provide samples whose maximum values are repeatable, and therefore readable by the digitizer in its peak-reading mode, within the accuracy of the digitizer. Using either of the two rf voltmeters mentioned above, which have basic accuracies of $1 \%$, the TAR would be either about $15 \% / 1 \%=15$ or $25 \% / 1 \%=25$.

The vendor should reexamine the proposed calibration support for the amplitude accuracy of the digitizer, providing an adequate means for performing a dynamic ac signal test of the digitizer using the procedures recommended in IEEE Std. 1057 or the methods outlined above. The self-alignment software should be modified to incorporate the necessary code changes and additions for implementing these dynamic tests.

\subsubsection{Input Channel Bandwidth}

Since the specified input channel bandwidth is $50 \mathrm{MHz}$ with the $50 \Omega$ input $[4,5,16,17]$, testing of this capability is needed for calibration support, and would necessitate a signal source having a leveled $50 \mathrm{MHz}$ sine-wave output. Since the maximum specified frequency for the sine-wave output of the internal AFG is only $2 \mathrm{MHz}$, an external, variable-frequency, sine-wave source with a maximum frequency of at least $50 \mathrm{MHz}$ will be required.

With such a source, of course, the sine-wave amplitude accuracy tests recommended above could be extended to the 1-50 $\mathrm{MHz}$ region. However, near the Nyquist frequency of $50 \mathrm{MHz}$ (using the $100 \mathrm{MHz}$ sampling rate of the digitizer), problems of aliasing arise as the number of samples/period becomes coarse and approaches two. To increase the effective sampling rate of the digitizer, a method has been developed at NIST for collecting an equivalent-time record of the real-time coarsely sampled waveform [10]. As described in [10], the sine-wave source should be a frequency-synthesized source in order for the frequency of the sinewave input to be precisely controlled relative to the (100 $\mathrm{MHz}$ ) sampling frequency of the digitizer. The equivalent-time sampling rate is chosen to be a multiple of the sampling frequency so that

$$
f_{q q}=D f_{s} \text {, }
$$

where $D$ is an integer number, $f_{e q}$ is the equivalent-time frequency, and $f_{g}$ is the sampling frequency.

Given a data record of length $M$, the number of real-time samples, $L$, taken during each period is $L$, the integer value of $M / D$. The test frequency of the source, $f_{r}$, is then determined from the expression

$$
f_{I}=f_{s}\left(\frac{D}{L D-1}\right)
$$


Since the sample storage depth of the digitizer is 1001 (the value of $M$ ), then choosing $D=500$, a signal source is needed with a test frequency of exactly

$$
f_{r}=100 \mathrm{MHz}\left(\frac{500}{1000-1}\right)=50.05 \mathrm{MHz} .
$$

The equivalent-time record left in the digitizer's storage would then be a 1001 point sampled $50 \mathrm{MHz}$ sine wave (an effective sampling interval of $20 \mathrm{ps} / \mathrm{sample}$ ) with an amplitude reading (peak or RMS) that is no less than 0.7071 (i.e., $-3 \mathrm{~dB}$ ) of the reading taken from the leveled source at $1 \mathrm{MHz}$.

The vendor should consider adding to the self-alignment program for the digitizer a procedure for making a bandwidth test that can verify the $50 \mathrm{MHz}$ specification. The use of a leveled-frequency, synthesized source is recommended, as described in [10], or a complete frequency response determination made using a fast step generator $[9,10]$.

\subsubsection{Other Performance Specifications}

Besides the Minimum Specifications for

(1) number of digitized bits,

(2) sample rates,

(3) memory length,

(4) input impedance,

(5) analog bandwidth, and

(6) input signal ranges,

the IEEE Std. 1057 (page 9) lists twenty-nine Additional Specifications that are recommended for characterizing the performance of digitizing waveform recorders [9]. The Calibration/Measurement Requirements Sumnary [5,6] for the digitizer contains several of these additional specifications, including amplitude accuracy (Gain and offset in the 1057 Standard), and trigger delay (Trigger delay and jitter in 1057).

However, because of the inherent capability of the digitizer for capturing a record of transient and repetitive pulses and arbitrary waveforms, it is important in many measurement applications of a digitizer to specify its linearity (1057: differential nonlinearity, harmonic distortion and spurious response, and integral nonlinearity), noise (1057: signal-to-noise ratio, effective bits, and random noise), and temporal response (1057: settling time, transition duration of step response (rise time), and slew limit). The vendor should consider making a more comprehensive set of performance specifications for the digitizer, together with the appropriate category II and III supporting equipment and self-alignment software, which can provide the means for fully characterizing the true dynamic performance that can be expected from the digitizer portion of the three-function card. 


\subsection{Arbitrary Function Generator}

With the availability of the most recent system specifications $[16,17]$, it is apparent that the specifications, and perhaps the design, for the AFG portion of the three-function card have been changing. The AFG is described under category I of $[5,6]$ with the usual columnar listing of items and associated specifications. The characteristics of the six available output modes are provided, but the information is described over several pages. A much improved description is provided in $[16,17]$ where the characteristics of the AFG are given in tabular form, making the comparison clearer between the six operating modes for each of the electrical parameters. Therefore, the following discussion will address the description and support categories of [5,6] with the latest specifications [17] in mind.

\subsubsection{Output Impedance}

Although $[5,6]$ specifies the output impedance as $50 \Omega$ or $<5 \Omega$, the specifications in $[16,17]$ simply show $50 \Omega$ under each of the six modes. Although the specified $50 \Omega$ value is a nominal "design parameter," for adequate performance in many applications, a tolerance on this value over the "dc" to $2 \mathrm{MHz}$ frequency range of interest is an important consideration. The vendor should consider setting a tolerance on the output-impedance specification over the full operatingfrequency range.

\subsubsection{Pulsed-DC Mode}

\section{3 .2 .1 Output Voltage}

For the $2 \mathrm{~V}, 4 \mathrm{~V}, 10 \mathrm{~V}$, and $20 \mathrm{~V}$ ranges, the tolerance specification given in $[5,6]$ is \pm ( $4 \%$ of the (peak-to-peak) Programmed Value (PV) $+5 \mathrm{mV}$ ). However, in $[16,17]$ this has been changed to $\pm(4 \%$ of the $P V+15 \mathrm{mV})$, and the ranges are now $1 \mathrm{~V}, 2 \mathrm{~V}, 5 \mathrm{~V}$, and $10 \mathrm{~V}$. To support this specification, the equipment shown under category II is the digitizer with its earlier amplitude accuracy specification of $\pm 1.4 \%$ (assumed to be of the full-scale input range) for a $1 \mathrm{~V}_{\text {peak }}$ ac input at $1 \mathrm{kHz}$. The TAR would then be calculated as

$$
\begin{aligned}
\mathrm{TAR} & =\frac{4 \%[(\text { peak-peak }) \mathrm{PV}]+15 \mathrm{mV}}{1.4 \%[\text { F.S. input range }]} \\
& =\frac{4 \%\left[2\left(1 \mathrm{~V}_{\text {peak }}\right)\right]+15 \mathrm{mV}}{1.4 \%[2 \mathrm{~V}]}=\frac{95 \mathrm{mV}}{28 \mathrm{mV}}=3.39 .
\end{aligned}
$$

Thus, the TAR is 3.39, not the value of 35 given under the tolerance specification of category II. Similar comments hold for the other three ranges as well.

However, since the new digitizer specification for amplitude accuracy is now $\pm 6 \%$ of full-scale input range [17], the TAR then would be $95 \mathrm{mV} / 120 \mathrm{mV}=0.792$, which is not acceptable. Again, an alternative approach is to connect the TVC in the SA-ICD (50 $\Omega$ input) and DMM (already "self-aligned" with a 1 M $\Omega$ input) 
in parallel to the output of the AFG via the Signal Distribution System (SDS), thus terminating the AFG output with an approximately $50 \Omega$ load. As described in Appendix B, the amplitude specification for the pulsed-dc mode of the AFG can be supported by using the reading of a true RMS-responding DMM to compare with the programmed value of the peak-to-peak amplitude of the pulsed waveform.

For example, from the analysis given in Appendix B, the programmed peak-to-peak amplitude of the AFG in the pulsed-dc mode can then be verified by using the internal DMM to measure a pulse train with $25 \%$ duty cycle $(D C=0.25)$, and a dc offset of zero ( $D C O=0$ ), where the total RMS value can be calculated to be half the peak-to-peak amplitude:

From equation (6) of Appendix B,

$$
\begin{aligned}
{\left[R_{\text {total }}\right]^{2} } & =\left(V_{p-p}\right)^{2} / 4+0\left(0+\left(V_{p-p}\right)[2(0.25)-1]\right\} \\
& =\left(V_{p-p}\right)^{2} / 4+0 ; \\
\therefore \quad R_{\text {total }} & =\left(V_{p-p}\right) / 2 .
\end{aligned}
$$

Similarly, from equation (15) of Appendix C,

$$
\begin{aligned}
\mathrm{RMS}_{\text {total }} & =\left\{\left[0+\left(V_{p-p}\right)(0.25-0.5)\right]^{2}+\left(V_{p-p}\right)^{2} 0.25(1-0.25)\right\}^{\frac{1}{2}}, \\
& =\left\{\left(V_{p-p}\right)^{2} / 4+3\left(V_{p-p}\right)^{2} / 4\right)^{\frac{1}{2}} ; \\
\therefore \text { RMS }_{\text {total }} & =\left(V_{p-p}\right) / 2 .
\end{aligned}
$$

Then, from the specifications for the internal DMM, the bandlimited accuracies are $\epsilon_{1}=0.48 \%$ up to $100 \mathrm{kHz}$, and $\epsilon_{2} \simeq 10 \%$, in order to represent (conservatively) the $3.96 \%$ accuracy from $100 \mathrm{kHz}$ to $300 \mathrm{kHz}$ and the $13.2 \%$ accuracy from $300 \mathrm{kHz}$ to $1 \mathrm{MHz}$. The maximum overall RMS error in the DMM (from equations (16) and (26) of Appendix C) is then

$$
\begin{aligned}
\text { RMS }_{\text {er } x x} & =\left[(10 \%)^{2}+\left((0.48 \%)^{2}-(10 \%)^{2}\right)\left(\mathrm{RMS}_{\mathrm{kth}-} / \mathrm{RMS}_{\mathrm{total}}\right)^{2}\right]^{\frac{1}{2}} \\
& =\left[0.01+(-0.00998)\left[\frac{\left(\mathrm{V}_{\mathrm{p}-\mathrm{p}}\right)^{2}\left[1 / 16+2 / \pi^{2} \sum_{n=1}^{k} \frac{\sin ^{2} n(\pi / 4)}{n^{2}}\right]}{\left(\mathrm{V}_{\mathrm{p}-\mathrm{p}}\right)^{2} / 4}\right]\right]^{\frac{1}{2}} \\
& =\left[0.01-0.00998\left[1 / 4+8 / \pi^{2} \sum_{n=1}^{k} \frac{\sin ^{2} n(\pi / 4)}{n^{2}}\right]\right]^{\frac{1}{2}} .
\end{aligned}
$$

Using $k=3$, i.e., only the fundamental, 2nd, and 3 rd harmonics measured with an RMS accuracy of $0.48 \%$,

$$
\text { RMS } \text { rror }=\left[0.01-0.00998\left[1 / 4+8 / \pi^{2}\left[\sin ^{2} \pi / 4+\frac{\sin ^{2} \pi / 2}{4}+\frac{\sin ^{2} 3 \pi / 4}{9}\right]\right]^{\frac{1}{2}}\right.
$$




$$
\begin{aligned}
\text { RMS }_{\text {error }} & =[0.01-0.00998[0.25+.811[0.5+0.25+0.0555]]]^{\frac{3}{2}} \\
\text { RMS }_{\text {error }} & =[0.01-0.00998[0.903]]^{\frac{1}{2}} \\
\therefore \text { RMS }_{\text {error }} & =[0.000988]^{\frac{1}{2}}=0.0314=3.14 \%
\end{aligned}
$$

Thus, the peak-to-peak programmed value (PV) of the pulsed-dc waveform would be measured with an uncertainty of about $\pm 3 \%$ of the total RMS value, and the TAR in this case would then be

$$
\begin{aligned}
& \operatorname{TAR}=\frac{4 \%[(\text { peak-peak }) \mathrm{PV}]+15 \mathrm{mV}}{3.14 \%[(\text { peak-peak }) / 2]} \\
& =\frac{4 \%\left[2 V_{p}-p\right]+15 \mathrm{mV}}{3.14 \%[(2 \mathrm{~V}) / 2]}=\frac{95 \mathrm{mV}}{31 \mathrm{mV}}=3.06
\end{aligned}
$$

which is adequate, and about the same as the TAR obtained with the vendor's recommended use of the digitizer (with its earlier amplitude accuracy specification of $1.4 \%$ of full-scale input range).

With the DMM change of accuracy occuring at $100 \mathrm{kHz}$, a pulse train (with a maximum fundamental frequency of $33 \mathrm{kHz}$ ) can be tested, as described above. Also, with rise and fall times specified for the AFG as $<50 \mathrm{~ns}$, the $33 \mathrm{kHz}$ pulsed-dc waveform would have fast transition edges relative to a $30 \mu \mathrm{s}$ period, in keeping with the ideal pulsed waveform assumed in the theoretical analysis shown in Appendix C.

To support the peak-to-peak amplitude accuracy specification up to $2 \mathrm{MHz}$, an external RMS-responding voltmeter having an effective accuracy of about $3 \%$ (calculated, if need be, as shown in Appendix C) would be necessary. There are commercial instruments available that have claimed accuracies of $1-3 \%$ over the $100 \mathrm{kHz}$ to $1 \mathrm{GHz}$ frequency range.

The vendor should reexamine the proposed calibration support for the amplitude accuracy of the AFG in the pulsed-dc mode, providing an adequate means for performing an RMS voltage measurement of the pulsed-dc output waveform from the AFG, as outlined above. The self-alignment software should be modified to incorporate the necessary code additions for implementing these tests in determining the accuracy of the programmed peak-to-peak amplitude.

\section{$\underline{5.3 .2 .2 \quad \mathrm{DC} \text { offset }}$}

The dc offset is specified in $[5,6]$ to range from -10 to +10 volts with a tolerance of $\pm(5 \%$ of the programmed value $\pm 20 \mathrm{mV})$, whereas the more recent specification [17] has changed the range to -5 to +5 volts, with a resolution of $5 \mathrm{mV}$, and a tolerance of $\pm(5 \%$ of the programmed value $+20 \mathrm{mV})$. Using the DMM in the dc voltage mode, as indicated in category II of [5,6], does provide 
a convenient means for calibrating the dc offset since the DMM accuracy specification is claimed to be $\pm(0.012 \%$ input +10 digits $)$. However, as described in [14], it is rather doubtful that the DMM can read dc voltage to the accuracy claimed over the full range from $\pm 20 \mathrm{mV}$ to $\pm 5 \mathrm{~V}$ because of the twopoint calibration procedure used by the vendor and the $\pm 5 \%$ limit allowed for the gain error in the self-alignment software. Assuming that the $\pm(0.012 \%$ input +10 digits) claimed accuracy for the DMM is valid, then the TAR with a programmed dc offset of $5 \mathrm{~V}$ would be

$$
\operatorname{TAR}=\frac{ \pm(5 \% 5 \mathrm{~V}+20 \mathrm{mV})}{ \pm\left(0.012 \% 5 \mathrm{~V}+10.100 \times 10^{-6} \mathrm{~V}\right)}=\frac{270 \mathrm{mV}}{1.6 \mathrm{mV}}=169
$$

rather than the TAR of 236 shown for the reading of $10 \mathrm{~V}$ in the category II column of $[5,6]$. Even if the accuracy of the DMM is 10 times worse, the TAR would still be more than adequate for calibrating the dc offset of the AFG.

Alternatively, from the analysis given in Appendix $B$, the programmed dc offset of the AFG in the pulsed-dc mode can be verified dynamically by again using the DMM to measure a pulse train with $25 \%$ duty cycle $(D C=0.25)$, only this time programmed to have a dc offset of half the peak-peak amplitude ( $\left.D C O=V_{p-p} / 2\right)$. The total RMS value can be calculated once again to be half the peak-to-peak amplitude:

From equation (6) of Appendix B,

$$
\begin{aligned}
{\left[\mathrm{RMS}_{\text {total }}\right]^{2} } & =\left(V_{p-p}\right)^{2} / 4+\left(V_{p-p}\right) / 2\left(\left(V_{p-p}\right) / 2+\left(V_{p-p}\right)[2(0.25)-1]\right\} \\
& =\left(V_{p-p}\right)^{2} / 4+\left(V_{p-p}\right) / 2\left(\left(V_{p-p}\right) / 2+\left(V_{p-p}\right)[-1 / 2]\right\} \\
& =\left(V_{p-p}\right)^{2} / 4+0 ; \\
\therefore \quad \text { RMS }_{\text {total }} & =\left(V_{p-p}\right) / 2 .
\end{aligned}
$$

Equation (15) of Appendix $C$ gives the same result.

Then, from the DMM specifications, the uncertainty in the RMS reading with $k=3$ is again shown (as calculated above in section 5.3.2.1 for the case of no dc offset), to be about $\pm 3 \%$ of the total RMS value. Hence, the programmed dc offset (as superimposed on a $25 \%$ duty cycle, pulsed-dc signal with a maximum fundamental frequency of $33 \mathrm{kHz}$ ) can be determined with a TAR of

$$
\begin{aligned}
\text { TAR } & =\frac{5 \%[P V]+20 \mathrm{mV}}{3.14 \%[(\text { peak-peak }) / 2]} \\
& \left.=\frac{5 \%[(2 \mathrm{~V}}{3.14 \%[(2 \mathrm{~V}) / 2]}\right) / 20 \mathrm{mV} \\
& =\frac{70 \mathrm{mV}}{31 \mathrm{mV}}=2.26,
\end{aligned}
$$

which is probably adequate.

The vendor should consider adding code to the self-alignment software for the AFG that would utilize the RMS-responding DMM to determine the accuracy of the dc offset, as reflected in a pulsed-dc output signal from the AFG. 


\section{3 .2 .3 Frequency Output}

The frequency range for the pulsed-dc mode is from $0.02 \mathrm{~Hz}$ to $25 \mathrm{MHz}[4,5,8]$, although it was specified at one time to go up only to $2 \mathrm{MHz}$ [16]. The tolerance specification for the frequency of $\pm(0.001 \%$ of programmed value $)$ was also changed [16], but is again the value specified in [17]. Equivalently, this specification calls for a frequency tolerance (accuracy) of $\pm 10 \mathrm{ppm}$ of the programmed frequency.

The category II equipment specified to support the frequency accuracy is the counter-timer of the system, which covers a frequency range of "dc" to $100 \mathrm{MHz}$, and has a tolerance specification of \pm 1 count \pm time-base error. Thus, the counter-timer can cover the needed frequency range, but as described above in section 1.4 , the \pm 1 count term in the counter-timer's tolerance specification (due to quantization error) means that the error for small input signal frequencies is large relative to a full-scale input frequency (unless the counter-timer can be used in an autoranging mode that would make the \pm 1 count be one digit out of the full-scale count on a given range). Then, assuming that for any input frequency the counter-timer can autorange with a quantizing error of 1 count in $10^{6}$, and that the time-base error is the maximum specified $\pm 12 \mathrm{ppm}$, the error band in measuring an output frequency from the AFG with the countertimer would be

$$
\begin{aligned}
\text { error } & = \pm\left(1 \text { count in } 10^{6}+12 \mathrm{ppm}\right)= \pm(1 \mathrm{ppm}+12 \mathrm{ppm}) \\
& = \pm 13 \mathrm{ppm} .
\end{aligned}
$$

Obviously, this error band would not be adequate to support the $\pm 10 \mathrm{ppm}$ tolerance of the programmed frequency from the AFG. However, if it is assumed that the time-base error in the counter-timer can be kept to $\pm 2 \mathrm{ppm}$ (the annual drift), then the error band would reduce to

$$
\begin{aligned}
\text { error } & = \pm\left(1 \text { count in } 10^{6}+2 \mathrm{ppm}\right)= \pm(1 \mathrm{ppm}+2 \mathrm{ppm}) \\
& = \pm 3 \mathrm{ppm} .
\end{aligned}
$$

In this case, the TAR would be $10 / 3=3.33$, which is probably adequate.

However, according to [6], the self-alignment software for the AFG performs a "timebase alignment" by measuring a programmed $1 \mathrm{MHz}$ frequency signal from the AFG using the counter-timer, and accepting the value if it is within the limits of $\pm 500 \mathrm{~Hz}$. This limit allows an error band in the measured frequency of

$$
\text { error }= \pm 500 / 10^{6}= \pm 0.05 \%= \pm 500 \mathrm{ppm} \text {, }
$$

which is $500 / 10=50$ times worse than the tolerance specification $[4,5,8] !$ With the use of a multiplicative time-base alignment factor for measuring signal frequency from the AFG, the vendor should change the allowed error limits in the self-alignment software to be more consistent with the tolerance specification. Otherwise, the self-alignment correction process could produce a worse error in the output-signal frequency than if there were no self alignment at all. 


\subsubsection{Pulse Width}

The pulse-width range for the pulsed-dc mode is $20 \mathrm{~ns}$ to $39.995 \mathrm{~s}$ [17], although it was specified at one time [16] to be $5 \%$ to $95 \%$ of the programmed period. The tolerance specification for the pulse width of $\pm(0.001 \%$ of programmed value) was also changed [16], but is again the value specified in [17]. Equivalently, this specification calls for a pulse-width tolerance of $\pm 10 \mathrm{ppm}$ of the programmed pulse width, which amounts to \pm 200 fs for a 20 ns pulse width!

The category II equipment specified [5,6] to support the pulse-width accuracy is the counter-timer of the system, with a specified range from 100 ns to $10,000 \mathrm{~s}$, the same as the range for time measurement (interval and period). Also, the tolerance specification is shown as $\pm 2 \mathrm{ppm}+1$ count, which is not the $\pm 10 \mathrm{~ns} \pm 1$ count \pm time-base error specification given for time measurements made by the counter-timer. Thus, the counter-timer does not cover the needed pulsewidth range (down to $20 \mathrm{~ns}$ ), nor is the specified accuracy even close to being adequate.

To support the pulse-width accuracy specification over the 20 ns to $40 \mathrm{~s}$ range, an external counter-timer would be required, having the best available accuracy. For example, there are commercial instruments that have minimum pulse width capabilities of 1 to $10 \mathrm{~ns}$ with claimed accuracies of 1 to $5 \mathrm{~ns}$. The vendor should reexamine the proposed claims and calibration support for the pulsewidth accuracy of the AFG in the pulsed-dc mode, particularly at the minimum desired pulse widths. An external counter-timer having the necessary range and best available accuracy likely will be required for measuring the pulse width in'the pulsed-dc output waveform from the AFG. The self-alignment software should be modified to incorporate the code additions necessary for implementing these tests.

\section{$\underline{5.3 .3}$ Square Wave}

Since the square-wave output mode is the same as the pulsed-dc mode with the duty cycle (DC) set at $50 \%$, the discussion in section 5.3 .2 also applies to supporting the square-wave specifications, with minor differences.

\subsubsection{Output Voltage}

From the analysis given in Appendix B, the programmed peak-to-peak amplitude of the AFG in the square-wave mode can then be verified by using the internal DMM to measure a square wave (pulse train with $50 \%$ duty cycle $(D C=0.50$ ), and a dc offset of zero, where the total RMS value can be calculated to be half the peakto-peak amplitude:

$$
\begin{aligned}
& \text { From equation (6) of Appendix } B \\
& \begin{aligned}
{\left[\mathrm{RMS}_{\text {tot a } 1]^{2}}\right.} & =\left(\mathrm{V}_{p-p}\right)^{2} / 4+0\left(0+\left(\mathrm{V}_{p-p}\right)[2(0.50)-1]\right) \\
& =\left(V_{p-p}\right)^{2} / 4+0 ; \\
\therefore \quad \text { RMS }_{\text {tot a }} & =\left(V_{p-p}\right) / 2 .
\end{aligned}
\end{aligned}
$$


Similarly, from equation (15) of Appendix C,

$$
\begin{aligned}
{\left[R M S_{\text {total }}\right]^{2} } & =\left\{\left(0+\left(V_{p-p}\right)(0.50-0.5)\right]^{2}+\left(V_{p-p}\right)^{2} 0.50(1-0.50)\right\}, \\
& =\left\{0+\left(V_{p-p}\right)^{2} / 4\right\} ; \\
\therefore \quad R M S_{\text {total }} & =\left(V_{p-p}\right) / 2 .
\end{aligned}
$$

Then, from the specifications for the internal DMM, the bandlimited accuracies are $\epsilon_{1}=0.48 \%$ up to $100 \mathrm{kHz}$, and $\epsilon_{2} \approx 10 \%$, in order to represent (conservatively) the $3.96 \%$ accuracy from $100 \mathrm{kHz}$ to $300 \mathrm{kHz}$ and the $13.2 \%$ accuracy from $300 \mathrm{kHz}$ to $1 \mathrm{MHz}$. The maximum overall RMS error in the DMM (from equations (16) and (26) of Appendix C) is then

$$
\begin{aligned}
& \text { RMS }_{\text {eror }}=\left[(10 \%)^{2}+\left((0.48 \%)^{2}-(10 \%)^{2}\right)\left(\mathrm{RMS}_{\mathrm{kth}}-/ \mathrm{RMS}_{\mathrm{total}}\right)^{2}\right]^{\frac{1}{2}}, \\
& =\left[0.01+(-0.00998)\left[\frac{\left(V_{p-p}\right)^{2}\left[2 / \pi^{2} \sum_{n=1}^{k} \frac{\sin ^{2} n(\pi / 2)}{n^{2}}\right.}{\left(V_{p-p}\right)^{2} / 4}\right]\right]^{\frac{1}{2}} \\
& =\left[0.01-0.00998\left[8 / \pi^{2} \sum_{n=1}^{k} \frac{\sin ^{2} n(\pi / 2)}{n^{2}}\right]\right]^{\frac{1}{2}} \text {. }
\end{aligned}
$$

Using $k=3$, i.e., only the fundamental, 2nd, and 3 rd harmonics measured with an RMS accuracy of $0.48 \%$,

$$
\begin{aligned}
\operatorname{RMS}_{\text {error }} & =\left[0.01-0.00998\left[8 / \pi^{2}\left[\sin ^{2} \pi / 2+\frac{\sin ^{2} \pi}{4}+\frac{\left.\sin ^{2} 3 \pi / 2\right]}{9}\right]\right]^{3 / 2}\right. \\
R_{\text {error }} & =[0.01-0.00998[0.811[1.0+0+0.111]]]^{\frac{1}{2}} \\
\operatorname{RMS}_{\text {error }} & =[0.01-0.00998[0.901]]^{\frac{1}{2}} \\
\therefore \operatorname{RMS}_{\text {error }} & =[0.00101]^{\frac{1}{3}}=0.0318=3.18 \%
\end{aligned}
$$

Thus, the programmed peak-to-peak value of the square-wave signal would be measured with an uncertainty of about $\pm 3 \%$ of the total RMS value, and the TAR in this case would then be 


$$
\begin{aligned}
\text { TAR } & =\frac{4 \%[(\text { peak-peak }) P V]+15 \mathrm{mV}}{3.18 \%[(\text { peak-peak }) / 2]} \\
& =\frac{4 \%[2 \mathrm{~V}}{3.18 \%\left[\left(2 \frac{\mathrm{p}}{\mathrm{V}) / 2]} \mathrm{mV}\right.\right.}=\frac{95 \mathrm{mV}}{32 \mathrm{mV}}=2.97,
\end{aligned}
$$

which is probably adequate.

With the DMM change of accuracy occuring at $100 \mathrm{kHz}$, then a square wave can be tested, as described above, with a maximum fundamental frequency of $33 \mathrm{kHz}$. Also, with rise and fall times specified for the AFG as less than 50 ns, the $33 \mathrm{kHz}$ square wave would have fast transitions relative to a $30 \mu \mathrm{s}$ period, in keeping with the ideal square wave ( $50 \%$ duty cycle pulsed waveform) assumed in the theoretical analysis of Appendix $C$.

To support the peak-to-peak amplitude accuracy specification up to $2 \mathrm{MHz}$, an external RMS-responding voltmeter having an effective accuracy of about $3 \%$ (calculated if need be as shown in the Appendix) would be necessary, as described above in section 5.3.2.1.

The vendor should reexamine the proposed calibration support for the amplitude accuracy of the AFG in the square-wave mode, providing an adequate means for performing an RMS voltage measurement of the square-wave output waveform from the AFG, as outlined above. The self-alignment software should be modified to incorporate the necessary code additions for implementing these tests in determining the accuracy of the programmed peak-to-peak amplitude.

\section{$\underline{5.3 .3 \quad \text { DC Offset }}$}

Essentially the same comments apply as are given in section 5.3.2.2.

\subsubsection{Frequency Output}

Essentially the same comments apply as are given in section 5.3.2.3.

\section{$\underline{5.3 .4 \quad \pm D C \text { Mode }}$}

The $\pm d c$ output mode is specified in $[5,6]$ to cover $2 \mathrm{~V}, 4 \mathrm{~V}, 10 \mathrm{~V}$, and $20 \mathrm{~V}$ ranges with a tolerance of $\pm(4 \%$ of programmed value $+5 \mathrm{mV})$, whereas the more recent specification [17] has changed the range to -5 to +5 volts, with a resolution of $5 \mathrm{mV}$, and a tolerance of \pm ( $5 \%$ of programmed value $+20 \mathrm{mV}$ ). Using the DMM in the dc voltage mode, as indicated in category II of $[5,6]$, does provide a convenient means for calibrating the accuracy of the dc mode level since the DMM accuracy specification is claimed to be $\pm(0.012 \%$ input +10 digits). However, as described in [14], it is rather doubtful that the DMM can read dc voltage to the accuracy claimed over the full range from $\pm 20 \mathrm{mV}$ to $\pm 5 \mathrm{~V}$ because of the two-point calibration procedure used by the vendor and the $\pm 5 \%$ limit allowed for the gain error in the self-calibration software for the DMM. Assuming that the $\pm(0.012 \%$ input +10 digits $)$ claimed accuracy for the DMM is valid, then the TAR with a programmed dc output of $1 \mathrm{~V}$ would be 


$$
\operatorname{TAR}=\frac{ \pm(5 \% 1 \mathrm{~V}+20 \mathrm{mV})}{ \pm\left(0.012 \% 1 \mathrm{~V}+10.100 \times 10^{-6} \mathrm{~V}\right)}=\frac{70 \mathrm{mV}}{1.12 \mathrm{mV}}=62.5
$$

rather than the TAR of 250 shown for the reading of $1 \mathrm{~V}$ in the category II column of $[5,6]$. However, even if the accuracy of the DMM is 10 times worse, the TAR would still be more than adequate for calibrating the dc output mode of the AFG.

\section{$\underline{5.3 .5}$ Sine Wave}

\subsubsection{Output Voltage}

For the $2 \mathrm{~V}, 4 \mathrm{~V}, 10 \mathrm{~V}$, and $20 \mathrm{~V}$ ranges, the tolerance specification given in $[5,6]$ is \pm ( $5 \%$ of the (peak-to-peak programmed value) $+5 \mathrm{mV}$ ). However, in $[16,17]$ this has been changed to $\pm(5 \%$ of the $P V+15 \mathrm{mV})$, and the ranges are now $1 \mathrm{~V}, 2 \mathrm{~V}, 5 \mathrm{~V}$, and $10 \mathrm{~V}$. To support this specification, the equipment shown under Category II is the DMM with the tolerance specification of $0.12 \%+50$ digits (counts) for its $1 \mathrm{~V}, 10 \mathrm{~V}$, and $100 \mathrm{~V}$ ranges at $20 \mathrm{kHz}$. Obviously, with the new specification [17], then only the $1 \mathrm{~V}$ and $10 \mathrm{~V}$ ranges of the DMM would be needed.

Then, with the AFG outputting a programmed peak-to-peak sine-wave voltage and the DMM reading the RMS value, the TAR for a programmed $1 \mathrm{~V}_{\mathrm{p}-\mathrm{p}}$ value at $20 \mathrm{kHz}$ would be calculated as

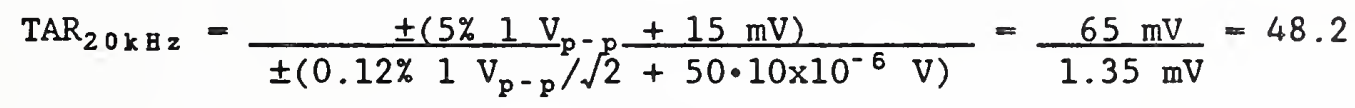

rather than the TAR of 36 shown in the Category II column of $[5,6]$, which used the earlier tolerance specification of the AFG and did not account for the programmed peak-to-peak value of the AFG signal vs. RMS reading of the DMM. Similar comments hold for the other three ranges as well.

Of course, the performance of the AFG at higher frequencies must also be confirmed with a calibration test, since there is no assurance that the output is flat with frequency. Therefore, the DMM should be used to make measurements of the sine-wave output at least up to $100 \mathrm{kHz}$, where the TAR would be

$$
\text { TAR } 100 \mathrm{kBz}=\frac{ \pm\left(5 \% 1 \mathrm{~V}_{\mathrm{p}} \mathrm{p}+15 \mathrm{mV}\right)}{ \pm\left(0.36 \% 1 \mathrm{~V}_{\mathrm{p}-\mathrm{p}} / \sqrt{2}+120 \cdot 10 \times 10^{-6} \mathrm{~V}\right)}=\frac{65 \mathrm{mV}}{3.75 \mathrm{mV}}=17.3
$$

which is more than adequate. Even if the DMM is used up to $300 \mathrm{kHz}$, the TAR would be

$$
\mathrm{TAR}_{300 \mathrm{kBz}}=\frac{ \pm\left(5 \% 1 \mathrm{~V}_{\mathrm{p}}-\mathrm{p}+15 \mathrm{mV}\right)}{ \pm\left(3.6 \% 1 \mathrm{~V}_{\mathrm{p}-\mathrm{p}} / \sqrt{2}+360 \cdot 10 \times 10^{-6} \mathrm{~V}\right)}=\frac{65 \mathrm{mV}}{29 \mathrm{mV}}=2.24
$$

which is probably adequate.

To support the sine-wave amplitude accuracy specification up to $2 \mathrm{MHz}$, an external RMS-responding voltmeter having an effective accuracy of about $1 \%$ would be necessary, as described above in section 5.3.2.1. 
As described in [6], however, the self-alignment procedure used for correcting the amplitude of the sine-wave output of the AFG is to store a "range alignment factor" that is created by setting up a $20 \mathrm{kHz}$ sinusoidal signal with a $500 \mathrm{mV}$ peak value and reading the true RMS value of the waveform using the DMM. The reading is converted to peak voltage and is accepted if it is within $\pm 15 \%$ of the $500 \mathrm{mV}$ programmed peak value. If it is acceptable, the measured peak value is subtracted from the programmed peak value of the signal to create an additive voltage alignment factor for the $50 \mathrm{mV}-1 \mathrm{~V}$ peak-to-peak range. Similarly, range alignment factors are created for the other ( $2 \mathrm{~V}, 5 \mathrm{~V}$, and $10 \mathrm{~V})$ ranges and accepted if within limits of $\pm 10 \%$ of the programmed value. This limit allows an error in the programmed amplitude that is either about $\pm 15 \% / \pm 5 \%=3$ times, or $\pm 10 \% / \pm 5 \%=2$ times worse than the specification $[4,5,8]$ tolerance. These limits are not unreasonable, but they certainly are not consistent with the performance expected, based on the tolerance specification.

The vendor should reexamine the proposed calibration support for the amplitude accuracy of the AFG in the sine-wave mode, providing an adequate means for performing an RMS voltage measurement of the sine-wave output from the AFG over the full specified operating frequency range, as outlined above. The selfalignment software should be modified to incorporate the necessary code additions for implementing these tests in determining the accuracy of the programmed peakto-peak amplitude.

\section{$\underline{5.3 .5 .2}$ DC Offset}

Essentially the same comments apply as are given in section 5.3.2.2.

\subsubsection{Frequency Output}

Essentially the same comments apply as are given in section 5.3.2.3.

\section{$\underline{5.3 .6}$ Arbitrary Wave}

Since the CMRS specifications given in $[5,6]$ for the arbitrary-wave output mode are similar to the pulsed-dc and square-wave modes, the discussion describing the calibration support for these output waveforms (from sections 5.3.2 and 5.3.3 above) also applies to supporting the arbitrary wave capability of the AFG, with some minor differences.

\subsubsection{Output Voltage}

For the $2 \mathrm{~V}, 4 \mathrm{~V}, 10 \mathrm{~V}$, and $20 \mathrm{~V}$ ranges, the tolerance specification given in $[5,6]$ is \pm (6\% of the (peak-to-peak programmed value) $+5 \mathrm{mV}$ ). However, in $[16,17]$ this has been changed to $\pm(6 \%$ of the $P V+15 \mathrm{mV})$, and the peak-to-peak ranges are now $1 \mathrm{~V}, 2 \mathrm{~V}, 5 \mathrm{~V}$, and $10 \mathrm{~V}$. Again, to support this specification, the equipment shown under category II is the digitizer with its earlier specification of $1.4 \%$ (assumed to be of the full-scale input range). As discussed before in sections 5.3.2.1. and 5.3.3.1., with the newest digitizer specifications [17] of $\pm 6 \%$ (of full-scale input range), the TAR to support the AFG tolerance would not be adequate. In this case, with a programmed arbitrary waveform of $2 \mathrm{~V}_{\mathrm{p}-\mathrm{p}}$ for example, the TAR would be only 


$$
\begin{aligned}
& \mathrm{TAR}=\frac{ \pm(6 \% \text { peak-peak } \mathrm{PV}+15 \mathrm{mV})}{ \pm 6 \%(\mathrm{~F} . \mathrm{S} . \text { input range })} \\
& \mathrm{TAR}=\frac{ \pm\left(6 \% 2 \mathrm{~V}_{\mathrm{p}}-\mathrm{p} \frac{+15 \mathrm{mV})}{ \pm 6 \%}-\frac{135 \mathrm{mV}}{120 \mathrm{mV}}=1.125,\right.}{125},
\end{aligned}
$$

as compared with the TAR of 4.46 shown in the tolerance specification column of Category II $[5,6]$. An alternative approach is to use the same calibration method described above in sections 5.3.2.1 and 5.3.3.1. In this case, the output voltage amplitude accuracy of the arbitrary-waveform mode of the AFG would be determined by programming a pulsed-dc or square-wave output signal, and then using a wideband, true RMS-responding voltmeter to measure the RMS value of the signal, which is related to the peak-to-peak voltage, dc offset, and other waveform parameters.

\subsubsection{DC Offset}

Essentially the same comments apply as are given in section 5.3.2.2.

\section{$\underline{5.3 .7}$ Triangle Wave}

Since the CMRS specifications given in $[5,6]$ for the triangle-wave output mode are similar to the pulsed-dc, square-wave, and arbitrary-wave modes, then the discussion describing the calibration support for these output waveforms (from sections 5.3.2, 5.3.3, and 5.3.6 above) also applies to supporting the trianglewave capability of the AFG.

\section{$\underline{5.3 .7 .1}$ Output Voltage}

From the analysis given in Appendix B, the programmed peak-to-peak amplitude of the AFG in the triangle-wave mode can be verified by using the internal DMM to measure the RMS value of the triangle wave, where the total RMS value (with a zero offset) can be calculated to be:

From equation (8) of Appendix B,

$$
\begin{aligned}
{\left[\mathrm{RMS}_{\text {tota } 1}\right]^{2} } & =\left(\left(\mathrm{V}_{\mathrm{p}-\mathrm{p}}\right)^{2} / 12+(\mathrm{DCO})^{2}\right) \\
& =\left(\mathrm{V}_{\mathrm{p}-\mathrm{p}}\right)^{2} / 12+0 ; \\
\therefore \quad \mathrm{RMS}_{\text {total }} & =\left(\mathrm{V}_{\mathrm{p}-\mathrm{p}}\right) / 2 \sqrt{3} .
\end{aligned}
$$

Then, from the specifications for the internal DMM (with $\epsilon_{1}=0.48 \%$ up to $100 \mathrm{kHz}$ and $\epsilon_{2}$ made approximately 10\%), the maximum overall RMS error in the DMM (from equations (20) and (26) of Appendix C) is then

$$
\begin{aligned}
\text { RMS }_{\text {error }} & =\left[(10 \%)^{2}+\left((0.48 \%)^{2}-(10 \%)^{2}\right)\left(\mathrm{RMS}_{\mathrm{kth}-} / \mathrm{RMS}_{\mathrm{total}}\right)^{2}\right]^{\frac{2}{2}}, \\
& =\left[0.01+(-0.00998)\left[\frac{(D C O)^{2}+8\left(V_{p-p}\right)^{2} / \pi^{4} \sum_{n=0}^{k} 1 /(2 n+1)^{4}}{(D C O)^{2}+\left(V_{p-p}\right)^{2} / 12}\right]\right]^{\frac{k}{2}} .
\end{aligned}
$$


With zero dc offset,

$$
\operatorname{RMS}_{\text {error }}=\left[0.01+(-0.00998)\left[96 / \pi^{4} \sum_{n=0}^{k} 1 /(2 n+1)^{4}\right]\right]^{\frac{1}{2}} \text {. }
$$

Using $k=1$, i.e., only the fundamental measured with an RMS accuracy of $0.48 \%$,

$$
\begin{aligned}
& \left.\operatorname{RMS}_{\text {error }}=\left[\begin{array}{lll}
0.01 & -0.00998\left[96 / \pi^{4}\right. & \left\{1 / 1^{4}\right\}
\end{array}\right]\right]^{\frac{1}{2}} \text {, } \\
& \text { RMS } \text { error }=\left[0.01-0.00998\left[96 / \pi^{4}\right]\right]^{3 / 2} \text {, } \\
& =\left[\begin{array}{lll}
0.01-0.00998 & {[0.986]}
\end{array}\right]^{\frac{1}{2}} \text {, } \\
& =[0.01-0.00984]^{\frac{1}{2}}=0.0126=1.26 \%
\end{aligned}
$$

Thus, the peak-to-peak programmed value (PV) of the triangle waveform would be measured with an uncertainty of about $\pm 1.3 \%$ of the total RMS value, and the TAR in this case for a $2 \mathrm{~V}_{\mathrm{p}-\mathrm{p}}$ signal at up to $100 \mathrm{kHz}$ would then be

$$
\begin{aligned}
\operatorname{TAR}_{100 \mathrm{kHz}} & =\frac{6 \%[\text { (peak-peak }) \mathrm{PV}]+15 \mathrm{mV}}{1.26 \%\left[\left(\mathrm{~V}_{\mathrm{p}-\mathrm{p}}\right) / 2 \sqrt{3}\right]}, \\
& =\frac{6 \%\left[2 \mathrm{~V}_{\mathrm{p}}-\mathrm{p}\right]+15 \mathrm{mV}}{1.26 \%[(2 \mathrm{~V}) / 2 \sqrt{3}]}=\frac{135 \mathrm{mV}}{7.3 \mathrm{mV}}=18.5,
\end{aligned}
$$

which is quite adequate, and approximately four times the TAR obtained with the vendor's recommended use of the digitizer (with its earlier amplitude accuracy specification of $1.4 \%$ of full-scale input range).

To support the peak-to-peak amplitude accuracy specification up to $2 \mathrm{MHz}$, an external RMS-responding voltmeter having an effective accuracy of about $1 \%$ (calculated if need be as shown in Appendix $C$ ) would be necessary, as described in section 5.3.2.1.

The vendor should reexamine the proposed calibration support for the amplitude accuracy of the AFG in the triangle-wave mode, providing an adequate means for performing an RMS voltage measurement of the triangle-wave output from the AFG, as outlined above. The self-alignment software should be modified to incorporate the necessary code additions for implementing these tests in determining the accuracy of the programmed peak-to-peak amplitude. 
Essentially the same comments apply as are given in section 5.3.2.2.

\subsubsection{Frequency Output}

Essentially the same comments apply as are given in section 5.3.2.3.

5.3.8 Frequency. Pulse Width, DC Offset, and Amplitude Stability

5.3.8.1 Frequency/Pulse-Width Stability

The frequency/pulse-width stability for all of the output modes of the AFG is specified as $\pm 0.0025 \%[4,5,17]$. It was specified at one time to be $\pm 0.005 \%$ [16]. In either case, this specification for frequency/pulse-width stability is rather stringent and should include the time and/or temperature intervals over which the deviation is expected to hold, just like many of the other parameter drift tolerances that are given in these documents. Also, this item may be a desired "design parameter," but only by making actual measurements can the realized stability be determined. The vendor should revise the frequency/pulse-width stability specification in the CMRS and IFTE Specification to include the appropriate time and/or temperature intervals allowed for the expected deviation. Also, the appropriate test and measurement equipment needed to support the specification should be spelled out in the CMRS, and the selfalignment software modified to include a test procedure for verifying the frequency/pulse-width stability specification.

\subsubsection{DC offset/Amplitude Stability}

The dc offset/amplitude stability for all of the output modes of the AFG was specified as $\pm 1 \%[5,6]$. It is no longer specified for the various output modes of the AFG $[16,17]$. In any case, this specification for dc offset/amplitude stability should include the time and/or temperature intervals over which the deviation is expected to hold, just like many of the other parameter drift tolerances that are given in these documents. The vendor should revise the dc offset/amplitude stability specification in the CMRS and IFTE Specification to include the appropriate time and/or temperature intervals allowed for the expected deviation. Also, the appropriate test and measurement equipment needed to support the specification should be spelled out in the CMRS, and the selfalignment software modified to include a test procedure for verifying the dc offset/amplitude stability specification.

\subsubsection{Output Delay (Phase Shift)}

The characteristics given in $[16,17]$ include specifications for the output delay for all of the output modes of the AFG (except dc level, of course). The range covered is $\pm 180^{\circ}$ and the resolution is $0.1^{\circ}$. However, for accuracy the specification at one time was $\pm 3^{\circ}[16]$, but was changed to $\pm 0.5^{\circ}$ [17]. Without describing over what frequency range this specification is expected to apply, the $\pm 0.5^{\circ}$ accuracy up to $25 \mathrm{MHz}$ (for the pulsed-dc and square-wave output waveforms) corresponds to a time interval of only 55.5 ps! Even if the phase shift accuracy specification applies only up to $2 \mathrm{MHz}$ (similar to the amplitude 
accuracy specification), the corresponding time interval would be 0.694 ns. This kind of phase uncertainty is not easy to verify; certainly the counter-timer internal to the IFTE station does not have this performance (see section 5.1.6). The vendor should review the accuracy specification for the output delay (phase shift) of the AFG and provide the external test equipment and corresponding selfalignment test procedures needed to support the present $\pm 0.5^{\circ}$ accuracy called for in [17]. 


\section{Test Results and Analysis}

Performance verification tests were run on the DMM, arbitrary function generator, counter-timer, and high-speed digitizer instrument functions contained in one IFTE station (SN 017) and two SA-ICDs (SN 009 and SN 015) during trips made to Tobyhanna Army Depot (TOAD) on January 16, 1991, and on July 30-31, 1991. For these tests a set of NIST-calibrated instrument standards were transported by vehicle to TOAD: An 8\% digit multimeter (Hewlett-Packard Model 3458A), a 5\% digit portable calibrator (Fluke Model 515A), a 6\% digit dual-channel universal source (Hewlett-Packard Model 3245A), and a 16 digit universal time-interval counter (Stanford Research Systems Model SR620). Although performing these tests once on each instrument function of one IFTE station is not a statistically significant sample, these test results may be indicative of the adequacy of the proposed calibration support procedures.

\subsection{Digital Multimeter (DMM)}

The DMM instrument board on the IFTE station (SN 017) was programmed to measure the output from the reference calibrator via a test fixture ICD connected to the "Gold Dot" input/output connector panel. Measurement data on the dc/ac voltage and dc resistance outputs from the reference calibrator were obtained before and then after running a self-alignment program on the station. Two alignments were performed - one using the ICD provided with the station and the second using the ICD (SN 030) associated with a second IFTE station. Table 1 below shows a summary of the results, as well as the IFTE specifications at each test point:

\section{$\underline{\text { Table } 1}$}

IFTE (SN 017) Corrections*

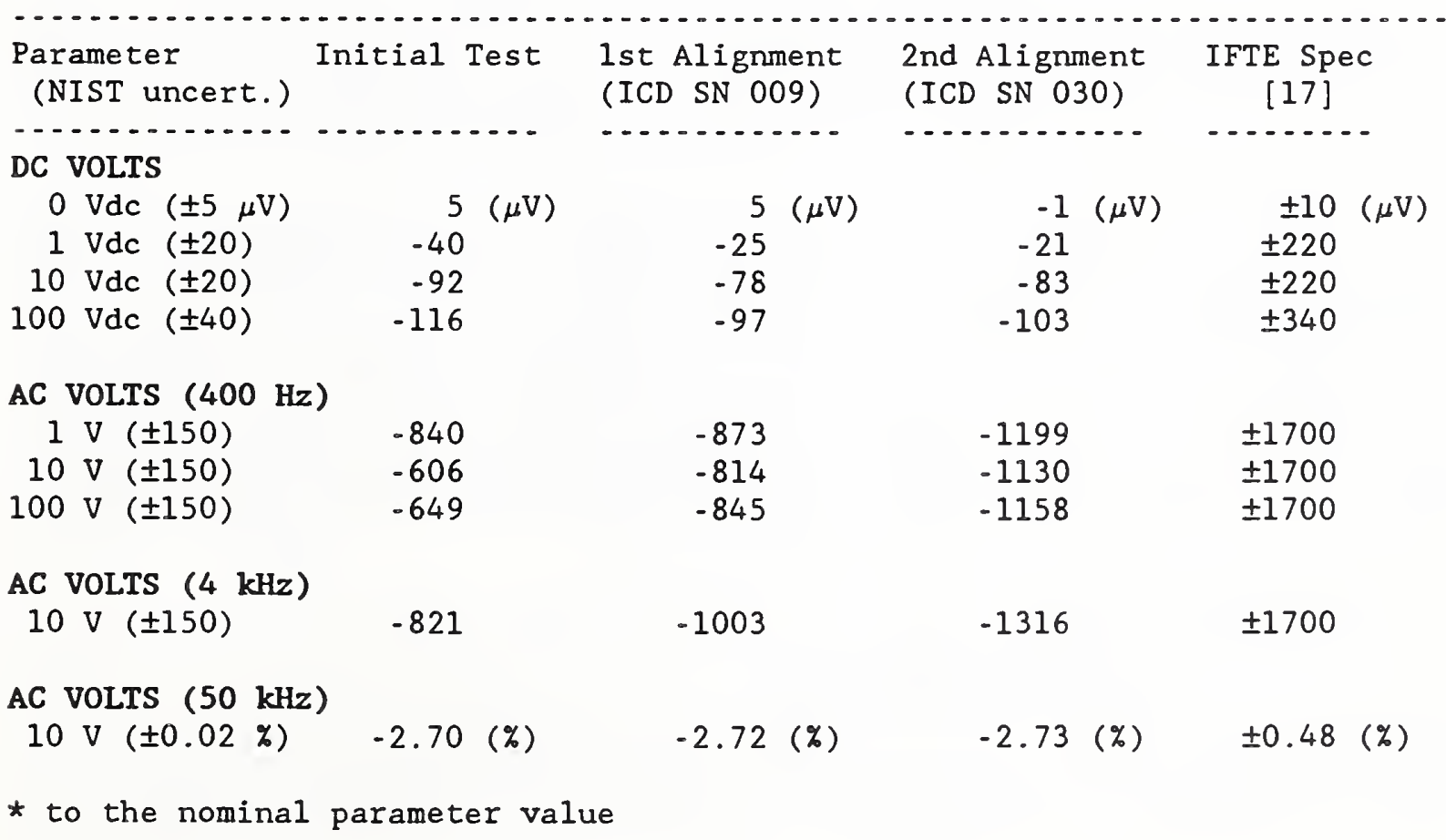


Table 1 (Continued)

IFTE (SN 017) Corrections* (in Ppm unless otherwise indicated)

\begin{tabular}{|c|c|c|c|c|}
\hline $\begin{array}{l}\text { Parameter } \\
\text { (NIST uncert.) }\end{array}$ & Initial Test & $\begin{array}{l}\text { 1st Alignment } \\
\text { (ICD SN 009) }\end{array}$ & $\begin{array}{l}\text { 2nd Alignment } \\
\text { (ICD SN } 030)\end{array}$ & $\begin{array}{c}\text { IFTE Spec } \\
{[17]}\end{array}$ \\
\hline$\ldots$ & $\ldots \ldots$ & $\ldots \ldots$ & $\ldots \ldots$ & $\ldots . . .$. \\
\hline \multicolumn{5}{|l|}{ DC RESISTANCE } \\
\hline $0 \Omega( \pm 0.01 \Omega)$ & $-0.2421(\Omega)$ & $-0.1623(\Omega)$ & $-0.1853(\Omega)$ & $2(\Omega)$ \\
\hline $10 \Omega( \pm 0.05 \%)$ & $-2.508(\%)$ & $-1.687(\%)$ & $-1.893(\%)$ & $\pm 20.12 \quad(\%)$ \\
\hline $100 \Omega( \pm 0.01 \%)$ & $-0.259(\%)$ & $-0.176(\%)$ & $-0.191(\%)$ & $\pm 2.03(\%)$ \\
\hline $1 \mathrm{k} \Omega( \pm 30)$ & -369 & -304 & -294 & \pm 2300 \\
\hline $10 \mathrm{k} \Omega( \pm 20)$ & -20 & -17 & -19 & \pm 500 \\
\hline $100 \mathrm{k} \Omega( \pm 30)$ & -38 & -29 & -23 & \pm 360 \\
\hline $1 \mathrm{M} \Omega( \pm 100)$ & -334 & -288 & -292 & \pm 702 \\
\hline $10 \mathrm{M} \Omega( \pm 200)$ & -4 & -107 & -135 & \pm 1300 \\
\hline
\end{tabular}

* to the nominal parameter value

From these test results, it can be seen that the software alignments for dc voltage made a slight improvement in the DMM performance, which was well within the tolerance specifications both before and after alignment. However, for ac voltage, the alignments degraded the performance, putting some of the DMM reading errors close to the tolerance specifications. In particular, note that the $50 \mathrm{kHz}$ measurement is in error by over five times the specification. Unfortunately, other high frequency output signals were not available from the reference calibrator with which to fully test the DMM in its higher frequency ranges. However, this limited result would appear to underscore the caution described above under section 5.4.2.4 that the vendor should reexamine the basis for the error analysis given in the "DMM AC Measurement Frequency Response."

Two-wire resistance measurements were made since four-wire was not available on the reference calibrator. Thus, the low-valued resistance measurements had large errors, apparently due to lead and contact resistance in the interconnections. Also, the approximately $0.2 \Omega$ measured offset resistance would seem to bear out the difficulty with the software alignment used for lead compensation and zero offset corrections, as described above in section 5.4.3.1. Nevertheless, all of the resistance measurements indicated that this IFTE station easily met the dc resistance specification. The resistance software alignments improved (or at least did not seriously degrade) the DMM performance, except at $10 \mathrm{M} \Omega$.

\subsection{Counter-Timer}

\subsubsection{Period Measurements}

Tests were performed on the counter-timer function (contained in one of the four "three-function" boards available on the IFTE station (SN 017) to determine its ability to make period measurements. The tests were performed by applying a 
$2 \mathrm{~V}_{\mathrm{p}-\mathrm{p}}\left( \pm 1 \mathrm{~V}_{\mathrm{peak}}\right)$ square-wave signal from the universal source to the input of the counter-timer via a test fixture ICD connected to the "Gold Dot" input/output connector panel. The counter-timer input impedance was set for $50 \Omega$. The applied signal was measured simultaneously by the reference time-interval counter.

Figure 4 shows the error of the IFTE counter-timer in nanoseconds, plotted as a function of the period in ms, relative to the reference time-interval counter. The IFTE specification for the accuracy of the counter-timer is also graphed in figure 4, based on the time measurement accuracy specification of \pm 10 ns \pm 1 count \pm time-base error [17]. Since the specification is unclear as to what the \pm 1 count applies to (full-scale range, reading, etc. - see section 5.1.5), the time error used for this term was the largest value of either 10 ns (the resolution of the counter-timer) or 1 part in $10^{8}$ of the period (based on the specified "8h digit" display). If a $10 \mathrm{~s}$ integration time is used to obtain the maximum resolution, then the internal $10 \mathrm{MHz}$ clock will produce 100000000 counts. Because of the specified $12 \mathrm{ppm}$ time-base (clock) maximum error, the uncertainty in this count $c$ an be as much as 1200 counts. To convert the total count into a corresponding period, the decimal point in the period display (normally positioned at 10.0000000 ) is moved $n$ places to the left, where $10^{\mathrm{n}}$ is the number of periods of the signal that are averaged in order to get the full 10 s resolution. For example:

$\begin{array}{lll}\text { Signal frequency } & \frac{\text { Period }}{10.0000000 \pm 1200(120000 \mathrm{~ns})} \\ 0.1 \mathrm{~Hz} & 1.00000000 \pm 1200(12000 \mathrm{~ns}) \\ 1.0 \mathrm{~Hz} & 0.10000000 \pm 120(1200 \mathrm{~ns}) \\ 10 \mathrm{~Hz} & 0.01000000 \pm 12(120 \mathrm{~ns}) \\ 100 \mathrm{~Hz} & 0.00100000 \pm 1.2(12 \mathrm{~ns}) \\ 1 \mathrm{kHz} & 0.00010000 \pm 0.12(1.2 \mathrm{~ns}) \\ 10 \mathrm{kHz} & \end{array}$

Below $10 \mathrm{kHz}(0.0001 \mathrm{~s}$, or $0.1 \mathrm{~ms})$, the $\pm 10 \mathrm{~ns}$ and the \pm 1 count in the IFTE accuracy specification become more significant than the $\pm 12 \mathrm{ppm}$ time-base error. The total accuracy specification can be summarized:

\begin{tabular}{lll} 
Period in ms (corr. freq.) & IFTE Spec. in $\mathrm{ns}$ & Min. ave. time in ms \\
\hline $10000(0.1 \mathrm{~Hz})$ & $\pm(10+100+120,000)= \pm 120,110$ & 10,000 \\
$1000(1 \mathrm{~Hz})$ & $\pm(10+10+12,000)= \pm 12,020$ & 10,000 \\
$100(10 \mathrm{~Hz})$ & $\pm(10+10+1200)= \pm 1,220$ & 1,000 \\
$10(100 \mathrm{~Hz})$ & $\pm(10+10+120)= \pm 140$ & 100 \\
$1(1 \mathrm{kHz})$ & $\pm(10+10+12)= \pm 32$ & 10 \\
$0.1(10 \mathrm{kHz})$ & $\pm(10+10+1.2)= \pm 21.2$ & 1 \\
$0.01(100 \mathrm{kHz})$ & $\pm(10+10+0.12)= \pm 20.12$ & 0.1 \\
$0.001(1 \mathrm{MHz})$ & $\pm(10+10+0.012)= \pm 20.012$ & 0.01 \\
$0.0001(10 \mathrm{MHz})$ & $\pm(10+10+$ negl. $)= \pm 20$ & 0.001
\end{tabular}

Consequently, the IFTE specification is plotted as shown in figure 4. The uncertainty of the reference time-interval counter is barely discernable in the figure because it is so small relative to the vertical resolution of the graph, except between the 10 and 100 ms test periods. 


\section{PERIOD MEASUREMENT \\ (into $50 \mathrm{Ohms}$ )}

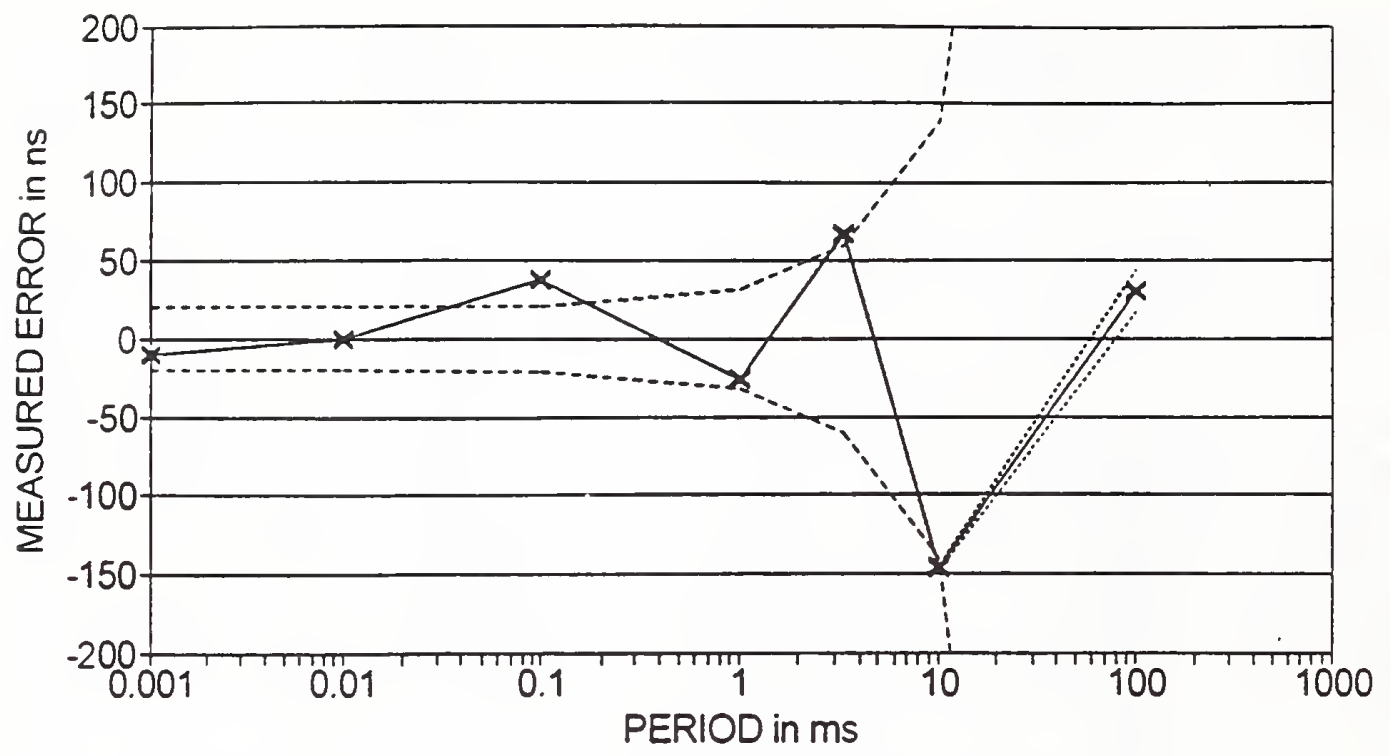

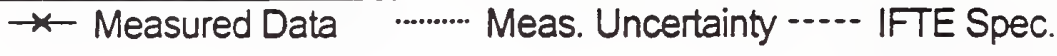

Figure 4. Measured error of IFTE counter-timer vs, period

\section{PULSE-WIDTH MEASUREMENT (into 50 Ohms)}

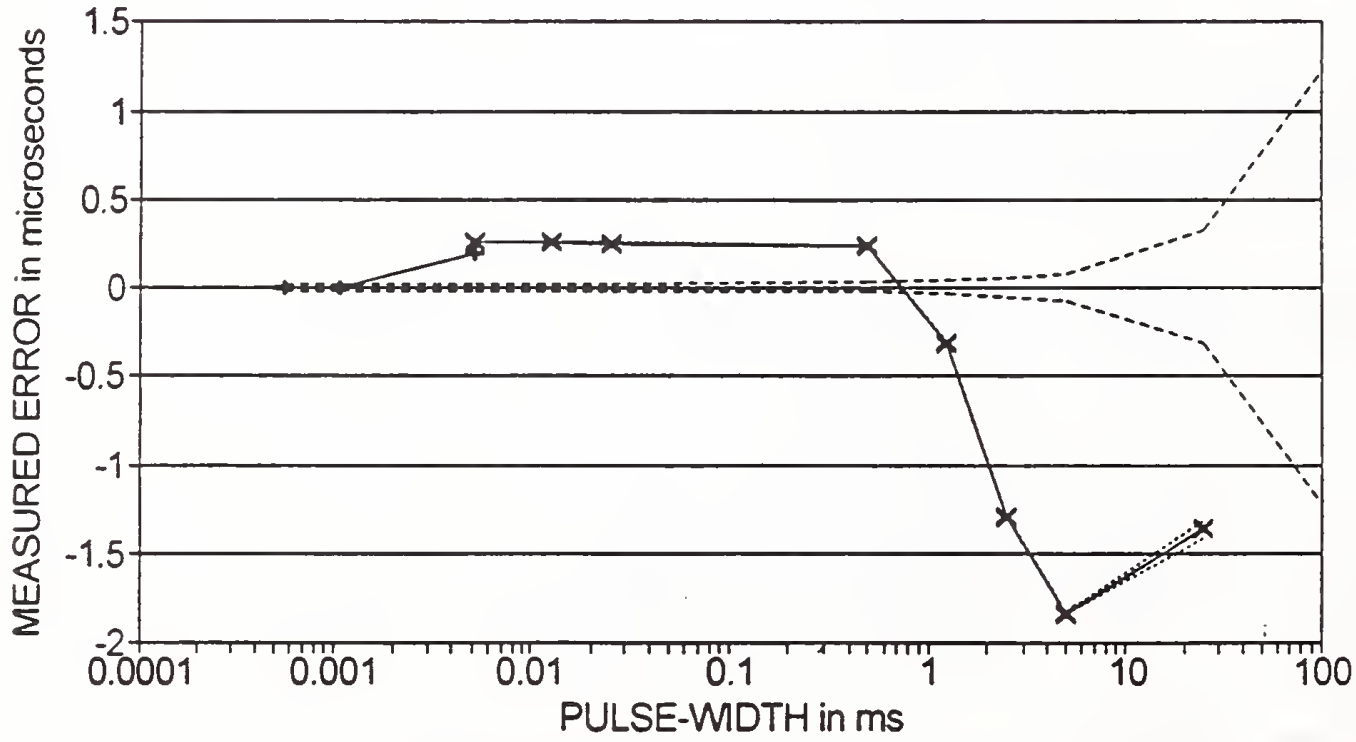

$\rightarrow$ Measured Data ......... Meas. Uncertainty -....- IFTE Spec.

Figure 5. Measured error of IFTE counter-timer vs. pulse-width 
From these limited test data, the conclusions are that the counter-timer on this particular three-function board is out of specification at a period of $0.1 \mathrm{~ms}$ and $3.3 \mathrm{~ms}$, and is borderline at the 1 and $10 \mathrm{~ms}$ periods. Otherwise, the data are within specification, particularly at the $100 \mathrm{~ms}$ test period, due to the expanding time-base error term in the IFTE specification, relative to the first two error terms. Unfortunately, with the upper frequency limitation of $1 \mathrm{MHz}$ for the universal source, period measurements could not be made out to the 100 $\mathrm{MHz}$ maximum signal frequency of the counter-timer. From the test period data at $0.001 \mathrm{~ms}(1 \mu \mathrm{s})$, it appears that testing the counter-timer out to $100 \mathrm{MHz}$ would be desireable in order to verify the IFTE specification of \pm 20 ns when the signal period is only $10 \mathrm{~ns}$.

\subsubsection{Pulse-width Measurements}

Tests were performed to determine the ability of the counter-timer to make pulsewidth measurements. The tests were made by applying a $2 V_{p-p}\left( \pm 1 v_{p e a k}\right)$ pulseddc signal from the universal source to the input of the counter-timer via a test fixture ICD connected to the "Gold Dot" input/output connector panel. The counter-timer input impedance was set for $50 \Omega$. The applied signal was measured simultaneously by the reference time-interval counter. Figure 5 shows a plot of the error of the counter-timer in the IFTE station in microseconds, relative to the reference time-interval counter, as a function of the measured pulse width. The measured data shown with an $\mathrm{X}$ are the pulse-width measurements taken on a $25 \%$ duty cycle pulsed-dc waveform, whereas the measured data shown with $a+$ are the pulse-width measurements taken on a (50\% duty cycle) square wave. The IFTE specification for the accuracy of the counter-timer is graphed in fugure 5, based on \pm 10 ns \pm 1 count \pm time-base error [17]. Again, since the specification is unclear as to what the \pm 1 count applies to (full-scale range, reading, etc. - see section 5.1.5), the largest value of $10 \mathrm{~ns}$, or 1 part in $10^{8.5}$ of the pulse width (based on the specified "83/2 digit" display) was used.

It can be seen that the counter-timer badly failed to meet the IFTE specification for pulse widths longer than $5 \mu \mathrm{s}$, even though the measurements at 560 ns and $1 \mu s$ are well within specification. The fact that both the $25 \%$ duty cycle and square-wave signals produced about the same measurement error at the $5 \mu$ pulse width substantiates the error of the counter-timer at that point. Not having access to the functional design of the counter-timer, it is difficult to explain the mechanism of why the errors could be positive tenths of a microsecond between $5 \mu \mathrm{s}$ and $0.5 \mathrm{~ms}$, and then suddenly drop off to large negative errors of 0.3 microseconds and more in the 1 to $25 \mathrm{~ms}$ range. The fact that the period measurement errors over this same time interval were not this far out of specification is inconsistent with the pulse-width measurement results, unless the period measurements were really (the more accurate) frequency measurements instead, with the reciprocal value taken for the period.

However, it is evident from these pulse-width measurements that the sources of error in making time-interval measurements with the counter-timer (see section 5.1.5) need to be investigated. In particular, the IFTE trigger-level threshold alignment is suspected to be in error since the pulse width being measured in this set of tests is at the zero volt level (for both rising and falling edges) rather than the rising edge only, 1.2 volt level used in the vendor's proposed software alignment procedure. Again, the $1 \mathrm{MHz}$ maximum frequency limitation of 
the universal source prevented testing of pulse widths less than $500 \mathrm{~ns}$, whereas the counter-timer should have a minimum pulse-width measurement capability of $5 \mathrm{~ns}$ since the maximum input frequency is $100 \mathrm{MHz}$ [17].

\subsubsection{Phase Measurements}

The counter-timer was programmed to determine its ability to make phase angle measurements. The tests were performed by applying two $2 \mathrm{~V}_{\mathrm{p}-\mathrm{p}}\left( \pm 1 \mathrm{~V}_{\mathrm{p} \text { ak }}\right)$ squarewave signals from the dual-channel universal source to the inputs of the countertimer via a test fixture ICD connected to the "Gold Dot" input/output connector panel. The counter-timer input impedance was set for $50 \Omega$. The phase angle between the applied signals was measured simultaneously by the reference timeinterval counter. Figures 6 and 7 show the error of the counter-timer in degrees, relative to the reference time-interval counter, for signal frequencies of $1 \mathrm{kHz}$ and $100 \mathrm{kHz}$, respectively, plotted as a function of phase angle. The IFTE specification for the accuracy of the counter-timer is graphed in figures 6 and 7 , based on the \pm 10 ns \pm 2 counts \pm 2 (time-base error) expression derived in section 5.1.6. The error band in making a phase measurement at $1 \mathrm{kHz}$ is then given by

$$
\text { error } \phi_{\mathrm{A}-\mathrm{B}}=\frac{ \pm\left(10 \mathrm{~ns}+20 \mathrm{~ns}+24 \mathrm{ppm} \cdot 10^{6} \mathrm{~ns}\right) 360^{\circ}}{10^{6} \mathrm{~ns}}= \pm 0.01944^{\circ} \text {. }
$$

Similarly, the error band at a frequency of $100 \mathrm{kHz}$ is $\pm 1.166^{\circ}$. These are the IFTE specification limits shown in figures 6 and 7.

It can be seen from figure 6 that at $1 \mathrm{kHz}$ the counter-timer badly failed to meet the IFTE specification over the whole range of phase measurements. Whereas the measured phase error is nearly the same from $0^{\circ}$ to $180^{\circ}\left(0.01^{\circ}\right.$ variation) as expected, the measured errors over the phase interval from $180^{\circ}$ to $315^{\circ}$ have a large $0.1^{\circ}$ variation $\left(-0.04^{\circ}\right.$ to $\left.-0.14^{\circ}\right)$. This $0.1^{\circ}$ kind of a discontinuity may be related to the same kind of unexplained large errors discussed above in section 6.2 .2 on pulse-width measurements.

At the $100 \mathrm{kHz}$ signal frequency (see figure 7), the measured error of the counter-timer again failed to meet the IFTE specification over the range of phase measurements taken, although not as far outside the specification limits as at $1 \mathrm{kHz}$. Also, the errors are nearly the same over the entire phase interval of the measurements, as expected. The larger errors at $215^{\circ}$ and $270^{\circ}$ may be due to similar large errors at these phase angles observed at $1 \mathrm{kHz}$ in figure 6 .

Except for the larger errors in the phase range of $180^{\circ}$ to $315^{\circ}$, the phase measurements appear to have a significant phase offset, which could likely be corrected simply by adding a few lines of code in the self-alignment software (as discussed in section 5.1.5) to correct for the channel A to channel B offset error. Consequently, the vendor's procedure for self aligning the countertimer needs to be modified. Once again, phase testing beyond $100 \mathrm{kHz}$ was limited by the lack of good phase resolution of the universal source above this frequency. Therefore, the phase measurement capability of the counter-timer out to its $100 \mathrm{MHz}$ maximum signal frequency was not investigated. 


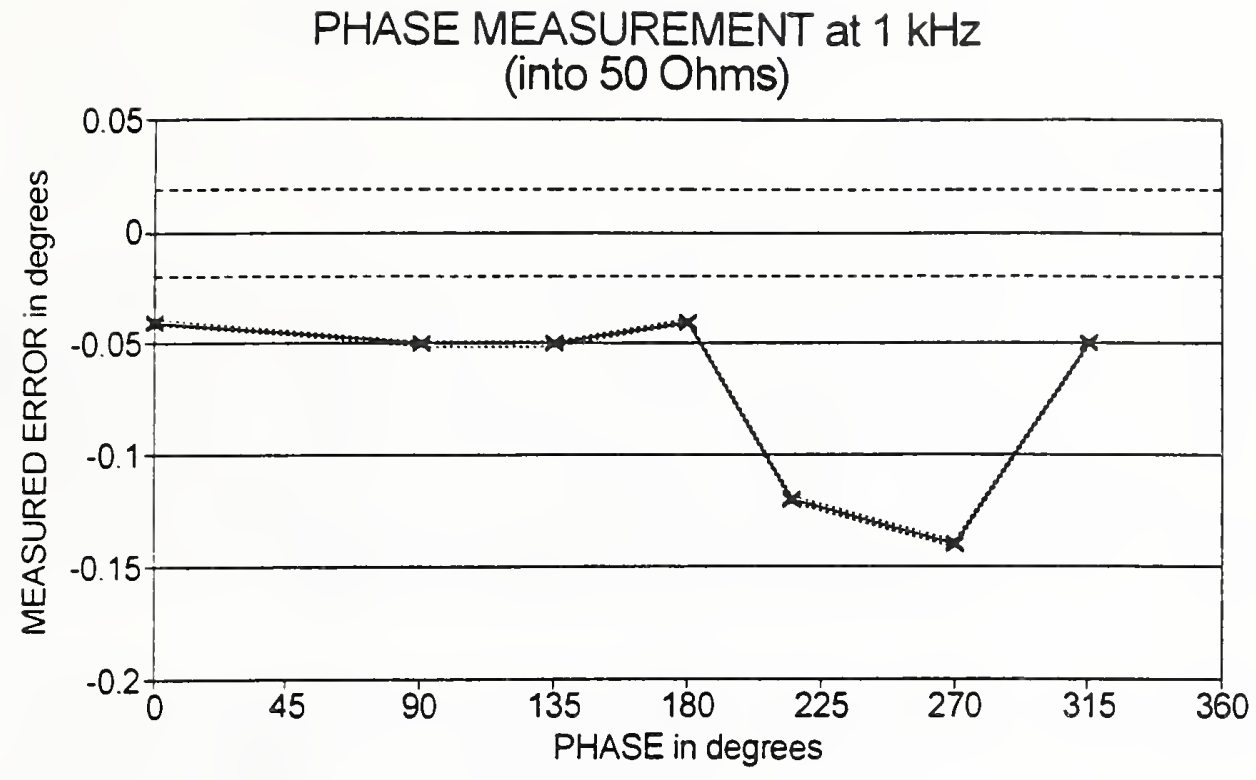

$\rightarrow$ - Measured Data ……. Meas. Uncertainty --.-- IFTE Spec.

Figure 6. Measured error of IFTE counter-timer vs. phase angle at $1 \mathrm{kHz}$

PHASE MEASUREMENT at $100 \mathrm{kHz}$ (into $50 \mathrm{Ohms}$ )

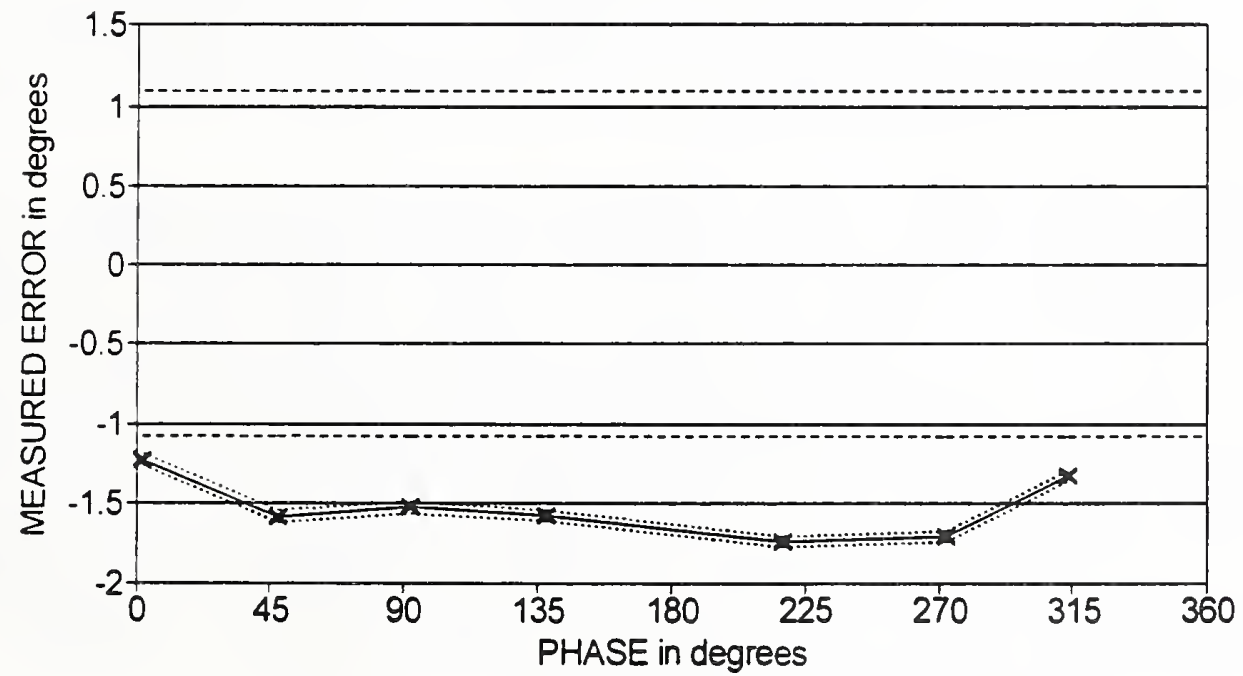

$\rightarrow$ Measured Data $\quad$-........ Meas. Uncertainty ----- IFTE Spec.

Figure 7. Measured error of IFTE counter-timer vs. phase angle at $100 \mathrm{kHz}$ 


\section{3 High-speed Digitizer}

\subsubsection{Sine-Wave Measurements}

The high-speed digitizer function (contained in one of the four "three-function" boards available on the IFTE station (SN017)) was programmed to measure the $2 \mathrm{~V}_{\mathrm{p}-\mathrm{p}}$ sine-wave output from the universal source via a test fixture ICD connected to the "Gold Dot" input/output connector panel. The digitizer was programmed to provide a $50 \Omega$ termination and to read the input signal in both peak-to-peak and RMS voltage. The sampling interval of the digitizer was set to $1 / 200$ th of the signal period down to a minimum interval of $10 \mathrm{~ns}$. The input signal was simultaneously measured with the reference DMM.

Figure 8 (2.0 $\mathrm{V}_{\mathrm{p}-\mathrm{p}}$ Sine-Wave Measurement) shows the measured error of the digitizer in making peak-to-peak measurements (deviations with respect to the reference DMM) in percent, relative to a full-scale input signal range (FSR) of $2.5 \mathrm{~V}_{\mathrm{p}-\mathrm{p}}$. Similarly, figure 9 (0.7 V RMS Sine-Wave Measurement) shows the measured error of the digitizer in making RMS measurements with respect to the reference DMM using the same FSR of $2.5 \mathrm{~V}_{\mathrm{p}-\mathrm{p}}$. The figures also show the IFTE specification based on $\pm 6 \%$ of the FSR for all measurements up to the $1 \mathrm{MHz}$ point, and $\pm 15 \%$ of FSR for the $1 \mathrm{MHz}$ point and higher [17].

The fact that the digitizer has 6 -bits of resolution means that it has a quantization error of $1 / 2^{6}(100)=1.56 \%$. Apparently, with other offset and gain errors included, the overall IFTE accuracy specification for the high-speed digitizer has been set at $\pm 6 \%$ of FSR up to $1 \mathrm{MHz}$. From the measured errors shown in figures 8 and 9 , this digitizer is only marginally meeting the $\pm 6 \%$ of FSR specification. The extrapolation line between $100 \mathrm{kHz}$ and $1 \mathrm{MHz}$ would indicate that at these frequencies the digitizer exceeded the $\pm 6 \%$ of FSR specification. Unfortunately, the universal source was limited to an upper frequency of $1 \mathrm{MHz}$ so that testing the digitizer above this input signal frequency (in order to verify the $\pm 15 \%$ of FSR specification) was not investigated.

The $-4 \%$ offset is likely due to the resistive voltage drops of the connectors and Signal Distribution System (SDS) conductors internal to the IFTE station, ahead of the programmed 50 input termination of the digitizer. Supposedly, these offsets are corrected by running the digitizer self-alignment software, which applies the $0.9 \mathrm{~V}$ dc reference voltage from the SA-ICD to the digitizer, averages the readings, and subtracts the average from 0.900 volts to store a correction [7]. The rolloff of the response with frequency is also likely due to distributed capacitances in the connector/SDS paths to the digitizer, as reflected in the $50 \mathrm{MHz}$ bandwidth specification. Consequently, the vendor's recommended procedure of using only a dc reference voltage from the SA-ICD to correct the digitizer amplitude readings (see section 5.2 .3 above) probably needs to be further investigated and revised.

\subsubsection{Triangle-Wave Measurements}

The high-speed digitizer function was programmed to measure the $2 \mathrm{v}_{\mathrm{p}-\mathrm{p}}$ trianglewave output from the universal source via a test fixture ICD connected to the "Gold Dot" input/output connector panel. The digitizer was programmed in this case to provide a $1 \mathrm{M} \Omega$ termination and to read the input signal in both peak- 


\subsection{Vp-p SINE WAVE MEASUREMENT \\ (into $50 \mathrm{Ohms}$ )}

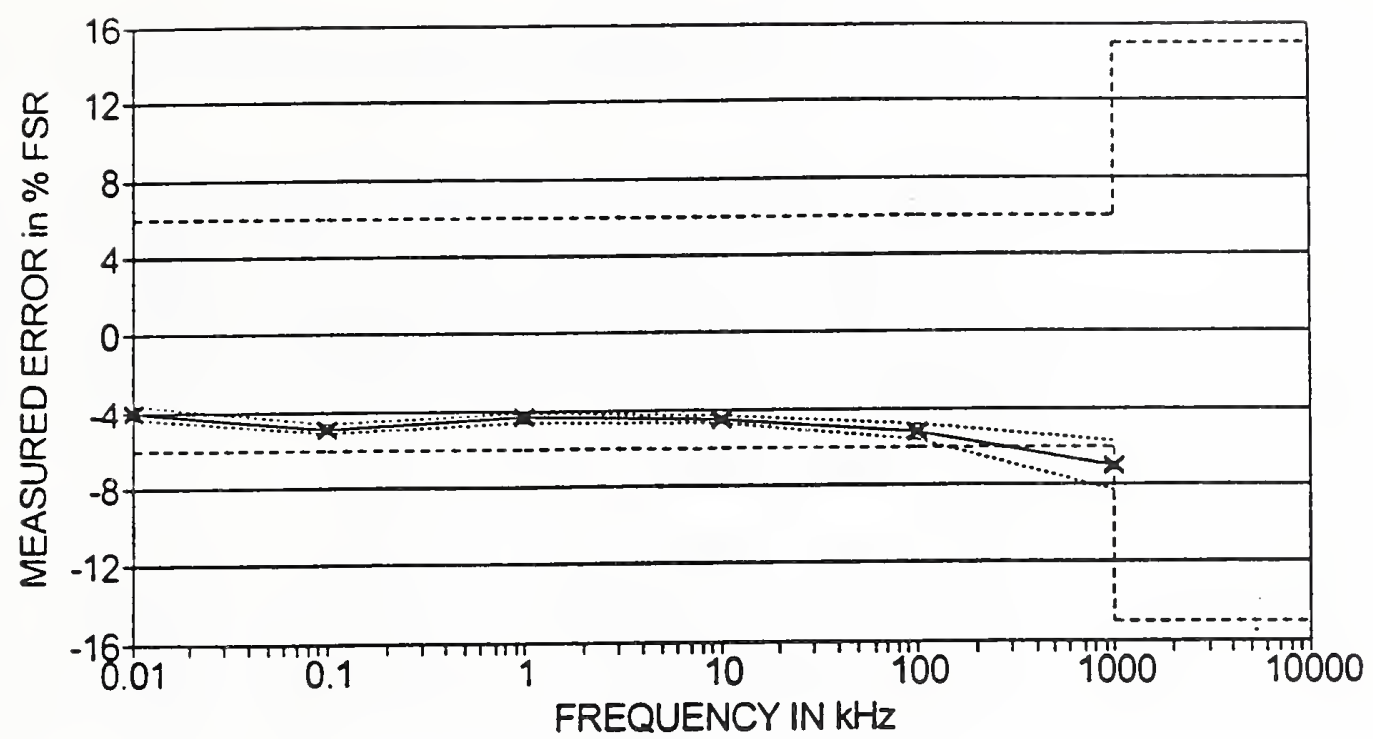

$-\star-$ Measured Data $\quad$ ……... Meas. Uncertainty -..-- IFTE Spec.

Figure 8. Measured error of IFTE digitizer vs. frequency for sine waves $\left(V_{p-p}\right)$

\subsection{RMS SINE WAVE MEASUREMENT (into 50 Ohms)}

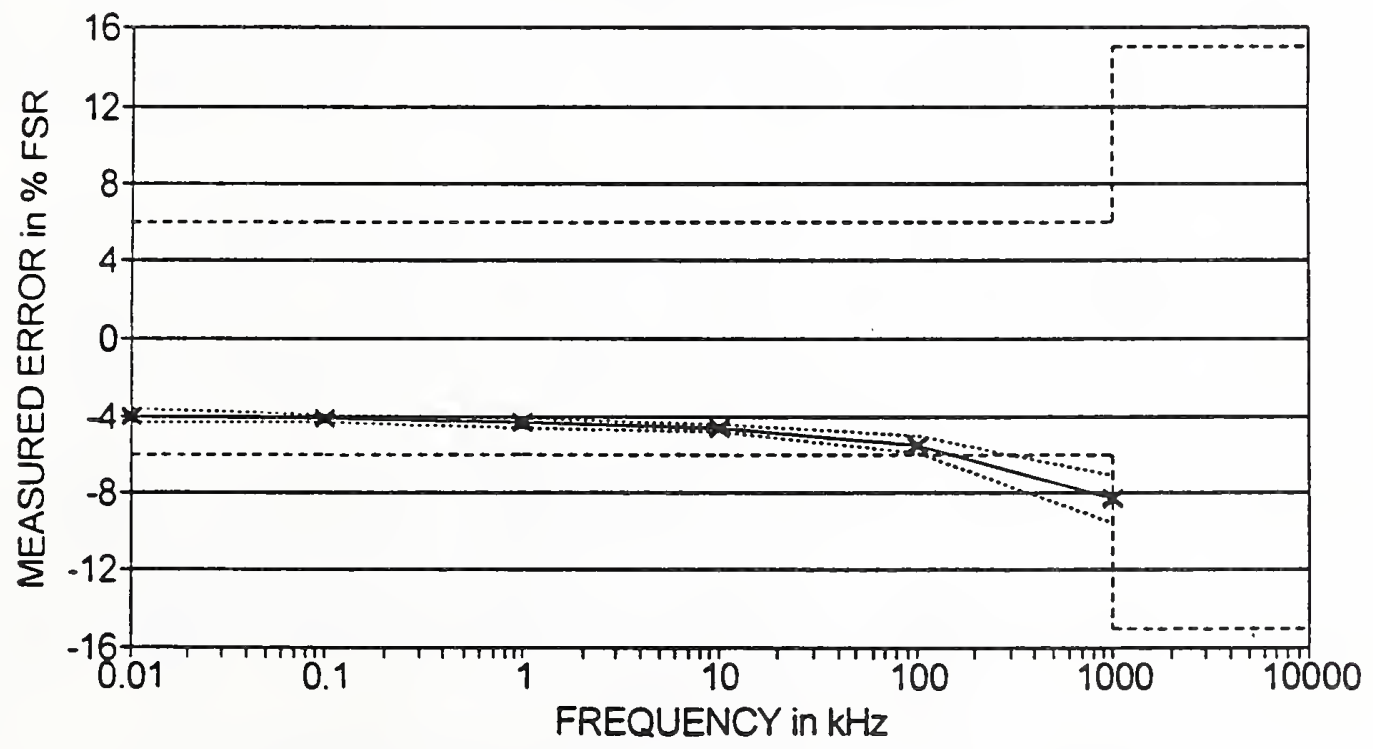

* Measured Data $\quad$-......... Meas. Uncertainty --.-- IFTE Spec.

Figure 9. Measured error of IFTE digitizer vs. frequency for sine waves $\left(V_{R M S}\right)$ 
to-peak and RMS voltage. The sampling interval of the digitizer was set to $1 / 200$ th of the signal period down to a minimum interval of $10 \mathrm{~ns}$. The input signal was measured simultaneously with the reference DMM.

Figure 10 (2.0 $\mathrm{V}_{\mathrm{p}-\mathrm{p}}$ Triangle-Wave Measurement) shows the measured error of the digitizer in making peak-to-peak measurements (deviations with respect to the reference DMM) in percent, relative to a full-scale input signal range (FSR) of $2.5 \mathrm{~V}_{\mathrm{p}-\mathrm{p}}$. Similarly, figure 11 (0.57 V RMS Triangle-Wave Measurement) shows the measured error of the digitizer in making RMS measurements with respect to the reference DMM using the same FSR of $2.5 \mathrm{~V}_{\mathrm{p}-\mathrm{p}}$. The figures also show the IFTE specification, based on $\pm 6 \%$ of the FSR for all measurements up to the $1 \mathrm{MHz}$ point, and $\pm 15 \%$ of FSR for the $1 \mathrm{MHz}$ point and higher [17].

From the plots of measured error data taken on triangle-wave signals, it can be seen that with the digitizer programmed to provide a $1 \mathrm{M} \Omega$ input, the offset error is now virtually gone (compare with the sine-wave measurements made with a $50 \Omega$ input termination described in section 6.3.1). Although measurements were not taken beyond $1 \mathrm{MHz}$, it also appears that at this frequency there may be a slight peaking in the digitizer response, correcting for the inherent input connector/SDS rolloff with frequency. Consequently, in both the peak-to-peak and RMS measurements of the triangle-wave signal, the digitizer met the $\pm 6 \%$ of FSR IFTE specification.

\section{$6.3,3$ Square-Wave Measurements}

The high-speed digitizer function was programmed to measure the $2 \mathrm{~V}_{\mathrm{p} \text {-p }}$ squarewave output from the universal source via a test fixture ICD connected to the "Gold Dot" input/output connector panel. As with the triangle-wave measurements, the digitizer was programmed to provide a $1 \mathrm{M} \Omega$ termination; however, in this case the digitizer was programmed to read the input signal in peak-to-peak voltage only. The sampling interval of the digitizer was set to $1 / 200$ th of the signal period down to a minimum interval of 10 ns. The input signal was measured simultaneously with the reference DMM.

Figure 12 shows the measured error of the digitizer in making square-wave, peakto-peak measurements (deviations with respect to the reference DMM) in percent, relative to a full-scale input signal range (FSR) of $2.5 \mathrm{~V}_{\mathrm{p}-\mathrm{p}}$. The figure also shows the IFTE specification, based on $\pm 6 \%$ of the FSR for all measurements up to the $1 \mathrm{MHz}$ point, and $\pm 15 \%$ of FSR for the $1 \mathrm{MHz}$ point and higher [17].

As observed with the triangle-wave measurements described in section 6.3 .2 , the offset error observed with the sine-wave measurements using a $50 \Omega$ input (see section 6.3.1) is now virtually gone. However, the extrapolation line between the $100 \mathrm{kHz}$ and $1 \mathrm{MHz}$ test points would indicate that at these frequencies the digitizer exceeded the $\pm 6 \%$ of FSR specification. Unfortunately, the universal source was limited to an upper frequendy of $1 \mathrm{MHz}$ so that testing the digitizer above this input-signal frequency (in order to verify the $\pm 15 \%$ of FSR specification) was not investigated. However, with the measured error at nearly $15 \%$ of FSR at the $1 \mathrm{MHz}$ test point, and the upward trend of the measured error plotted at lower frequencies, it appears that the digitizer would not meet the $\pm 15 \%$ of FSR specification for square-wave signals in the 1 to $50 \mathrm{MHz}$ frequency range. 
2.0 Vp-p TRIANGLE WAVE MEASUREMENT

(into 1 Megohm)

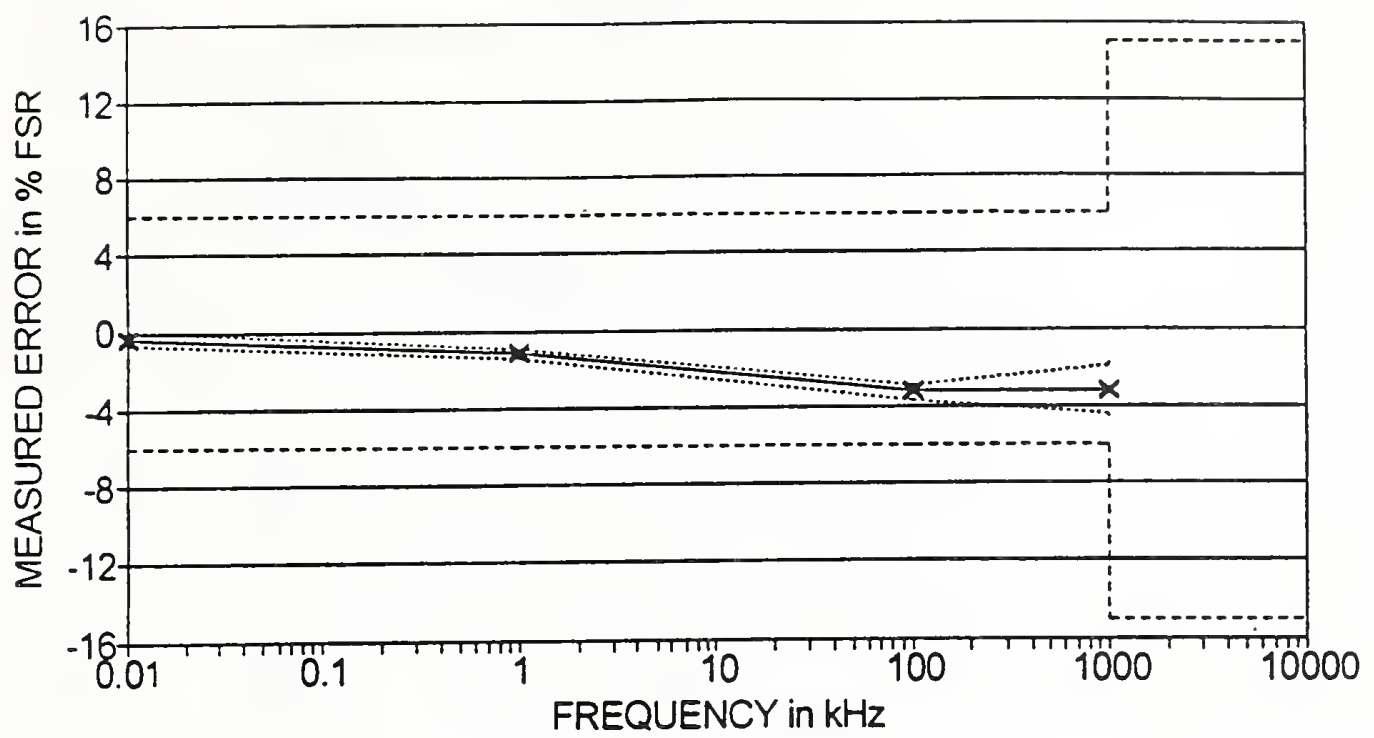

- - Measured Data ……. Meas. Uncertainty -..-- IFTE Spec.

Figure 10. Measured error of IFTE digitizer vs. frequency for triangle waves $\left(v_{p-p}\right)$

\subsection{RMS TRIANGLE WAVE MEASUREMENT (into 1 Megohm)}

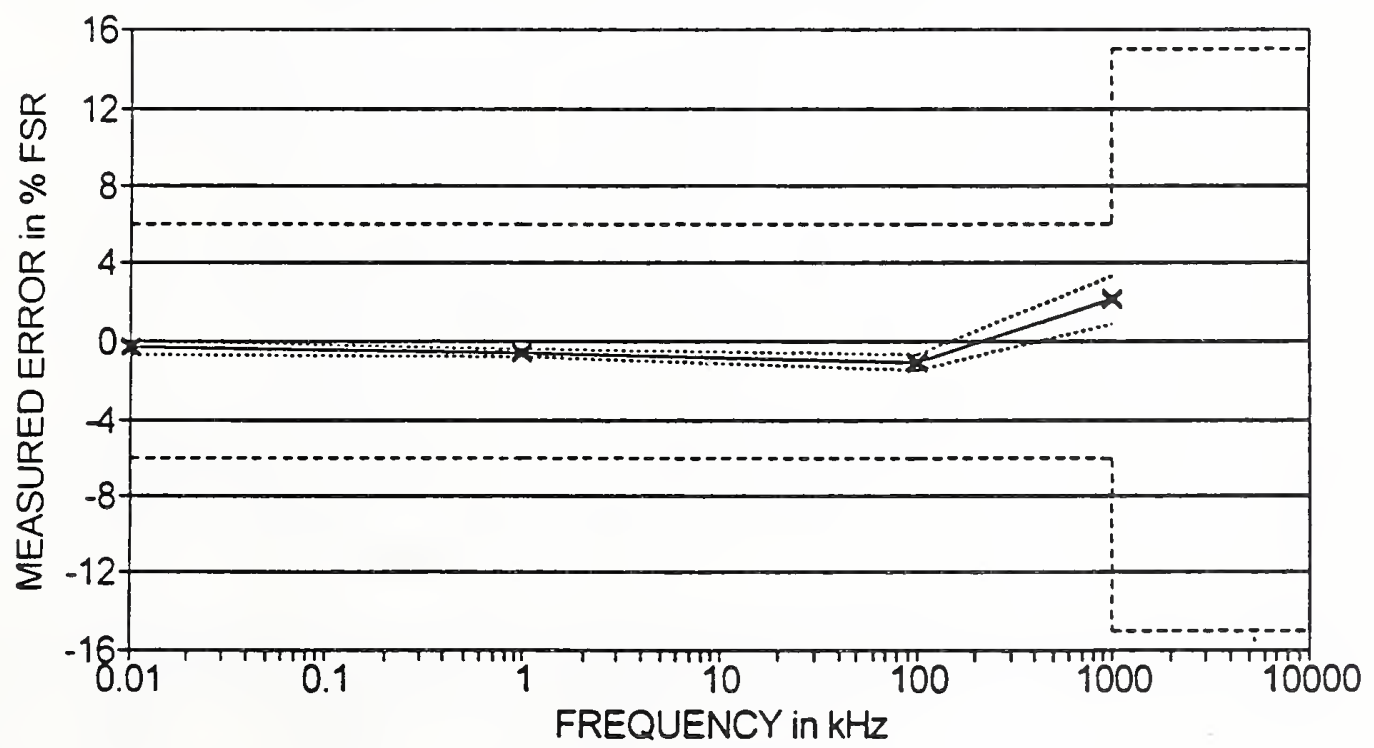

$\rightarrow \star-$ Measured Data $\quad$ …….... Meas. Uncertainty --.-- IFTE Spec.

Figure 11. Measured error of IFTE digitizer vs. frequency for triangle waves $\left(V_{\text {RMS }}\right)$ 


\subsection{Vp-p SQUARE WAVE MEASUREMENT (into 1 Megohm)}

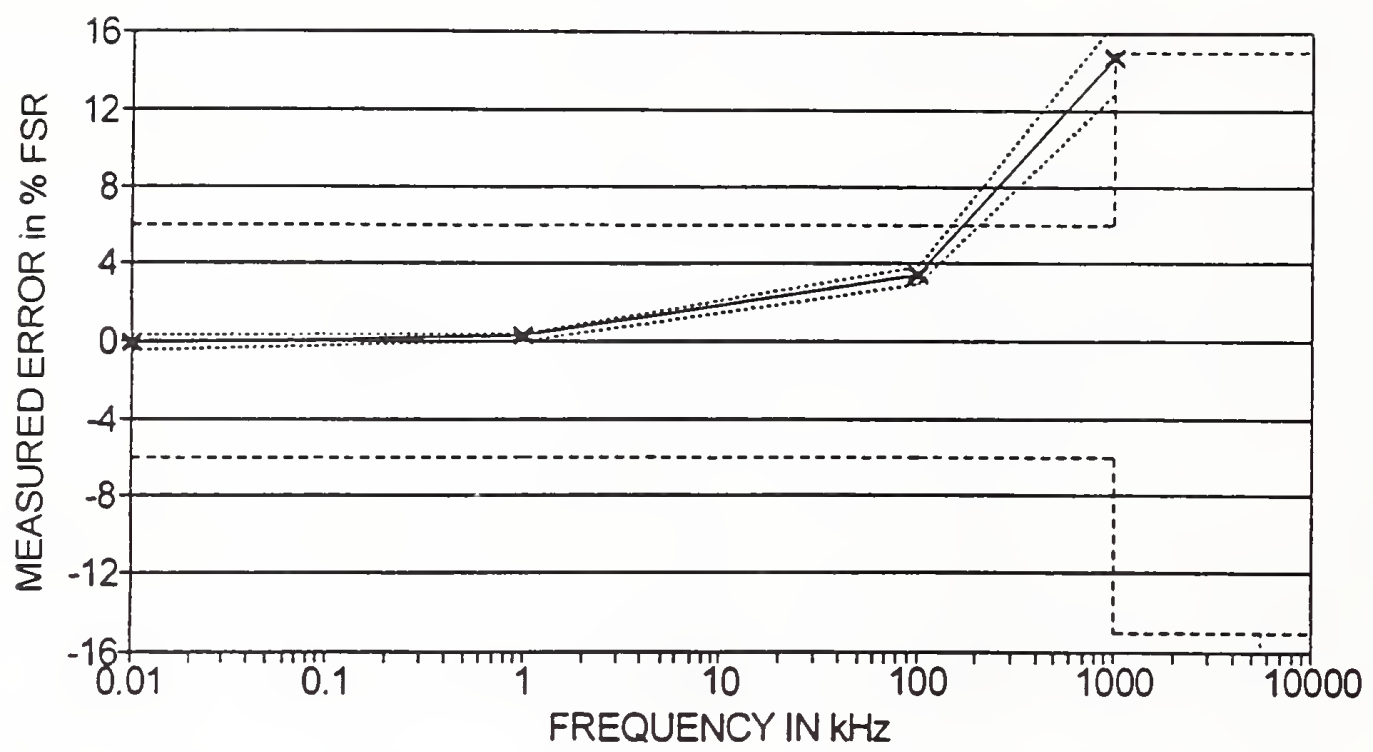

* Measured Data $\quad$ ……... Meas. Uncertainty -...- IFTE Spec.

Figure 12. Measured error of IFTE digitizer vs. frequency for square waves $\left(v_{p-p}\right)$

\subsection{Vp-p PULSED-DC GENERATION}

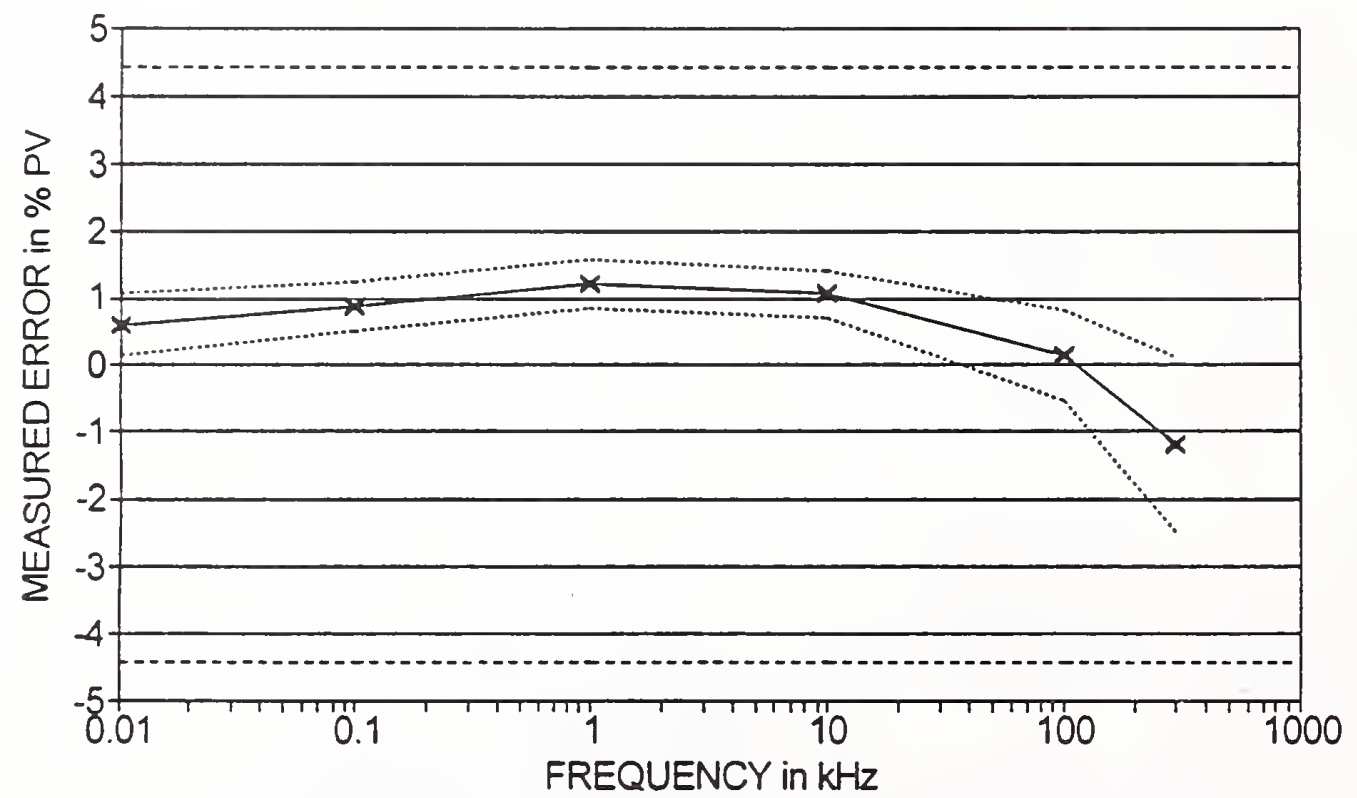

$-\star-$ Measured Data $\quad$........... Meas. Uncertainty -...- IFTE Spec.

Figure 13. Measured error of IFTE arbitrary function generator vs. frequency for pulsed dc $\left(3.5 \mathrm{~V}_{\mathrm{p}-\mathrm{p}}\right)$ 


\subsection{Arbitrary Function Generator}

\section{4 .1 Pulsed-DC (25\% Duty-cycle) Generation}

The ability of the Arbitrary Function Generator (AFG) to provide pulsed-dc output signals with a $25 \%$ duty-cycle, having a known peak-to-peak voltage, was tested at $0.035,0.350$, and $3.500 \mathrm{~V}_{\mathrm{p}-\mathrm{p}}$. The tests were performed by applying the signal from the AFG in the IFTE station, through a test fixture ICD, to the calibrated reference DMM. The AFG was programmed to output a pulsed-dc signal having the desired frequency, $25 \%$ duty cycle, dc offset, and peak-to-peak output voltage levels. The RMS values of the output signal were then measured by the reference DMM, and converted to their corresponding peak-to-peak values. Figures 13, 14, and 15 show the measured error of the AFG in generating pulsed-dc waveforms (deviations with respect to the reference DMM) in percent, relative to the peak-to-peak programmed value (PV), as a function of frequency. The figures also show the IFTE specification based on $\pm(4 \%$ of PV $+15 \mathrm{mV})$ [17].

The upper test frequency of $300 \mathrm{kHz}$ was chosen because of the increasing measurement uncertainty in the reference DMM in making an accurate measurement of the RMS value of the $25 \%$ pulsed-dc voltage waveform from the AFG. From the manufacturer's specifications, confirmed by independent calibration testing at NIST, the error band of the reference DMM can be approximated conservatively by an uncertainty of $\epsilon_{1}= \pm 1.03 \%$ up to $1 \mathrm{MHz}$ and $\epsilon_{2}= \pm 10.03 \%$ above $1 \mathrm{MHz}$. Thus, by using equation (6) of Appendix B and equations (25) and (16) from Appendix C, the error band in reading the RMS value of the $25 \%$ pulsed-dc voltage waveform with a $300 \mathrm{kHz}$ fundamental can be computed to be $(k=3)$ :

$$
\begin{aligned}
& \operatorname{RMS}_{\text {error }}= \pm\left[\left(10.03 \% \cdot \operatorname{RMS}_{\text {total }}\right)^{2}+\left((1.03 \%)^{2}-(10.03 \%)^{2}\right)\left(\mathrm{RMS}_{\mathrm{kth}-}\right)^{2}\right]^{\frac{1}{2}} \text {, } \\
& = \pm\left[0.01006\left(V_{p-p} / 2\right)^{2}+(-0.00995)\left(\left(-\frac{1}{4}\right)^{2}+2\left(V_{p}-p\right)^{2} / \pi^{2}\left(\frac{1}{2}+\frac{1}{4}+1 / 18\right)\right\}\right]^{\frac{1}{2}} \\
& = \pm V_{p-p}[0.00252+(-0.00995)(0.0625+0.163)]^{\frac{1}{2}} \\
& = \pm V_{p-p}[0.00252-0.00995(0.226)]^{\frac{3}{2}} \\
& = \pm V_{p-p}[0.00027]^{\frac{1}{2}}= \pm 0.0165 V_{p-p} \text {. }
\end{aligned}
$$

Relative to the programmed peak-to-peak voltage, the error band is therefore

$$
\text { RMS }_{\text {error }}= \pm 1.65 \% \text {. }
$$

For the programmed value (PV) of $3.5 \mathrm{~V}_{\mathrm{p}-\mathrm{p}}$, the IFTE specification for the AFG amplitude accuracy is $\pm(4 \% \cdot 3.5 \mathrm{~V}+15 \mathrm{mV}) 100 / 3.5 \mathrm{~V}= \pm 4.43 \%$. Thus, the TAR at $300 \mathrm{kHz}$ was $4.43 / 1.65=2.68$, which is adequate but which limited the testing with the reference DMM beyond $300 \mathrm{kHz}$.

For all three peak-to-peak voltage levels, the AFG readily met the IFTE amplitude accuracy specification up to the maximum test frequency of $300 \mathrm{kHz}$. However, at the $3.5 \mathrm{~V}_{\mathrm{p}-\mathrm{p}}$ level, the downward bend in the error plot with increasing frequency has a trend that would appear to extrapolate into the IFTE specification somewhere in the 1-2 $\mathrm{MHz}$ region where the specification still holds [17]. Also, at the $35 \mathrm{mV}_{\mathrm{p}-\mathrm{p}}$ level there was considerably more distortion and noise in the pulsed-dc waveform, which is reflected by the $3-4 \%$ of PV measured error shown in figure 15. 
350 mVp-p PULSED-DC GENERATION

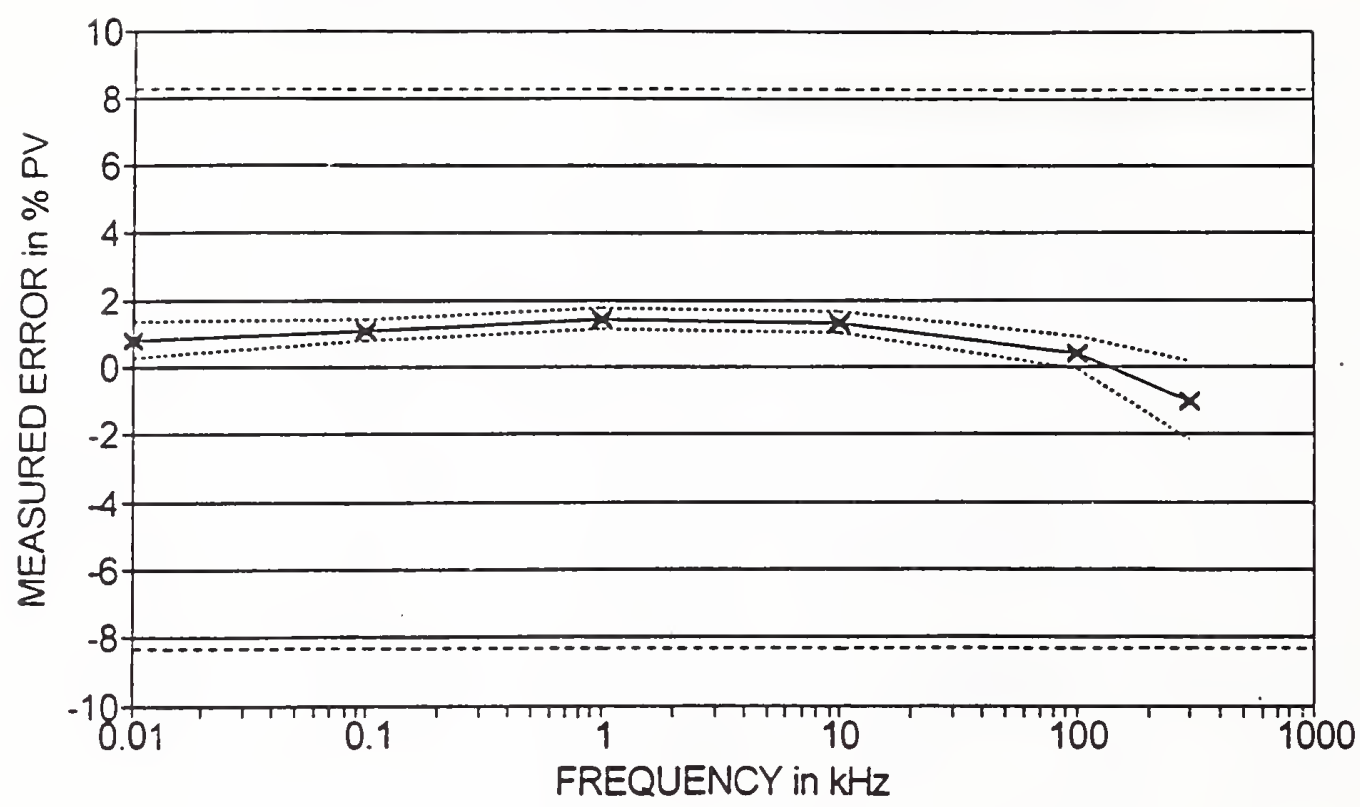

$\rightarrow$ * Measured Data $\quad \cdots . . . \cdots \cdot . \cdot$ Meas. Uncertainty -..... IFTE Spec.

Figure 14. Measured error of IFTE arbitrary function generator vs. frequency for pulsed dc $\left(350 \mathrm{mV}_{\mathrm{p}-\mathrm{p}}\right)$

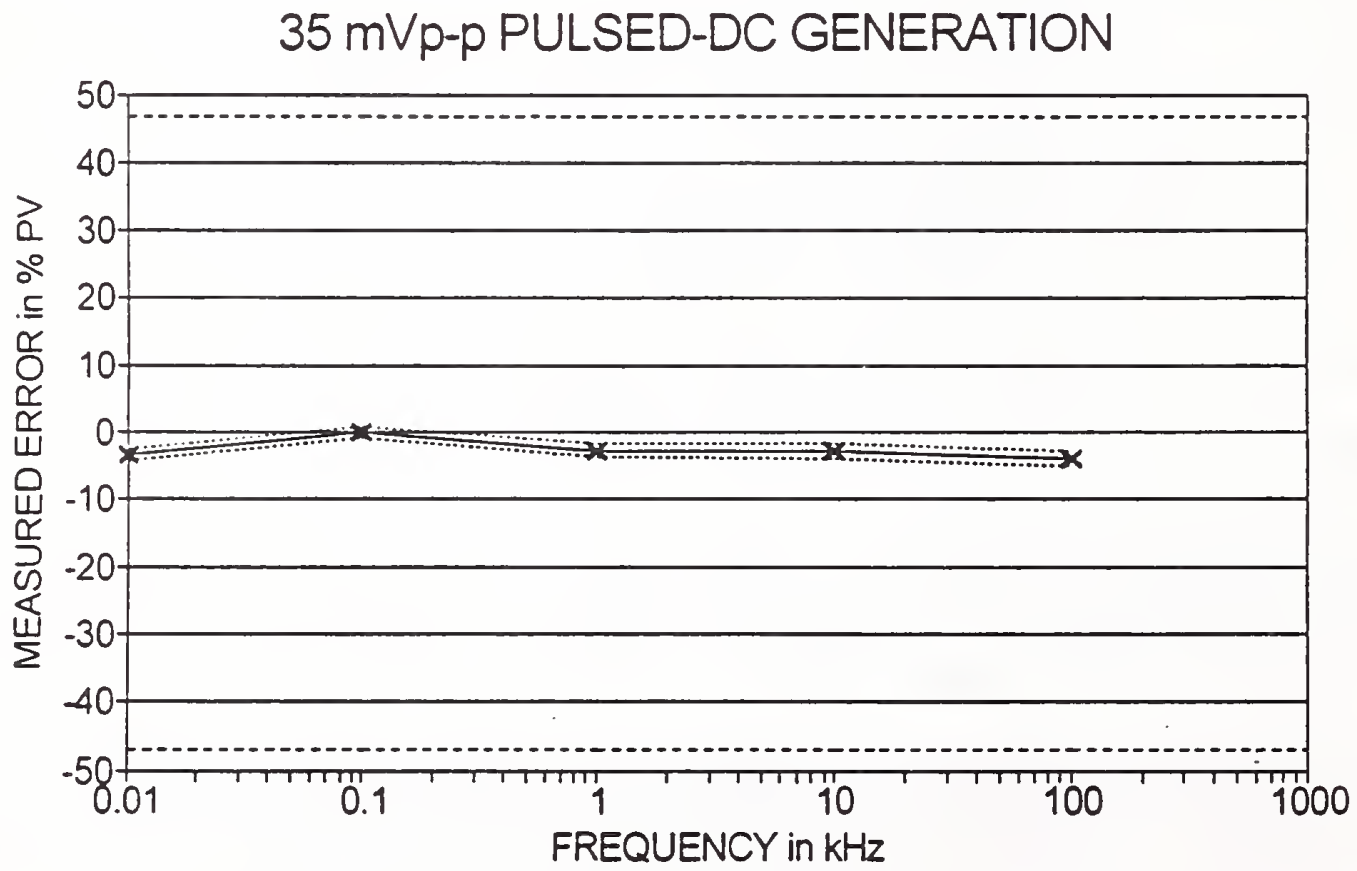

$\rightarrow x-$ Measured Data …..... Meas. Uncertainty -...- IFTE Spec.

Figure 15. Measured error of IFTE arbitrary function generator vs. frequency for pulsed dc $\left(35 \mathrm{mV}_{\mathrm{p}-\mathrm{p}}\right)$ 


\subsubsection{Square-Wave Generation}

The ability of the Arbitrary Function Generator (AFG) to provide square-wave output signals having a known peak-to-peak voltage was tested at $0.070,0.700$, and $7.000 \mathrm{~V}_{\mathrm{p}-\mathrm{p}}\left(0.035,0.350\right.$, and $\left.3.500 \mathrm{~V}_{\mathrm{RMS}}\right)$. The tests were performed by applying the signal from the AFG in the IFTE station, through a test fixture ICD, to the calibrated reference DMM. The AFG was programmed to output a squarewave signal having the desired frequency and peak-to-peak output voltage levels. The RMS values of the output signal were then measured by the reference DMM, and converted to their corresponding peak-to-peak values. Figures 16, 17, and 18 show the measured error of the AFG in generating square-wave signals (deviations with respect to the reference $D M M$ ) in percent, relative to the peak-to-peak programmed value (PV), as a function of frequency. The figures also show the IFTE specification based on $\pm(4 \%$ of $P V+15 \mathrm{mV})$ [17].

The results of these tests are quite similar to those of the pulsed-dc output waveform described above (section 6.4.1). Again, the upper test frequency of $300 \mathrm{kHz}$ was chosen because of the increasing measurement uncertainty in the reference DMM in making an accurate measurement of the RMS value of the squarewave voltage output from the AFG.

For the $70 \mathrm{mV}$ and $700 \mathrm{mV}$ peak-to-peak voltage levels, the AFG met the IFTE amplitude accuracy specification up to the maximum test frequency of $300 \mathrm{kHz}$, even though there was considerably more negative offset than in the case of the pulsed-dc signal generation. At the $7.0 \mathrm{v}_{\mathrm{p}-\mathrm{p}}$ level, the downward trend in the error with increasing frequency, together with the large negative offset, caused the measured error to exceed the IFTE specification at the $300 \mathrm{kHz}$ test frequency. Consequently, the IFTE specification is very likely not being met from this frequency out to the $2 \mathrm{MHz}$ upper frequency for the specification. From the downward trend in the data, it is also probable that the $700 \mathrm{mV}$ level squarewave signal exceeds its specification in the 1-2 MHz range. At the $70 \mathrm{mV}_{\mathrm{p}-\mathrm{p}}$ level there was considerably more distortion and noise in the generated squarewave signal, which is reflected by the 7-9\% of PV measured error shown in figure 18. Consequently, these tests indicate the need to modify the selfalignment software and to run an RMS voltage measurement of the square-wave output with a wideband RMS-responding voltmeter having an effective accuracy of about $\pm 3 z$ out to about $10 \mathrm{MHz}$, as described in section 5.3.2.1.

\subsubsection{Sine-Wave Generation}

The ability of the Arbitrary Function Generator (AFG) to provide sine-wave output signals having a known peak-to-peak voltage was tested at $0.070,0.700$, and $7.000 \mathrm{~V}_{p-p}\left(0.0247,0.2475\right.$, and $\left.2.475 \mathrm{~V}_{R M S}\right)$. The tests were performed by applying the signal from the AFG in the IFTE station, through a test fixture ICD, to the calibrated reference DMM. The AFG was programmed to output a sinewave signal having the desired frequency and peak-to-peak output voltage levels. The RMS values of the output signal were then measured by the reference DMM, and converted to their corresponding peak-to-peak values. Figures 19, 20, and 21 show the measured error of the AFG in generating sine-wave signals (deviations with respect to the reference DMM) in percent, relative to the peak-to-peak programmed value (PV), as a function of frequency. The figures also show the 
7.0 Vp-p SQUARE WAVE GENERATION

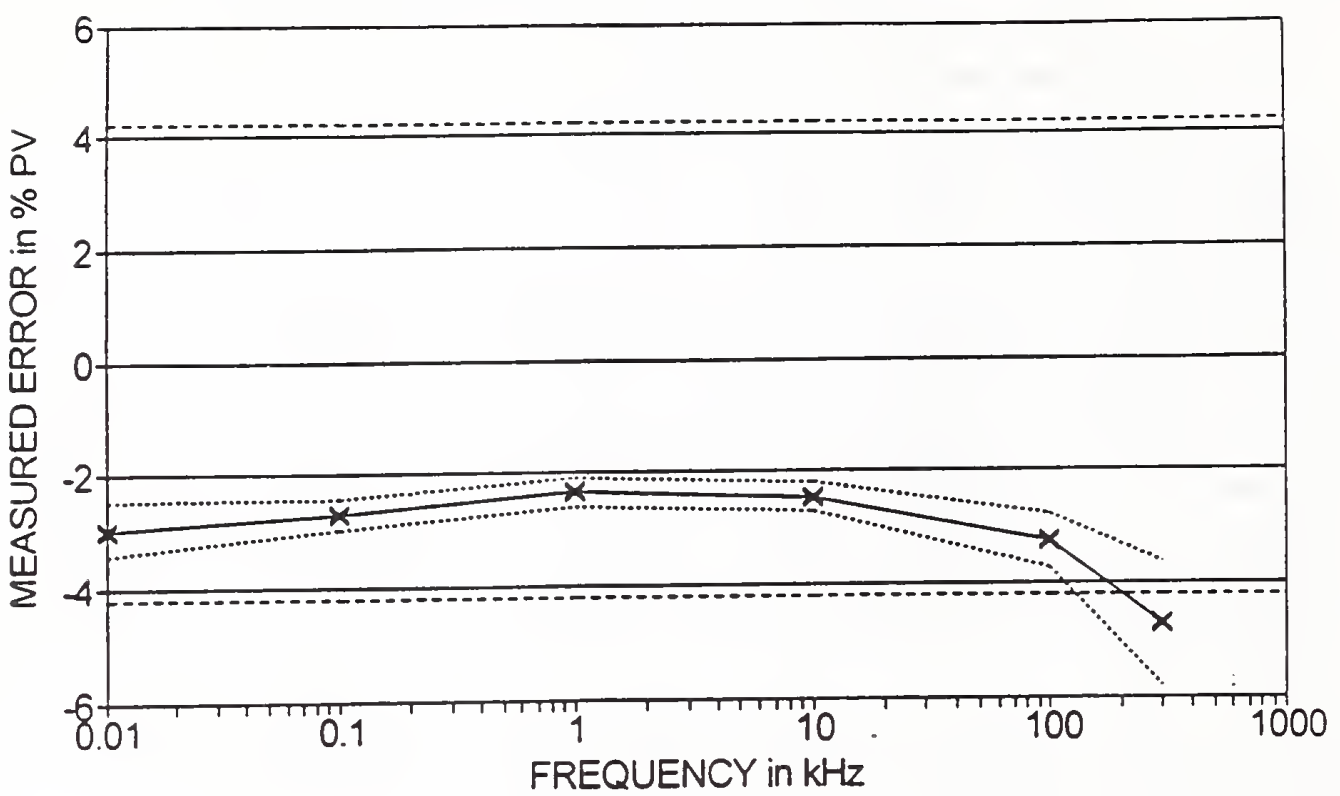

$\rightarrow$ Measured Data $\quad$........... Meas. Uncertainty -.... IFTE Spec.

Figure 16. Measured error of IFTE arbitrary function generator vs. frequency for square waves $\left(7.0 \mathrm{~V}_{\mathrm{p}-\mathrm{p}}\right)$

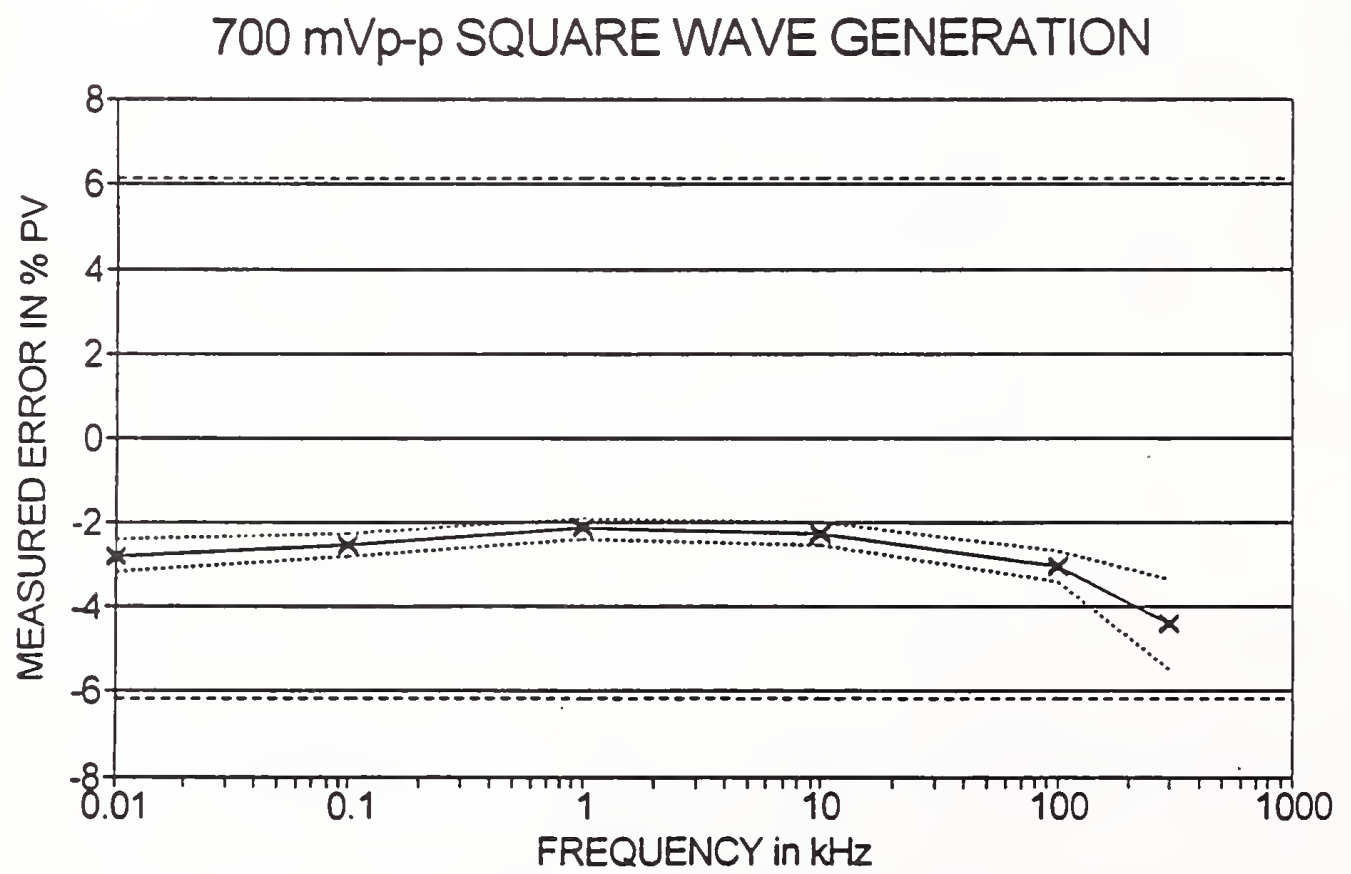

$\rightarrow-$ Measured Data $\quad$......... Meas. Uncertainty -..-- IFTE Spec.

Figure 17. Measured error of IFTE arbitrary function generator vs. frequency for square waves $\left(700 \mathrm{mV}_{\mathrm{p}-\mathrm{p}}\right)$ 
$70 \mathrm{mVp}$-p SQUARE WAVE GENERATION

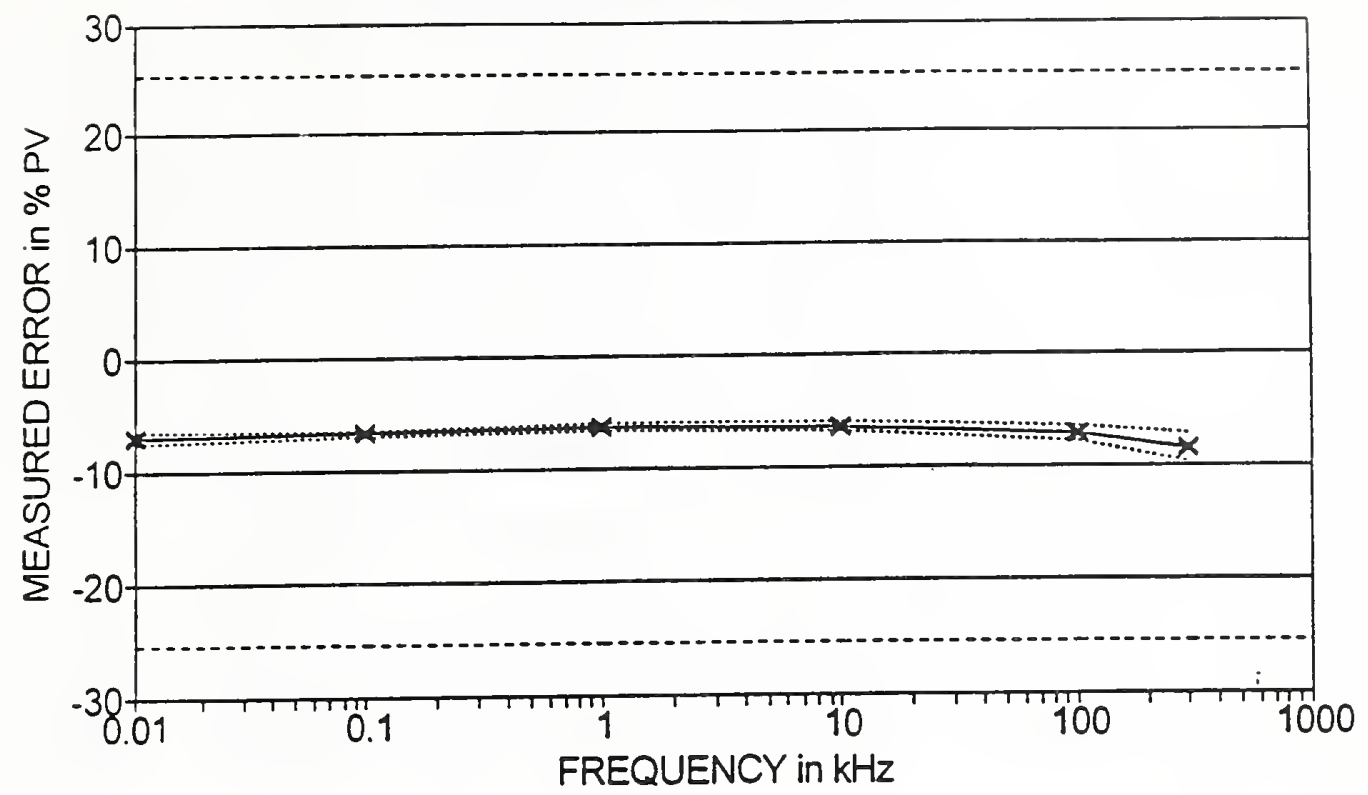

$-*$ Measured Data $\quad$-.......... Meas. Uncertainty --..- IFTE Spec.

Figure 18. Measured error of IFTE arbitrary function generator vs. frequency for square waves $\left(70 \mathrm{mV}_{\mathrm{p}-\mathrm{p}}\right.$ )

7.0 Vp-p SINE WAVE GENERATION

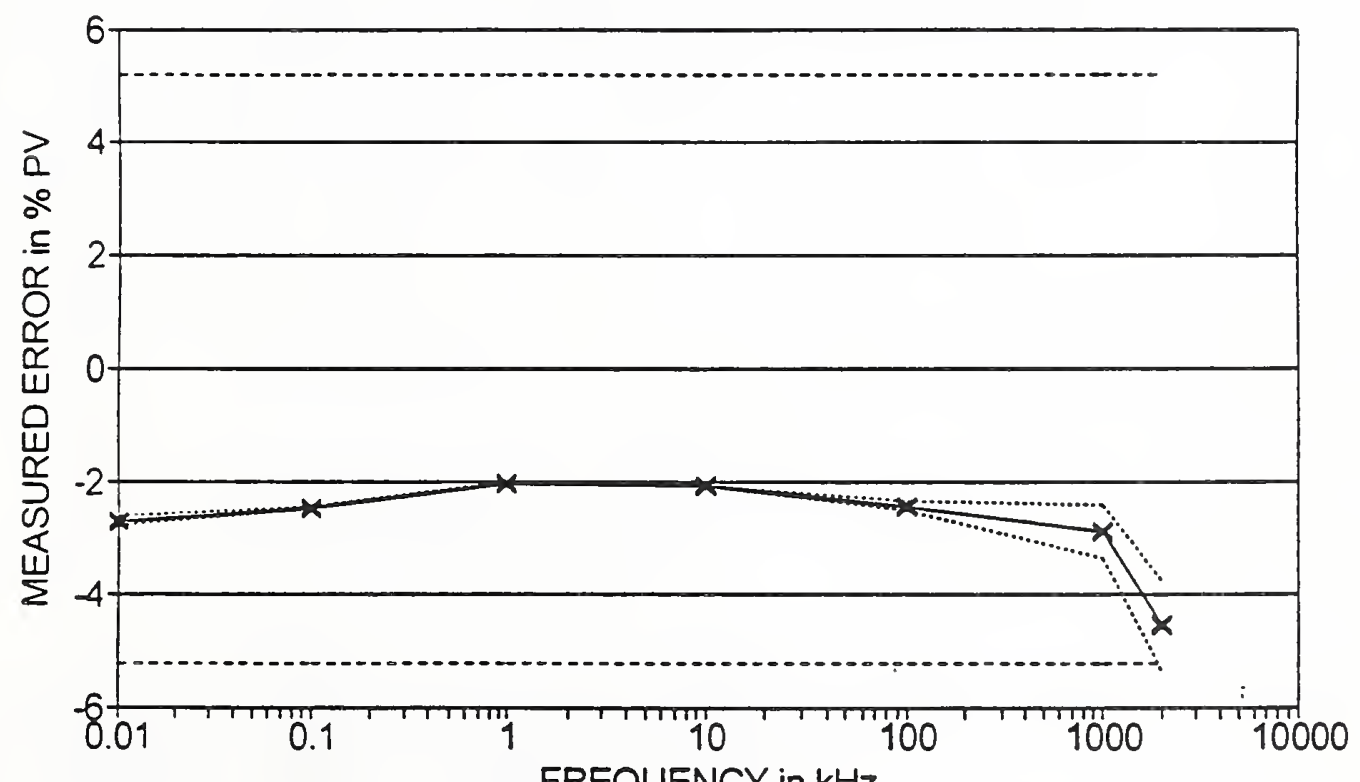

FREQUENCY in $\mathrm{kHz}$

$\rightarrow-$ Measured Data ……... Meas. Uncertainty :-..- IFTE Spec.

Figure 19. Measured error of IFTE arbitrary function generator vs. frequency for sine waves $\left(7.0 \mathrm{~V}_{\mathrm{P}-\mathrm{p}}\right)$ 
700 mVp-p SINE WAVE GENERATION

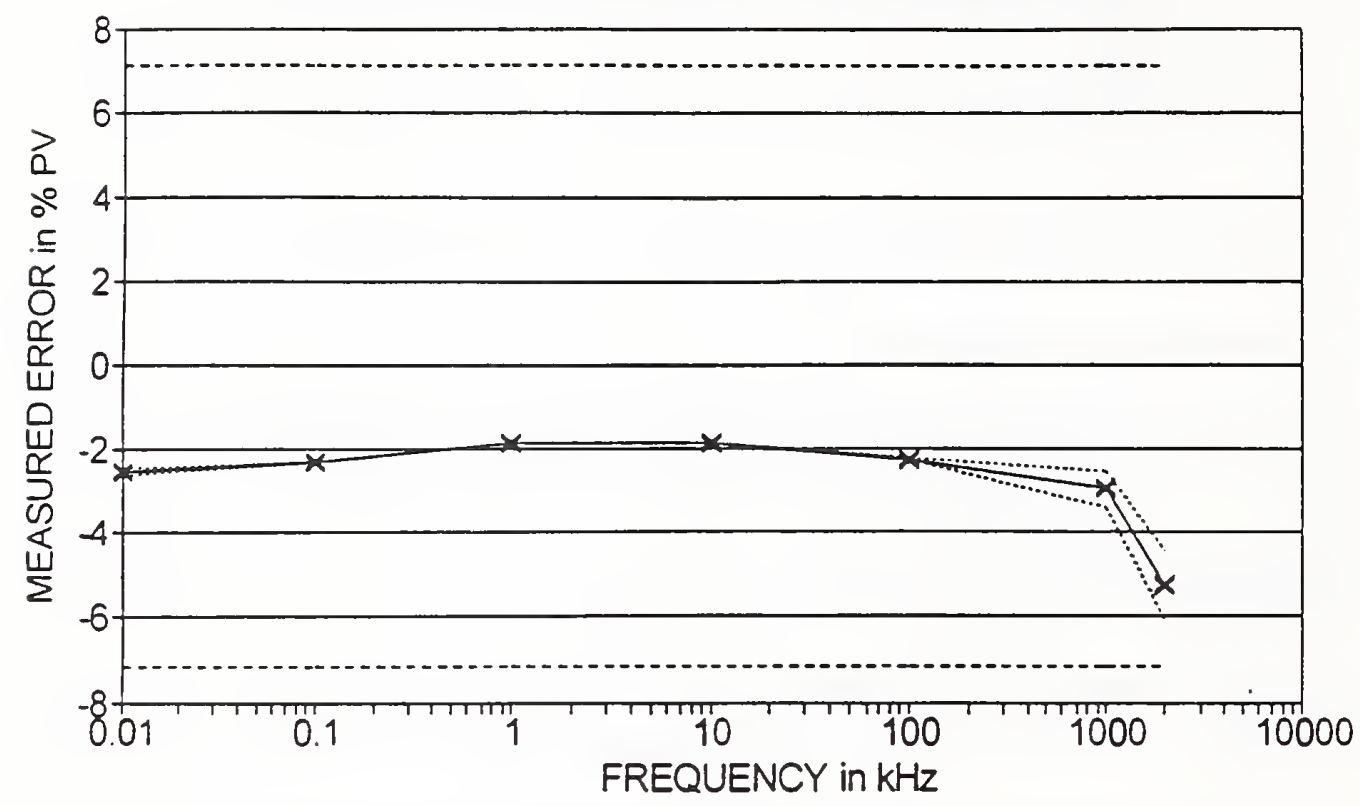

$\rightarrow$ - Measured Data ……... Meas. Uncertainty -...- IFTE Spec.

Figure 20. Measured error of IFTE arbitrary function generator vs. frequency for sine waves $\left(700 \mathrm{mV}_{\mathrm{p}-\mathrm{p}}\right.$ )

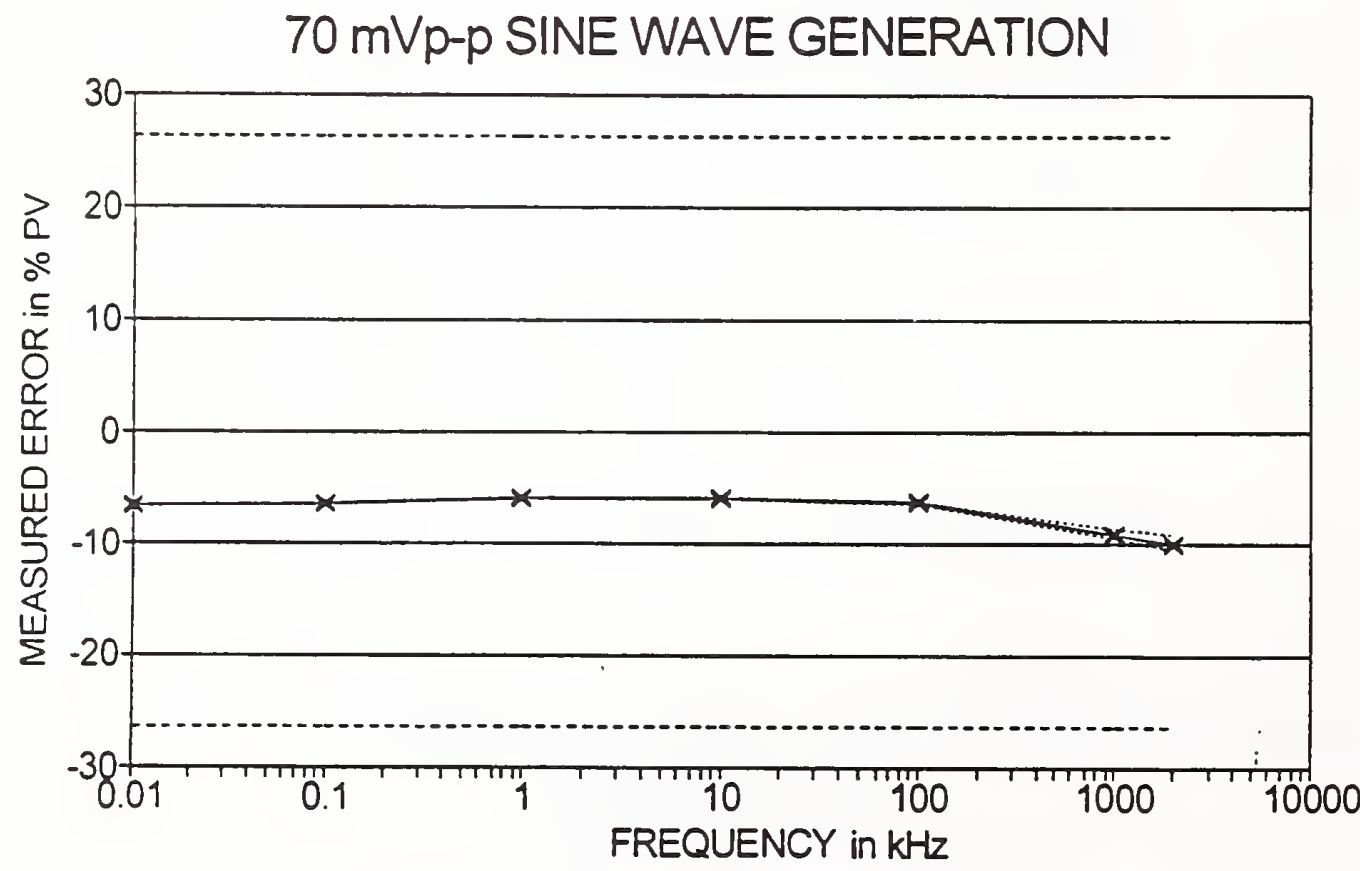

$\rightarrow x-$ Measured Data $\quad$.......... Meas. Uncertainty -...- IFTE Spec.

Figure 21. Measured error of IFTE arbitrary function generator vs. frequency for sine waves $\left(70 \mathrm{mV}_{p-p}\right)$ 
IFTE amplitude accuracy specification based on $\pm(5 \%$ of $\mathrm{PV}+15 \mathrm{mV})$ [17].

In this case, tests were carried out up to the full $2 \mathrm{MHz}$ maximum frequency range over which the IFTE amplitude accuracy specification holds. The same relative shapes and offsets are seen in this data as were observed with the pulsed-dc and square-wave signals from the AFG. With the additional $\pm 1 \%$ of PV in the IFTE accuracy specification, as compared with the pulsed-dc and squarewave amplitude accuracy specification, the AFG met the IFTE specifications, even though the data point at $2 \mathrm{MHz}$ on the $7.0 \mathrm{~V}_{\mathrm{p}-\mathrm{p}}$ range (see figure 19) was close to exceeding the specification limit.

\subsubsection{Triangle-Wave Generation}

The ability of the Arbitrary Function Generator (AFG) to output triangle-wave signals having a known peak-to-peak voltage was tested at 0.070 and $0.700 \mathrm{~V}_{\mathrm{p}-\mathrm{p}}$ $\left(0.0202\right.$, and $\left.0.202 \mathrm{~V}_{\mathrm{RMS}}\right)$. The tests were performed by applying the signal from the AFG in the IFTE station, through a test fixture ICD, to the calibrated reference DMM. The AFG was programmed to output a triangle-wave signal having the desired frequency and peak-to-peak output voltage levels. The RMS values of the output signal were then measured by the reference DMM, and converted to their corresponding peak-to-peak values. Figures 22 and 23 show the measured error of the AFG in generating triangle-wave signals (deviations with respect to the reference DMM) in percent, relative to the peak-to-peak programmed value (PV), as a function of frequency. The figures also show the IFTE amplitude accuracy specification based on $\pm(6 \%$ of $\mathrm{PV}+15 \mathrm{mV})$ [17].

In this case, the upper test frequency of $1 \mathrm{MHz}$ was chosen because of the increasing measurement uncertainty in the reference DMM in making an accurate measurement of the RMS value of the triangle-waveform voltage from the AFG above $1 \mathrm{MHz}$. From the manufacturer's specifications, confirmed by independent calibration testing at NIST, the error of the reference DMM can be approximated conservatively by an uncertainty of $\epsilon_{1}= \pm 1.03 \%$ up to $1 \mathrm{MHz}$ and $\epsilon_{2}= \pm 10.03 \%$ above $1 \mathrm{MHz}$. Thus, by using equation ( 8 ) of Appendix $B$ and equations (20) and (25) from Appendix $C$, the error band of the reference DMM in reading the RMS value of the triangle-wave voltage at $1 \mathrm{MHz}$ can be computed to be $(k=1)$ :

$$
\begin{aligned}
& \mathrm{RMS}_{\text {erxor }}= \pm\left[\left(10.03 \% \cdot \mathrm{RMS}_{\mathrm{total}}\right)^{2}+\left((1.03 \%)^{2}-(10.03 \%)^{2}\right)\left(\mathrm{RMS}_{\mathrm{kth}-}\right)^{2}\right]^{\frac{1}{2}} \text {, } \\
& = \pm\left[0.01006\left(V_{p-p} / 2 \sqrt{3}\right)^{2}+(-0.00995)\left(8\left(V_{p-p}\right)^{2} / \pi^{4}(1+1 / 81)\right)\right]^{\frac{2}{2}} \\
& = \pm V_{p-p}[0.000838+(-0.00995)(0.082(1.012))]^{\frac{1}{3}} \\
& = \pm V_{p}-p[0.000838-0.00995(0.083)]^{\frac{3}{2}} \\
& = \pm V_{p-p}[0.0000122]^{\frac{1}{2}}= \pm 0.00349 V_{p-p} \\
& = \pm 0.349 \% \text {, relative to the programmed peak-to-peak voltage. }
\end{aligned}
$$

For the programmed value (PV) of $0.7 \mathrm{~V}_{\mathrm{p}-\mathrm{p}}$ (see figure 22), the IFTE specification for the AFG amplitude accuracy is $\pm(6 \% \cdot 0.7 \mathrm{~V}+15 \mathrm{mV}) 100 / 0.7 \mathrm{~V}= \pm 8.14 \%$. Thus, the TAR at $1 \mathrm{MHz}$ was $8.14 / 0.349=23.3$, which is more than adequate.

For both the $700 \mathrm{mV}$ and $70 \mathrm{mV}$ peak-to-peak voltage levels, the AFG readily met the IFTE amplitude accuracy specification up to the maximum test frequency of $1 \mathrm{MHz}$. Unfortunately, triangle-wave tests at the $7.0 \mathrm{~V}_{\mathrm{p}-\mathrm{p}}$ level were not obtained; however, with similarity to the results obtained for sine-wave signals, 
700 mVp-p TRIANGLE WAVE GENERATION

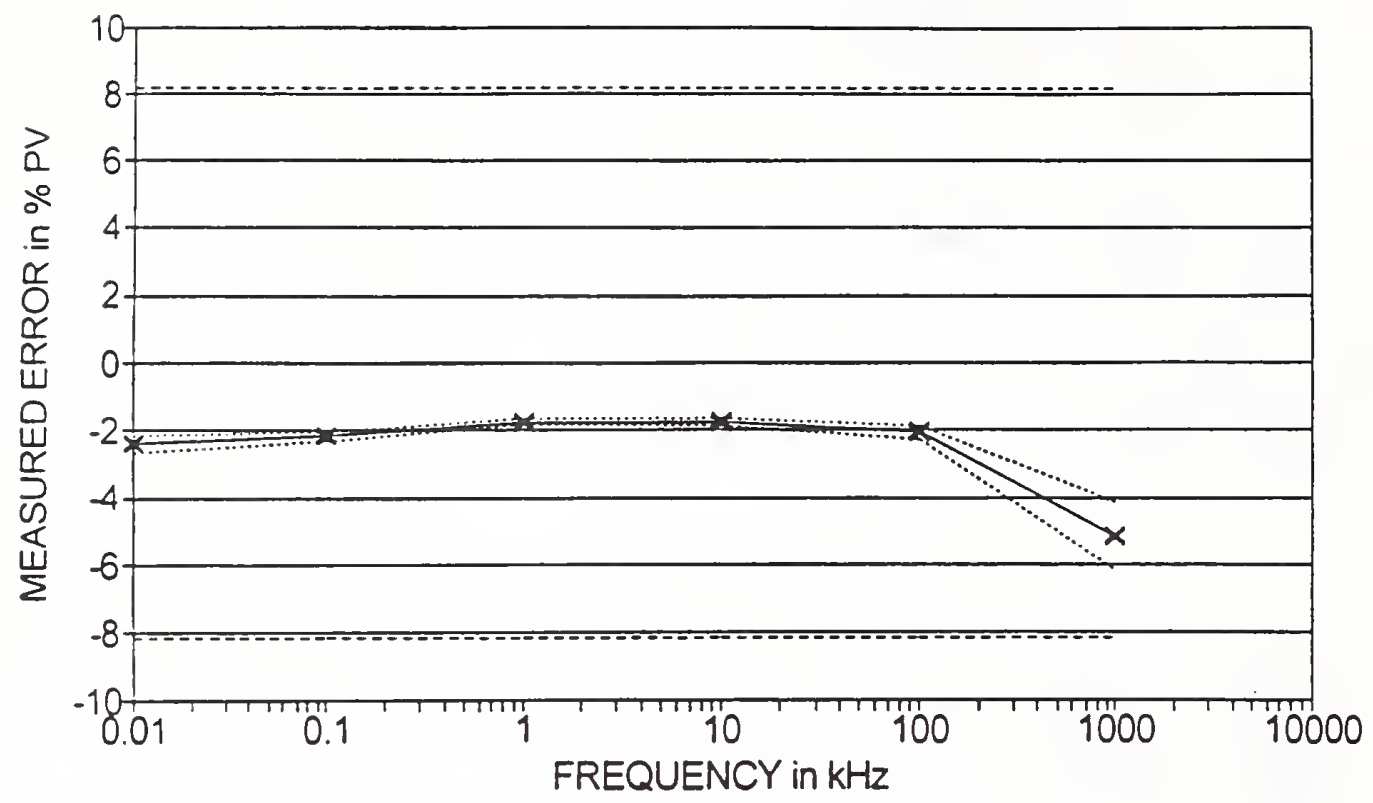

Figure 22. Measured error of IFTE arbitrary function generator vs. frequency for triangle waves $\left(700 \mathrm{mV}_{\mathrm{p}-\mathrm{p}}\right)$

\section{0 mVp-p TRIANGLE WAVE GENERATION}

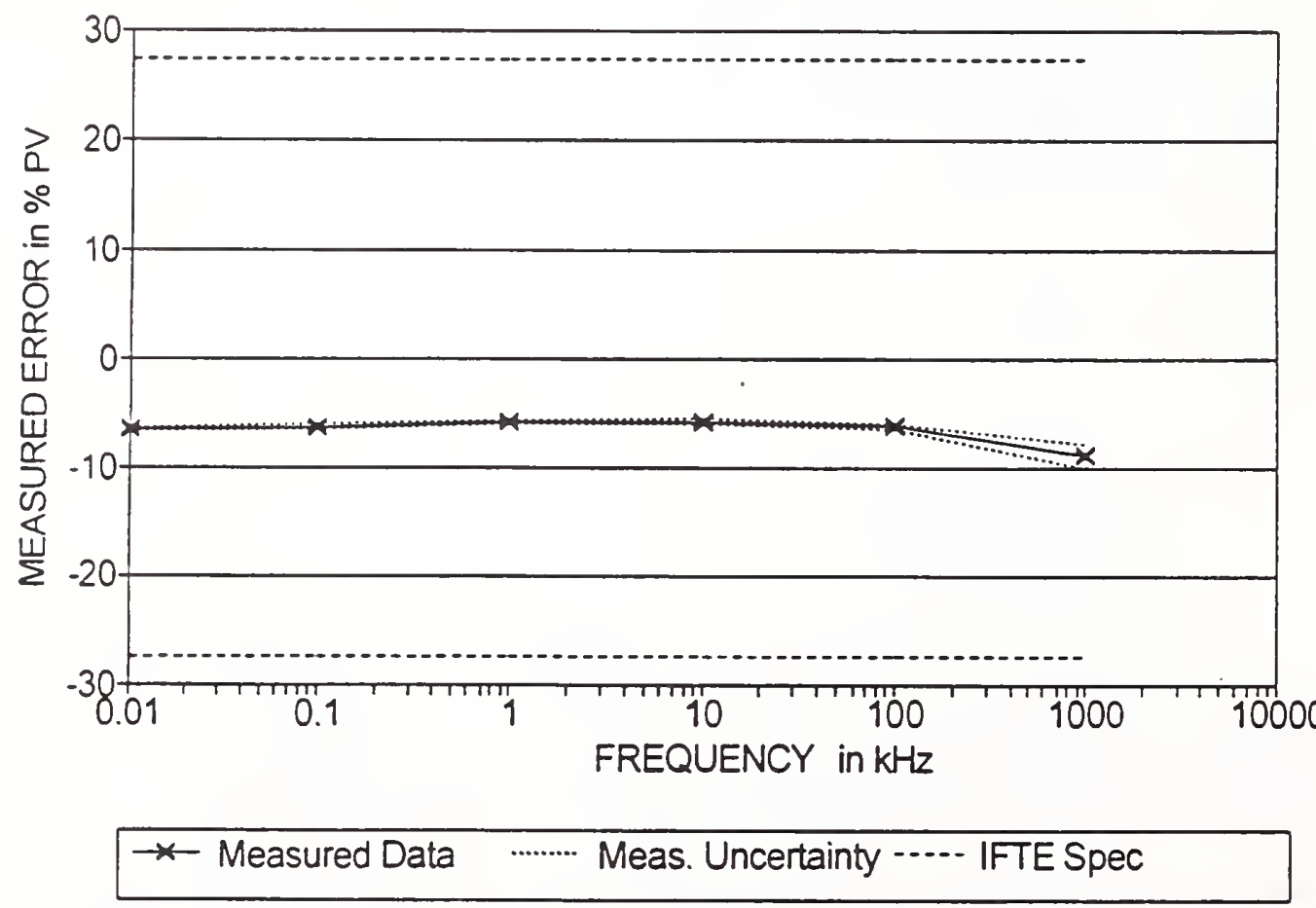

Figure 23. Measured error of IFTE arbitrary function generator vs. frequency for triangle waves $\left(70 \mathrm{mV}_{\mathrm{p}-\mathrm{p}}\right)$ 
it is likely that such tests would have shown that at the $7.0 \mathrm{~V}$ level the AFG would come close to not meeting the IFTE specification in the 1-2 MHz region. Again, at the $70 \mathrm{mV}_{\mathrm{p}-\mathrm{p}}$ level there was considerably more distortion and noise in the generated triangle-wave signal, which is reflected by the 6-8\% of PV measured error shown in figure 23.

\subsection{Self-alignment ICD}

Tests were performed on two SA-ICDs by applying power to the ICDs from the IFTE station (as applied during self-alignment testing), and then measuring the internal fixed-point ac and dc voltage, frequency, and dc resistance standards with the NIST-calibrated reference DMM. The tests were performed repeatedly over a one-hour time interval to measure any drift during the specified one-hour warmup period of the SA-ICD. The results of these tests are shown below in tables 2 and 3.

$\underline{\text { Table } 2}$

\begin{tabular}{|c|c|c|c|c|c|c|c|}
\hline \multirow[b]{2}{*}{ Time (1) } & \multicolumn{3}{|c|}{ Self-Alignment ICD } & S.N. 009 & \multicolumn{2}{|c|}{ Last Cal Oct 17,1990} & \multirow[b]{2}{*}{ Pass/Fail } \\
\hline & Test Point & Unit & Nominal & Measured & Tolerance $z$ & Deviation $x$ & \\
\hline 0 min & $\begin{array}{l}\text { TP23->TP22 } \\
\text { TP9->TP8 } \\
\text { TP9->TP7 } \\
\text { TP9->TP8 }\end{array}$ & $\begin{array}{l}\text { VDC } \\
\text { VAC } \\
\text { VAC } \\
\text { Hz }\end{array}$ & $\begin{array}{l}18 \\
1 \\
10 \\
20000\end{array}$ & $\begin{array}{l}17.99835 \\
1.0039152 \\
10.03731 \\
20081.5\end{array}$ & $\begin{array}{l}0.0112 \\
0.06 \\
0.06 \\
1 .\end{array}$ & $\begin{array}{r}-0.0092 \\
0.3915 \\
0.3731 \\
0.4075\end{array}$ & $\begin{array}{l}\text { ?* } \\
\text { FAIL } \\
\text { FAIL } \\
\text { PASS }\end{array}$ \\
\hline $40 \min$ & $\begin{array}{l}\text { TP23->TP22 } \\
\text { TP23-TP24 } \\
\text { TP23->TP25 } \\
\text { TP23->TP12 } \\
\text { TP9->TP8 } \\
\text { TP9->TP7 } \\
\text { TP15->TP2 } \\
\text { TP16->TP3 } \\
\text { TP17->TP4 } \\
\text { TP18->TP5 } \\
\text { TP19->TP6 }\end{array}$ & $\begin{array}{l}\text { VDC } \\
\text { VDC } \\
\text { VDC } \\
\text { VDC } \\
\text { VAC } \\
\text { VAC } \\
\text { Ohns } \\
K \text { Ohms } \\
K \text { Ohms } \\
K \text { Ohms } \\
M \text { Ohms }\end{array}$ & $\begin{array}{l}18 \\
9 \\
0.9 \\
0.09 \\
1 \\
10 \\
100 \\
1 \\
10 \\
100 \\
1\end{array}$ & $\begin{array}{l}17.9983 \\
8.999879 \\
0.8999813 \\
0.0899982 \\
1.00405 \\
10.038414 \\
100.0076 \\
1.0000293 \\
10.0001 \\
100.0034 \\
1.00002\end{array}$ & $\begin{array}{l}0.0112 \\
0.0187 \\
0.0187 \\
0.0187 \\
0.06 \\
0.06 \\
0.0055 \\
0.0055 \\
0.0055 \\
0.0055 \\
0.0055\end{array}$ & $\begin{array}{l}-0.0094 \\
-0.0013 \\
-0.0021 \\
-0.0020 \\
0.4050 \\
0.3841 \\
0.0076 \\
0.0029 \\
0.0010 \\
0.0034 \\
0.0020\end{array}$ & $\begin{array}{l}\text { ?* } \\
\text { PASS } \\
\text { PASS } \\
\text { PASS } \\
\text { FAIL } \\
\text { FAIL } \\
\text { FAIL } \\
\text { PASS } \\
\text { PASS } \\
\text { PASS } \\
\text { PASS }\end{array}$ \\
\hline $50 \min$ & $\begin{array}{l}\text { TP23->TP22 } \\
\text { TP23-TP24 } \\
\text { TP23->TP25 } \\
\text { TP23->TP12 } \\
\text { TP9 -> TP8 } \\
\text { TP9 ->TP7 }\end{array}$ & $\begin{array}{l}\text { VDC } \\
\text { VDC } \\
\text { VDC } \\
\text { VDC } \\
\text { VAC } \\
\text { VAC }\end{array}$ & $\begin{array}{l}18 \\
9 \\
0.9 \\
0.09 \\
1 \\
10\end{array}$ & $\begin{array}{l}17.99826 \\
8.9998662 \\
0.899977 \\
0.089996 \\
1.004089 \\
10.0387\end{array}$ & $\begin{array}{l}0.0112 \\
0.0187 \\
0.0187 \\
0.0187 \\
0.06 \\
0.06\end{array}$ & $\begin{array}{r}-0.0097 \\
-0.0015 \\
-0.0026 \\
-0.0044 \\
0.4089 \\
0.3870\end{array}$ & $\begin{array}{l}\text { ?* } \\
\text { PASS } \\
\text { PASS } \\
\text { PASS } \\
\text { FAIL } \\
\text { FAIL }\end{array}$ \\
\hline $65 \min$ & $\begin{array}{l}\text { TP23->IP22 } \\
\text { TP23-TP24 } \\
\text { TP23->TP25 } \\
\text { TP23->TP12 } \\
\text { TP9 -> TP8 } \\
\text { TP9 -> TP7 }\end{array}$ & $\begin{array}{l}\text { VDC } \\
\text { VDC } \\
\text { VDC } \\
\text { VDC } \\
\text { VAC } \\
\text { VAC }\end{array}$ & $\begin{array}{l}18 \\
9 \\
0.9 \\
0.09 \\
1 \\
10\end{array}$ & $\begin{array}{l}17.99828 \\
8.999861 \\
0.899975 \\
0.089996 \\
1.004 \\
10.03877\end{array}$ & $\begin{array}{l}0.0112 \\
0.0187 \\
0.0187 \\
0.0187 \\
0.06 \\
0.06\end{array}$ & $\begin{array}{r}-0.0096 \\
-0.0015 \\
-0.0028 \\
-0.0044 \\
0.4000 \\
0.3877\end{array}$ & $\begin{array}{l}\text { ?* } \\
\text { PASS } \\
\text { PASS } \\
\text { PASS } \\
\text { FAIL } \\
\text { FAIL }\end{array}$ \\
\hline $70 \mathrm{~min}$ & $\begin{array}{l}\text { TP15->TP2 } \\
\text { TP16->TP3 } \\
\text { TP17->TP4 } \\
\text { IP18->TPS } \\
\text { TP19->IP6 } \\
\text { TP 9->TP8 }\end{array}$ & $\begin{array}{l}\text { Ohms } \\
K \text { Ohms } \\
\text { K Ohms } \\
\text { K Ohms } \\
\text { M Ohms } \\
\mathrm{Bz}\end{array}$ & $\begin{array}{l}100 \\
1 \\
10 \\
100 \\
1 \\
20000\end{array}$ & $\begin{array}{l}100.0051 \\
1.00003 \\
10.00001 \\
100.0035 \\
1.00003 \\
20074 .\end{array}$ & $\begin{array}{l}0.0055 \\
0.0055 \\
0.0055 \\
0.0055 \\
0.0055 \\
1 .\end{array}$ & $\begin{array}{l}0.0051 \\
0.0030 \\
0.0001 \\
0.0035 \\
0.0030 \\
0.3700\end{array}$ & $\begin{array}{l}? \\
\text { PASS } \\
\text { PASS } \\
\text { PASS } \\
\text { PASS } \\
\text { PASS }\end{array}$ \\
\hline
\end{tabular}

?* Does not meet "at time of calibration" specification; would meet specification if allowance is made for up to one year of drift at the specified tolerance.

? The deviation between the measured error and the specification is less than the uncertainty of the measurement: these points are borderline.

(1) Time since power was applied to ICD 
$\underline{T a b l e ~} 3$

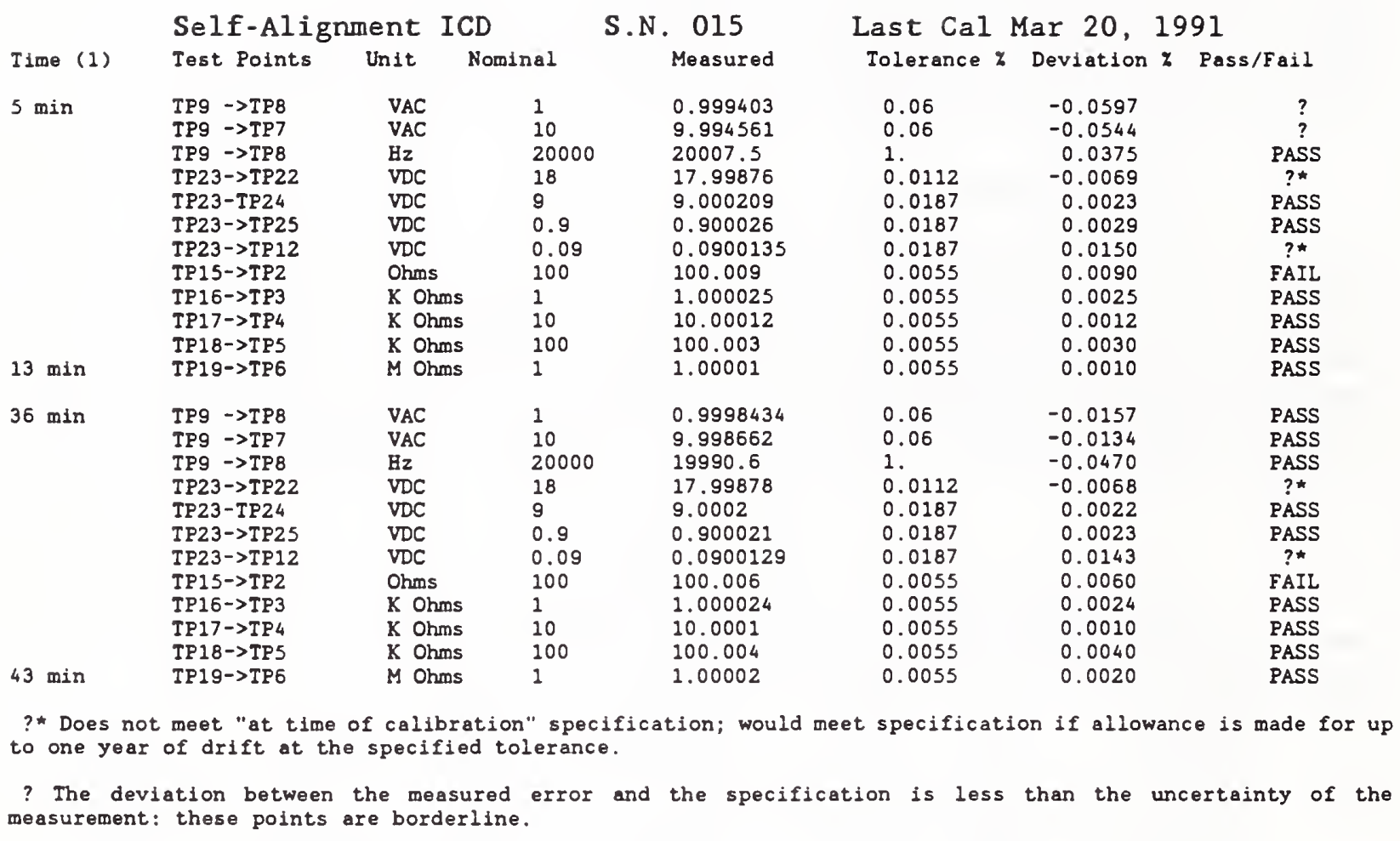

(1) Iime since power was applied to ICD

From the test data on the two SA-ICDs, it appears that the $18.00 \mathrm{~V}$ dc reference provides marginal performance. The $18.00 \mathrm{Vdc}$ references for both SA-ICDs were unable to meet their specification for "at time of calibration" specification; however, they meet the specification if the $\pm 0.0056 \% /$ year tolerance indicated in [5] and [17] is added to the initial "specification range and accuracy" of $17.999 \mathrm{~V}$ to $18.001 \mathrm{~V}$ given in [5]. The units thus meet a reasonable interpretation of the specification; however, the $18.00 \mathrm{~V}$ dc references in both SA-ICDs will fail their next calibration. The vendor should reconsider the dc reference used or adjust the specifications placed on the current unit.

The $10 \mathrm{~V}$ ac and $1 \mathrm{~V}$ ac references failed to meet the specified accuracy of $0.06 \%$ specified in [5] and [17] for SA-ICD S.N. 009. Although the last set of measurements taken on S.N. 015 showed the ac reference to be within the specified limits, these showed considerable drift $(0.045 \%)$ from the measurements made approximately 30 minutes earlier. Due to the lack of available time, test results after longer warmup times were unable to be obtained. However, the amount of drift that was observed indicates that the vendor should consider adding some mechanism to ensure that the recommended one-hour warmup time is always allowed prior to using the ICD to align an IFTE station.

All of the resistance standards of $1 \mathrm{k} \Omega$ or greater met the specified accuracy without any problems; however, the $100 \Omega$ standards in both ICDs were out of the specified tolerance. The vendor should examine the type of $100 \Omega$ reference standards used, or adjust the specification. 


\section{Summary and Recommendations}

This report provides an assessment of the calibration support scheme proposed for the $d c$ and low-frequency analog instrumentation functions of the Integrated Family of Test Equipment (IFTE) systems being procured by the U.S. Army. The calibration/measurement requirements summary and related documents for the IFTE system were analyzed, together with measurement data obtained from limited onsite testing of a commercial equipment equivalent (CEE) version of an IFTE station (SN 017) by NIST technical staff.

From these investigations, it was observed that there are inconsistencies in the proposed calibration support for the digital multimeter, counter-timer, highspeed digitizer, and arbitrary-function generator instrument functions contained in the various versions of the IFTE test systems. Most of these inconsistencies likely can be resolved by making modifications to the self-alignment software procedures, together with the use of some additional, or more accurate, test equipment. Results from the limited testing of the dc and low frequency analog instrumentation functions in one IFTE station (SN 017) have confirmed the need to implement these changes in the proposed calibration support procedures.

It is recommended that the Army make further performance tests on the dc and low frequency instrumentation of several IFTE systems in order to confirm the results contained in this report.

\section{Acknowledgements}

In preparing this report the authors acknowledge the encouragement of Messrs. R. Flemming and J. Ball of the U.S. Army TMDE Support Activity, Huntsville, AL and the assistance of Messrs. Joe Benuomo, Fred Kerr, and Steve Laise of the Tobyhanna Army Depot, Tobyhanna, PA. 
1. T. F. Leedy, Electrosystems Division Trip Report 非 722-178, December 12, 1985.

2. Lt. Col. L. E. Crapse, Jr., letter to C. K. Miller, Chief, Electromagnetic Fields Division, NBS, Boulder, CO, July 24, 1986.

3. Grumman-submitted briefing materials on the IFTE Self Alignment, October 27, 1986.

4. F. B. Seeley, et al, U.S. Army TMDE Support Group trip report, November 4, 1986.

5. G. Clarius, et al, Grumman-proposed Calibration/Measurement Requirements Summary for BSTS, December 5, 1986.

6. G. Clarius, et al, Grumman-proposed Calibration/Measurement Requirements Summary for BSTS, March 14, 1988.

7. W. C. Wanner, Jr., Grumman letter to DoA, Hdqtrs, USACECOM, with enclosure on Description of Self-Alignment of System Software Correction Factors, December 9, 1988.

8. USATSG-submitted Statement of Work for Automated Calibration Test Program Set, October 11, 1989.

9. USATSG-presented briefing materials on the calibration and repair concept for the IFTE, January, 1990.

10. PM/TMDE-proposed Statement of Work for Automated Calibration Test Program Set, February 8, 1990.

11. USATSG-submitted Statement of Work for Automated Calibration Test Program Set, March 15, 1990.

12. Statement of Work for Automated Calibration Test Program Set, DAAB07-89C-N001, undated [received June 14, 1990].

13. R. S. Turgel and D. F. Vecchia, "Precision Calibration of Phase Meters," IEEE Transactions on Instrumentation and Measurement, IM-36, No. 4, pp. 918-922, December, 1987.

14. B. A. Bell, Automated Electronic Test Equipment Calibration and Support Strategies Project, U.S. Army TMDE Support Group, Redstone Arsenal, AL 35898, Interim Report (No. 728-195), September 24, 1990.

15. B. A. Bell, N. M. Oldham, and P. S. Hetrick, Electricity Division Trip Report No. 811-1-24A, January 15-16, 1991. 
16. S. Sniegocki, et al, Grumman Aerospace Corp., Specification IFTE85B030102, Prime Item Development Specification for the Commercial Equivalent Equipment (CEE), P/N A31U17000-3, March 2, 1988.

17. E. Minasian, et al, Grumman Aerospace Corp., Specification IFTE85B030303, Prime Item Development Specification for the Commercial Equivalent Equipment (CEE), P/N A31U17000-101, July 9, 1990.

18. IEEE Std 1057 Trial-Use Standard for Digitizing Waveform Recorders, Institute of Electrical and Electronics Engineers, 345 East 47 th Street, New York, N.Y., SH12740, July 21, 1989.

19. T. M. Souders, D. R. Flach, J. J. Blair, "Step and Frequency Response Testing of Waveform Recorders," IMTC 90 Conference Record, pp.214-220, February $13-15,1990$.

20. R. W. Ramirez, "The FFT: Fundamentals and Concepts," SPS Information Group, Tektronix, Inc., December, 1975.

21. L. B. W. Jolley, Summation of Series, Second Revised Edition, Dover Publications, Inc., New York 14, N.Y., Pp. 98-99, 1961.

22. A. P. Prudnikov, Yu. A. Brychkov, and O. I. Marichev, Integrals and Series, Vol. 1, Elementary Functions, translated from the Russian by $N$. M. Queen, Gordon and Breach Science Publishers, New York, N.Y., p. 653, 1986. 
Appendix A

Tolerance Analysis of the DC Reference Voltages in the Self-Alignment ICD 
Appendix A

Tolerance Analysis of the DC Reference Voltages in the Self-Alignment ICD

With the $\pm 0.01 \%$ tolerance on the Vishay resistors of the dc voltage divider (see Figure 2),

$$
\begin{aligned}
& R_{1 \text { (max) }}=9.0009 \mathrm{k} \Omega \\
& R_{1(\min )}=8.9991 \mathrm{k} \Omega \\
& R_{2(\max )}=8.10081 \mathrm{k} \Omega \\
& \mathrm{R}_{2 \text { (min) }}=8.09919 \mathrm{k} \Omega \\
& R_{3 \text { (max) }}=810.081 \Omega \\
& R_{3(\min )}=809.919 \Omega \\
& R_{4(\max )}=90.009 \Omega \\
& \mathrm{R}_{4 \text { (min) }}=89.991 \Omega
\end{aligned}
$$

Let

$$
R_{T}=R_{1}+R_{2}+R_{3}+R_{4} \text {. }
$$

Then,

and

$$
V_{1}=\frac{R_{2}+R_{3}+R_{4}}{R_{I}} \quad V_{R}=9.0 \mathrm{~V} \text { nominal, }
$$

so that

$$
\begin{aligned}
V_{1(\max )} & =\frac{R_{2(\max )}+R_{3(\max )}+R_{4(\max )}}{R_{1(\min )}+R_{2(\max )}+R_{3(\max )}+R_{4(\max )}} V_{\left.R_{(\max }\right)} \\
& =\frac{9000.9 \Omega}{8999.1 \Omega+9000.9 \Omega} 18.001 \mathrm{~V} \\
& =9.0014 \mathrm{~V},
\end{aligned}
$$

$$
\begin{aligned}
\frac{V_{1}-V_{1(\max )}}{V_{1}} & =\frac{9.0-9.0014 \mathrm{~V}}{9.0 \mathrm{~V}}=-0.0001555 \\
& \approx-0.0155 \%(-155 \mathrm{ppm})
\end{aligned}
$$

Also,

$$
\begin{aligned}
V_{1(\min )} & =\frac{R_{2(\min )}+R_{3(\min )}+R_{4(\min )}}{R_{1(\max )}+R_{2(\min )}+R_{3(\min )}+R_{4(\min )}} V_{R(\min )} \\
& =\frac{8999.11 \Omega}{9000.9 \Omega+8999.11 \Omega} 17.999 \mathrm{~V} \\
& =8.99861 \mathrm{~V},
\end{aligned}
$$


so that

$$
\begin{aligned}
\frac{V_{1}-V_{1(\min )}}{V_{1}} & =\frac{9.0 \mathrm{~V}-8.99861 \mathrm{~V}}{9.0 \mathrm{~V}}=0.0001544 \\
& \approx 0.0154 \%(154 \mathrm{ppm})
\end{aligned}
$$

Similarly,

and

$$
V_{2}=\frac{R_{3}+R_{4}}{R_{T}} \quad V_{R}=0.9 V \text { nominal, }
$$

$$
\begin{aligned}
V_{2(\max )} & =\frac{R_{3(\max )}+R_{4(\max )}}{R_{1(\min )}+R_{2(\min )}+R_{3(\max )}+R_{4(\max )}} V_{R(\max )} \\
& =\frac{900.09 \Omega}{17,998.4 \Omega} 18.001 \mathrm{~V} \\
& =0.90022 \mathrm{~V},
\end{aligned}
$$

so that

$$
\begin{aligned}
\frac{V_{2}-V_{2(\max )}}{V_{2}} & =\frac{0.9 \mathrm{~V}-0.90022}{0.9 \mathrm{~V}}=-0.0002445 \\
& \approx-0.0244 \%(-244 \mathrm{ppm}) .
\end{aligned}
$$

Also,

so that

$$
\begin{aligned}
V_{2(\min )} & =\frac{R_{3(\min )}+R_{4(\min )}}{R_{1(\max )}+R_{2(\max )}+R_{3(\min )}+R_{4(\min )}} V_{R(\min )} \\
& =\frac{899.91 \Omega}{18,001.6 \Omega} 17.999 \mathrm{~V} \\
& =0.89978 \mathrm{~V},
\end{aligned}
$$

$$
\begin{aligned}
\frac{V_{2}-V_{2(\min )}}{V_{2}} & =\frac{0.9 \mathrm{~V}-0.89978 \mathrm{~V}}{0.9 \mathrm{~V}}=0.0002444 \\
& \approx 0.0244 \% \quad(244 \mathrm{ppm})
\end{aligned}
$$

For $\mathrm{V}_{3}$,

$$
V_{3}=\frac{R_{4} V_{R}}{R_{I}}=0.09 \mathrm{~V} \text { nominal, }
$$

and

$$
\begin{aligned}
V_{3(\max )} & =\frac{R_{4}(\max )}{R_{1(\min )}+R_{2(\min )}+R_{3(\min )}+R_{4(\max )}} V_{R(\max )} \\
& =\frac{90.009 \Omega}{17,998.2 \Omega} 18.001 \mathrm{~V}=0.090023 \mathrm{~V},
\end{aligned}
$$


so that

$$
\begin{aligned}
\frac{V_{3}-V_{3(\max )}}{V_{3}} & =\frac{0.09 \mathrm{~V}-0.090023 \mathrm{~V}}{0.09 \mathrm{~V}}=-0.0002555 \\
& \approx-0.0255 \% \quad(-255 \mathrm{ppm}) .
\end{aligned}
$$

Also,

$$
\begin{aligned}
V_{3(\min )} & =\frac{R_{4(\min )}}{R_{1(\max )}+R_{2(\max )}+R_{3(\max )}+R_{4(\min )}} V_{R_{(\min )}} \\
& =\frac{89.991 \Omega}{18,001.8 \Omega} 17.999 \mathrm{~V} \\
& =0.089977 \mathrm{~V},
\end{aligned}
$$

so that

$$
\begin{aligned}
\frac{V_{3}-V_{3(\min )}}{V_{3}} & =\frac{0.09 \mathrm{~V}-0.089977 \mathrm{~V}}{0.09 \mathrm{~V}}=0.0002555 \\
& \approx 0.0255 \%(255 \mathrm{ppm})
\end{aligned}
$$

73 
Appendix B

RMS Value vs. Waveform Parameters 
Appendix B

\section{RMS Value vs. Waveform Parameters}

By definition, the total rms value of a periodic function, $v(t)$, is given by

$$
\mathrm{RMS}_{t \circ \mathrm{tal}}=\left[1 / \mathrm{T} \int_{0}^{\mathrm{T}} \mathrm{v}^{2}(t) \mathrm{dt}\right]^{\frac{1}{2}}
$$

where $T$ is the period of the time-dependent function.

\section{Pulsed DC Waveforms}

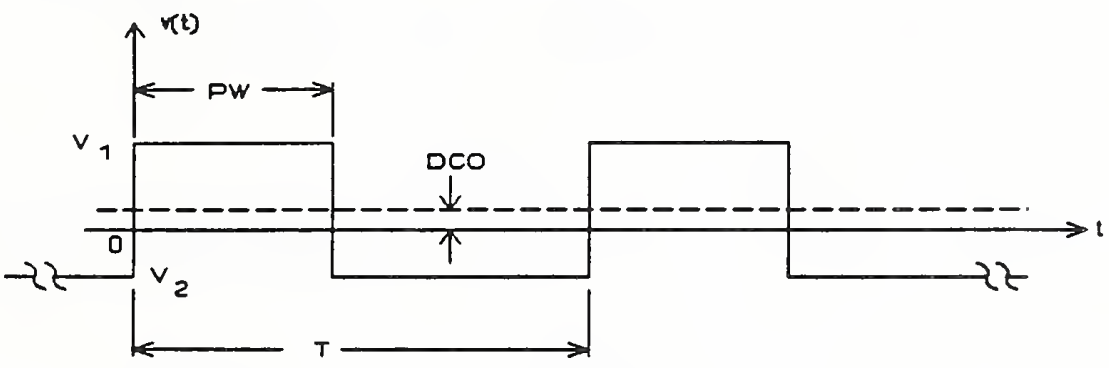

Figure 24. Ideal, periodic, bipolar, pulsed dc waveform and its associated time and amplitude parameters.

The general case of the pulsed dc waveform shown in figure 24 is described by its peak-to-peak amplitude, $V_{p-p}=V_{1}-V_{2}$, dc offset, DCO, pulse width, $P W$, and fundamental frequency component, $f_{0}=1 / T$. Using (1), the total rms value of this pulsed dc waveform is then

$$
\begin{aligned}
& \mathrm{RMS}_{t \circ t a I}=\left[1 / \mathrm{T} \int_{0}^{\mathrm{PW}}\left(\mathrm{DCO}+\mathrm{V}_{\mathrm{p}-\mathrm{p}} / 2\right)^{2} \mathrm{dt}+1 / \mathrm{T} \int_{\mathrm{PW}}^{\mathrm{T}}\left(\mathrm{DCO}-\mathrm{V}_{\mathrm{p}-\mathrm{p}} / 2\right)^{2} \mathrm{dt}\right]^{\frac{1}{2}} \\
& =\left[1 / T \int_{0}^{P W}\left[(D C O)^{2}+(D C O) V_{p-p}+\left(V_{p-p}\right)^{2} / 4\right] d t+\right. \\
& \left.1 / T \int_{P W}^{T}\left[(D C O)^{2}-(D C O) V_{p-p}+\left(V_{p-p}\right)^{2} / 4\right] d t\right]^{\frac{1}{2}} \\
& -\left[\left[(D C O)^{2}+(D C O) V_{p-p}+\left(V_{p-p}\right)^{2} / 4\right] / T \int_{0}^{P W} d t+\right. \\
& \left.\left[(D C O)^{2}-(D C O) V_{p-p}+\left(V_{p-p}\right)^{2} / 4\right] / T \int_{P W}^{T} d t\right]^{\frac{2}{2}} \text {, }
\end{aligned}
$$


which can be evaluated readily as

$$
\mathrm{RMS}_{\mathrm{t} \circ \mathrm{ta} 1}=\left\{\left(\mathrm{V}_{\mathrm{p}-\mathrm{p}}\right)^{2} / 4+\mathrm{DCO}\left[\mathrm{DCO}+\left(\mathrm{V}_{\mathrm{p}-\mathrm{p}}\right)\left[2\left(\mathrm{PW} \cdot \mathrm{f}_{\mathrm{o}}\right)-1\right]\right]\right\}^{\frac{1}{2}},
$$

where $V_{p-p}$ is the peak-to-peak value,

DCO is the dc offset,

$\mathrm{PW}$ is the pulse width, and

$f_{0}$ is the fundamental frequency of the waveform;

or,

$$
\mathrm{RMS}_{t \circ t a 1}=\left\{\left(V_{p-p}\right)^{2} / 4+D C O\left[D C O+\left(V_{p-p}\right)[2(D C)-1]\right]\right\}^{\frac{1}{2}},
$$

where $D C$ is the duty cycle $=\mathrm{PW} \cdot \mathrm{f}_{0}=\mathrm{PW} / \mathrm{T}$.

Obviously, when the dc offset (DCO) is zero, the total RMS value is simply half of the peak-to-peak value. Also, when the duty cycle is 0.5 (50\%), then

$$
\mathrm{RMS}_{t \circ t a 1}=\left[\left(\mathrm{V}_{\mathrm{p}-\mathrm{p}}\right)^{2} / 4+(\mathrm{DCO})^{2}\right]^{\frac{1}{2}} \text {. }
$$

\section{Triangle Waveforms}

By a similar analysis as given above for pulsed dc waveforms, it can be shown for a symmetrical triangle waveform that the total rms value is related to the programmed peak-to-peak value and the dc offset by

$$
\mathrm{RMS}_{\mathrm{t} \circ \mathrm{tal}}=\left[\left(\mathrm{V}_{\mathrm{p}-\mathrm{p}}\right)^{2} / 12+(\mathrm{DCO})^{2}\right]^{\frac{1}{2}} \text {, }
$$

$\begin{array}{ll}\text { where } V_{p-p} & \text { is the peak-to-peak value, and } \\ D C O & \text { is the dc offset. }\end{array}$

Obviously, when the dc offset (DCO) is zero, the total RMS value is simply the peak-to-peak value divided by $2 \sqrt{3}$. 
Appendix C

Harmonic Analysis 


\section{Appendix C}

\section{Harmonic Analysis}

\section{Pulsed DC Waveforms}

The harmonics contained in the pulsed dc waveform shown in figure 24 are given by the Fourier series expression

$$
v(t)=a_{0}+\sum_{n=1}^{\infty} a_{n} \cos [(2 n \pi / T) t]+b_{n} \sin [(2 n \pi / T) t]
$$

Evaluating the terms:

$$
\begin{aligned}
a_{0} & =1 / T \int_{0}^{P W}\left[D C O+V_{p-p} / 2\right] d t+1 / T \int_{P W}^{T}\left[D C O-V_{p-p} / 2\right] d t \\
& =D C O+\left(V_{p-p}\right)\left(D C-\frac{1}{2}\right),
\end{aligned}
$$

where $D C=$ duty cycle $=P W / T$,

$$
\mathrm{DCO}=\mathrm{dc} \text { offset; }
$$

$$
\begin{aligned}
a_{n} & =2 / T \int_{0}^{P W}\left[D C O+V_{p-p} / 2\right] \cos \{(2 \pi n / T) t\} d t+ \\
2 / T & \int_{P W}^{T}\left[D C O-V_{p-p} / 2\right] \cos \{(2 \pi n / T) t\} d t \\
& =2 V_{p-p} / n \pi \sin (n D C \pi) ;
\end{aligned}
$$

and

$$
b_{n}=0 \text { (even function). }
$$

Hence,

$$
v(t)=\left[D C O+\left(V_{p-p}\right)\left(D C-\frac{1}{2}\right)\right]+2 V_{p-p} / \pi \sum_{n=1}^{\infty} \frac{\sin (n D C \pi) \cos [(2 n \pi / T) t]}{n} .
$$

Thus, the contribution to the rms value of the pulsed dc waveform due to the $k$ th harmonic is proportional to $(1 / k)^{2} \sin ^{2}(k D C \pi)$, and the total rms value is proportional to

$$
\mathrm{RMS}_{\text {total } 1} \propto \sum_{n=1}^{\infty} \frac{\sin ^{2} n(D C \pi)}{n^{2}}
$$

From [21] this series can be evaluated by

$$
\sum_{n=1}^{\infty} \frac{\sin ^{2} n(D C \pi)}{n^{2}}=\frac{(D C \pi)[\pi-(D C \pi)]}{2}
$$


Hence, from equations (1) of Appendix B, (12), and (14), the total rms value can be determined to be

$$
\mathrm{RMS}_{t \circ t a 1}=\left[\left[D C O+\left(V_{p-p}\right)\left(D C-\frac{1}{2}\right)\right]^{2}+\left(V_{p-p}\right)^{2} D C(1-D C)\right]^{\frac{1}{2}} .
$$

By similar analysis, the contribution to the rms value from the dc offset and components up to the kth harmonic is given by

$$
\mathrm{RMS}_{\mathrm{kth}-}=\left[\left[\mathrm{DCO}+\left(\mathrm{V}_{\mathrm{p}-\mathrm{p}}\right)\left(\mathrm{DC}-\frac{1}{2}\right)\right]^{2}+2\left(\mathrm{~V}_{\mathrm{p}-\mathrm{p}}\right)^{2} / \pi^{2} \sum_{n=1}^{\mathrm{k}} \frac{\sin ^{2} n(D C \pi)}{n^{2}}\right]^{\frac{1}{2}} .
$$

\section{Triangle Waveforms}

The harmonics contained in a symmetrical triangle waveform given by the Fourier series expression of (9) can be evaluated in similar fashion as shown above for a pulsed dc waveform. The resulting time-function expression is

$$
v(t)=D C O+4 V_{p-p} / \pi^{2} \sum_{n=0}^{\infty} 1 /(2 n+1)^{2} \cos [(2 n+1)(2 \pi t / T)] .
$$

Thus, the contribution to the rms value due to the $(2 n+1)$ th harmonic is proportional to $1 /(2 n+1)^{4}$, and the total rms value is proportional to

$$
\text { RMS }_{\text {tota } 1} \propto \sum_{n=0}^{\infty} 1 /(2 n+1)^{4}=\pi^{4} / 96 .(\text { see }[21])
$$

Hence, from equations (1) of Appendix B, (17), and (18), the total rms value can be determined to be

$$
\begin{aligned}
\mathrm{RMS}_{\mathrm{t} \circ \mathrm{tal}} & =\left[(\mathrm{DCO})^{2}+8\left(\mathrm{~V}_{\mathrm{p}-\mathrm{p}}\right)^{2} / \pi^{4}\left[\pi^{4} / 96\right]\right]^{\frac{1 / 2}{2}} \\
& =\left[(D C O)^{2}+\left(\mathrm{V}_{\mathrm{p}-\mathrm{p}}\right)^{2} / 12\right]^{\frac{1}{2}} .
\end{aligned}
$$

By similar analysis, the contribution to the rms value from the dc offset and the components up to the kth harmonic is given by

$$
\mathrm{RMS}_{\mathrm{kth}-}=\left[(D C O)^{2}+8\left(V_{p-p}\right)^{2} / \pi^{4} \sum_{n=0}^{k} 1 /(2 n+1)^{4}\right]^{\frac{1}{2}} \text {. }
$$




\section{RMS Error vs. Waveform Parameters and Number of Harmonics}

With accuracy specifications that are different above and below a certain frequency, it is convenient to be able to express the rms error of an rmsresponding instrument (such as the IFTE DMM), in terms of the total rms value of the waveform being measured and the rms value of the dc and first $k$ harmonics of the spectral components:

$$
\mathrm{RMS}_{\text {error }}=\left[\sum_{n=0}^{k}\left(\epsilon_{1} \mathrm{RMS}_{n}\right)^{2}+\sum_{n=k+1}^{\infty}\left(\epsilon_{2} \operatorname{RMS}_{n}\right)^{2}\right]^{\frac{1}{2}},
$$

where $\epsilon_{1}$ is the rms accuracy at dc and up through the kth harmonic,

$\epsilon_{2}$ is the rms accuracy above the kth harmonic, and

$\mathrm{RMS}_{\mathrm{n}}$ is the rms value of the nth harmonic.

Alternately, using RMS $_{\mathrm{kth}}$ - to represent the rms value of the first $\mathrm{k}$ harmonics and any dc offset (see above discussion on Pulsed DC and Triangle Waveforms),

$$
\mathrm{RMS}_{\text {error }}=\left[\left(\epsilon_{1} \mathrm{RMS}_{\mathrm{kth}-}\right)^{2}+\sum_{n=k+1}^{\infty}\left(\epsilon_{2} \text { RMS }_{n}\right)^{2}\right]^{\frac{1}{2}} \text {. }
$$

Since

$$
\mathrm{RMS}_{\mathrm{t} \text { ot } \mathrm{I}}=\left[\left(\mathrm{RMS}_{\mathrm{kth}-}\right)^{2}+\sum_{n=k+1}^{\infty}\left(\mathrm{RMS}_{\mathrm{n}}\right)^{2}\right]^{\frac{1}{2}}
$$

then multiplying by $\epsilon_{2}{ }^{2}$ in (23) gives

$$
\left(\epsilon_{2} \mathrm{RMS}_{\mathrm{t} \circ \mathrm{tal} \mathrm{l}}\right)^{2}=\left(\epsilon_{2} \mathrm{RMS}_{\mathrm{kth}-}\right)^{2}+\sum_{\mathrm{n}=\mathrm{k}+1}^{\infty}\left(\epsilon_{2} \mathrm{RMS}_{\mathrm{n}}\right)^{2} .
$$

Substituting for the last sum in (22),

Rewriting,

$$
\mathrm{RMS}_{\text {error }}=\left[\left(\epsilon_{1} \mathrm{RMS}_{\mathrm{kth}-}\right)^{2}+\left(\epsilon_{2} \mathrm{RMS}_{\mathrm{total}}\right)^{2}-\left(\epsilon_{2} \mathrm{RMS}_{\mathrm{kth}-}\right)^{2}\right]^{\frac{1}{2}} .
$$

$$
\mathrm{RMS}_{\text {error }}=\left[\left(\epsilon_{2} \mathrm{RMS}_{\mathrm{t} \circ \mathrm{tal}}\right)^{2}+\left(\epsilon_{1}{ }^{2}-\epsilon_{2}{ }^{2}\right)\left(\mathrm{RMS}_{\mathrm{kth}-}\right)^{2}\right]^{\frac{1}{2}} \text {. }
$$

Then, normalized to the total rms value of the waveform,

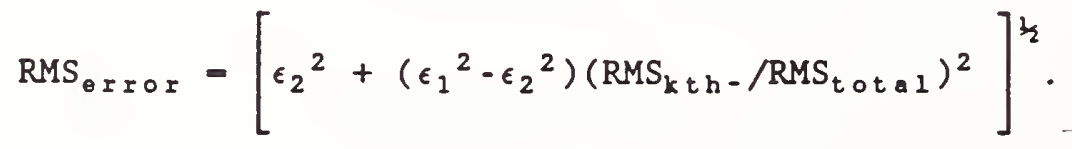

Given the values of the $\epsilon^{\prime} s$ and the waveform parameters for determining

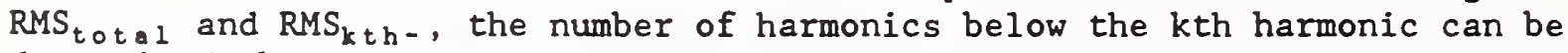
determined that are needed in order to achieve a certain overall RMS error. 
Appendix D

Tables of Test Data 


\section{Appendix D}

\section{Tables of Test Data}

Figure 4. Measured error of IFTE counter-timer vs. period

\begin{tabular}{|c|c|c|c|c|}
\hline Applied Period (s) & Measured Period (s) & Error in ns & IFTE Spec. (ns) & Meas. Uncert. (ns) \\
\hline $\begin{array}{l}1.00003 E-06 \\
1.00003 E-05 \\
1.00003 E-04 \\
1.00003 E-03 \\
3.33342 E-03 \\
1.00003 E-02 \\
1.00003 E-01\end{array}$ & $\begin{array}{l}9.90000 E-07 \\
1.00000 E-05 \\
1.00040 E-04 \\
1.00000 E-03 \\
3.33349 E-03 \\
1.00001 E-02 \\
1.00003 E-01\end{array}$ & $\begin{array}{l}-1.00257 E+01 \\
-2.56400 E-01 \\
3.74300 E+01 \\
-2.60000 E+01 \\
6.77800 E+01 \\
-1.46800 E+02 \\
3.00000 E+01\end{array}$ & $\begin{array}{l}2.00120 E+01 \\
2.01200 E+01 \\
2.12000 E+01 \\
3.20003 E+01 \\
6.00011 E+01 \\
1.40003 E+02 \\
1.22003 E+03\end{array}$ & $\begin{array}{l}1.35003 E-04 \\
1.35003 E-03 \\
1.35003 E-02 \\
1.35004 E-01 \\
4.50012 E-01 \\
1.35003 E+00 \\
1.35003 E+01\end{array}$ \\
\hline IFTE Spec: Error & $=20 \mathrm{~ns}+\left(12 \mathrm{pps}^{\star}\right.$ & d Period) $\star 100$ & 1) & \\
\hline Figure 5. Meas & ror of IFTE counte & & & \\
\hline REF. PW (s) & IFTE PW (s) & Error (s) & Meas. Uncert. ( $\mu s)$ & IFTE Spec. ( $\mu s)$ \\
\hline $\begin{array}{l}5.6090000 E-07 \\
1.0613000 E-06 \\
5.0734000 E-06 \\
5.1485000 E-06 \\
1.2696500 E-05 \\
2.5230500 E-05 \\
5.0132210 E-04 \\
1.2535960 E-03 \\
2.5067250 E-03 \\
5.0122160 E-03 \\
2.5051416 E-02 \\
1.0000000 E-01\end{array}$ & $\begin{array}{l}5.6000000 E-07 \\
1.0600000 E-06 \\
5.2600000 E-06 \\
5.4000000 E-06 \\
1.2960000 E-05 \\
2.5480000 E-05 \\
5.0156000 E-04 \\
1.2532800 E-03 \\
2.5054300 E-03 \\
5.0103800 E-03 \\
2.5050050 E-02\end{array}$ & $\begin{array}{r}-9.0000000 E-10 \\
-1.3000000 E-09 \\
1.8660000 E-07 \\
2.5150000 E-07 \\
2.6350000 E-07 \\
2.4950000 E-07 \\
2.3790000 E-07 \\
-3.1600000 E-07 \\
-1.2950000 E-06 \\
-1.8360000 E-06 \\
-1.3660000 E-06\end{array}$ & $\begin{array}{l}5.0112180 E-04 \\
5.0212260 E-04 \\
5.1014680 E-04 \\
5.1029700 E-04 \\
5.2539300 E-04 \\
5.5046100 E-04 \\
1.5026442 E-03 \\
3.0071920 E-03 \\
5.5134500 E-03 \\
1.0524432 E-02 \\
5.0602832 E-02\end{array}$ & $\begin{array}{l}2.0012736 E-02 \\
2.0060881 E-02 \\
2.0061782 E-02 \\
2.0152358 E-02 \\
2.0302766 E-02 \\
2.6015865 E-02 \\
3.5043152 E-02 \\
5.0080700 E-02 \\
8.0146592 E-02 \\
3.2061699 E-01 \\
1.2200000 E+00\end{array}$ \\
\hline
\end{tabular}

IFTE Spec: Error (ns) $=10 \mathrm{~ns}+\left(12 \mathrm{ppa}\right.$ (Applied Pulse width) $\left.{ }^{100000000}\right)$

Figure 6. Measured error (in degrees) of IFTE counter-timer vs. phase angle at $1 \mathrm{kHz}$

\begin{tabular}{|c|c|c|c|c|}
\hline REF. Phase & IFTE Phase & REF. uncert & EIror & IFTE Spec \\
\hline 0 & -0.04 & 0.00136 & -0.04 & 0.01944 \\
\hline 90.15 & 90.1 & 0.00136 & -0.05 & 0.01944 \\
\hline 135.12 & 135.07 & 0.00136 & -0.05 & 0.01944 \\
\hline 180.21 & 180.17 & 0.00136 & -0.04 & 0.01944 \\
\hline 215.16 & 215.04 & 0.00136 & -0.12 & 0.01944 \\
\hline 270.19 & 270.05 & 0.00136 & -0.14 & 0.01944 \\
\hline $\begin{array}{l}315.23 \\
360\end{array}$ & 315.18 & 0.00136 & -0.05 & $\begin{array}{l}0.01944 \\
0.01944\end{array}$ \\
\hline
\end{tabular}

IFIE Spec: Error (deg) $=360 \mathrm{deg}$. * (IFTE F error + IFTE T error) * Frequency.

where IFTE $F$ error $=1 E-08+(1.2 \mathrm{E}-05 / 1000)$ (in seconds)

and IFTE $T$ error $=1 E-08+1 E-08+(1 / 1000) * 1.2 E-05$ (in seconds) 
Figure 7. Measured error (in degrees) of IFTE counter-timer vs, phase angle at $100 \mathrm{kHz}$

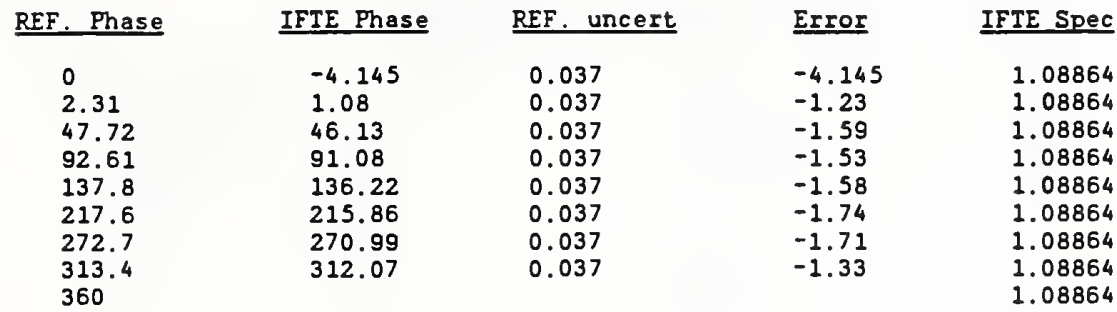

Note: 1st point $(0 \mathrm{deg}$.) not used;

the large error may be due to loading and not the IFTE station.

IFTE Spec: Error $(\mathrm{deg})=360 \mathrm{deg}$. * (IFTE F error + IFTE I error) * Frequency

where IFTE $F$ error $=1 E-08+(1.2 E-05 / 100000)$ (1n seconds)

and IFTE $I$ error $=1 E-08+1 E-08+(1 / 100000) * 1.2 E-05$ (1n seconds)

Figure 8. Measured error of IFTE digitizer vs. frequency for sine waves ( $\left.V_{p-p}\right)$

\begin{tabular}{|c|c|c|c|c|c|}
\hline Freq in $\mathrm{kBz}$ & IFTE $V_{p}-p$ & Corrected Vp-p & IFTE Error ZFSR & IFTE Spec (Z) & Meas. Uncert. ( $z$ ) \\
\hline $\begin{array}{l}0.01 \\
0.1 \\
1 \\
10 \\
100 \\
1000 \\
1001 \\
10000\end{array}$ & $\begin{array}{l}1.9450495 \\
1.9242792 \\
1.93650794 \\
1.93650794 \\
1.92941176 \\
1.78823529\end{array}$ & $\begin{array}{l}2.04504156 \\
2.04541981 \\
2.04556405 \\
2.04970382 \\
2.05977354 \\
1.96352469\end{array}$ & $\begin{array}{l}-3.99968242 \\
-4.84562443 \\
-4.36224452 \\
-4.52783509 \\
-5.21447112 \\
-7.01157595\end{array}$ & $\begin{array}{l}6 \\
6 \\
6 \\
6 \\
6 \\
6 \\
15 \\
15\end{array}$ & $\begin{array}{l}0.3684 \\
0.226 \\
0.2136 \\
0.2136 \\
0.4278 \\
1.2364\end{array}$ \\
\hline
\end{tabular}

IFTE Spec: Error $($ ZFSR $)=100 z *($ IFTE Vp-p $-($ Corrected Vp-p))/FSR

Figure 9. Measured error of IFTE digitizer vs. frequency for sine waves (V RMS)

\begin{tabular}{|c|c|c|c|c|c|}
\hline IFTE VRMS & Corrected VRMS & IFTE Error \&FSR & Frea. in $\mathrm{kBz}$ & IFTE Spec ( $(z)$ & Meas. Uncert \\
\hline 0.687548627 & 0.722977277568 & -4.00829425039 & 0.01 & 6 & 0.3684 \\
\hline 0.686148093 & 0.723107277183 & -4.18145436209 & 0.1 & 6 & 0.2266 \\
\hline 0.684542556 & 0.723159762906 & -4.36903821979 & 1 & 6 & 0.2138 \\
\hline 0.683515341 & 0.724616326145 & -4.65004564946 & 10 & 6 & 0.2142 \\
\hline 0.679473273 & 0.728180161405 & -5.51055537309 & 100 & 6 & 0.4278 \\
\hline 0.62065168 & 0.6942871529 & -8.33090275575 & $\begin{array}{l}1000 \\
1000\end{array}$ & $\begin{array}{l}6 \\
15\end{array}$ & 1.2364 \\
\hline
\end{tabular}

IFTE Spec: Error (YFSR) $=100 \%$ (IFTE VRMS - Corrected RMS)/FSR

Figure 10. Measured error of IFTE digitizer vs. frequency for triangle waves ( $\left.v_{p-p}\right)$

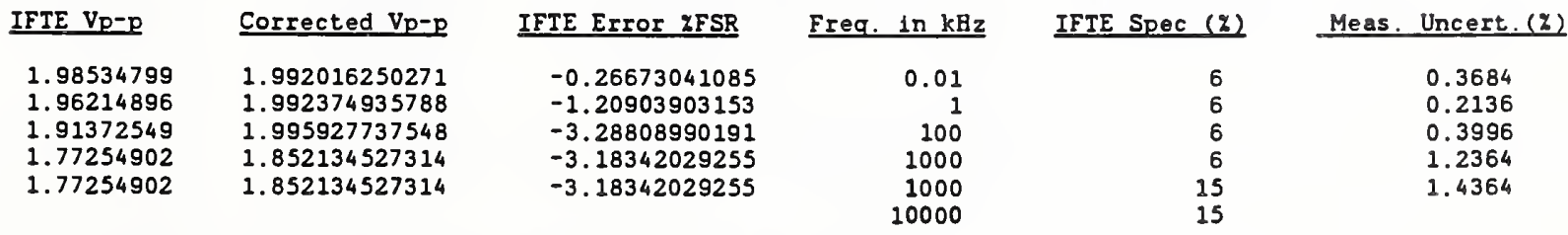

Corrected $V_{p-p}=$ DMM - RMS*DMM correction factor*2*3^0.5

IFTE Spec: Error (ZFSR) $=100 z^{*}$ (IFTE Vp-p - Corrected Vp-p)/FSR

Figure 11. Measured error of IFTE digitizer vs. frequency for triangle waves ( $V_{\text {RMS }}$ )

$\begin{array}{llrrrrr}\text { IFTE VRMS } & \text { Corrected RMS } & \text { IFTE Error ZFSR } & \text { Freq in kHz } & \text { IFTE SpeC (z) } & \text { Meas. Uncert. (z) } \\ 0.572797108 & 0.575039160001 & -0.31066783825 & & 0.0 & 1 & 0 \\ 0.570464446 & 0.575137102512 & -0.64746227881 & 100 & 6 & 0.3684 \\ 0.568209737 & 0.576158215423 & -1.10137347766 & 1000 & 6 & 0.4278 \\ 0.550126928 & 0.53468280418 & 2.14000057077 & 1000 & 15 & 1.2364 \\ & & & 10000 & 15 & \end{array}$

IFTE Spec: Error (zFSR) $=100 \% \star($ IFTE Vp-p - Corrected Vp-p)/FSR 
Figure 12. Measured error of IFTE digitizer vs. frequency for square waves (V $p-p$ )

\begin{tabular}{|c|c|c|c|c|c|}
\hline Freq $\mathrm{kHz}$ & IFTE $\mathrm{Vp}-\mathrm{P}$ & Corrected Vp-p & IFTE Error XFSR & IFTE Spec ( $(Z)$ & Meas. Uncert. (z) \\
\hline $\begin{array}{r}0.01 \\
1 \\
100 \\
1000 \\
1000 \\
10000\end{array}$ & $\begin{array}{l}1.9856899 \\
1.99389499 \\
2.05490196 \\
2.08627451\end{array}$ & $\begin{array}{l}1.988501 \\
1.988328 \\
1.969943 \\
1.718646\end{array}$ & $\begin{array}{r}-0.112434 \\
0.222685 \\
3.398373 \\
14.705149\end{array}$ & $\begin{array}{r}6 \\
6 \\
6 \\
6 \\
15 \\
15\end{array}$ & $\begin{array}{l}0.3684 \\
0.2136 \\
0.4778 \\
1.9046\end{array}$ \\
\hline
\end{tabular}

IFTE Spec: Error $($ FSR $)=100 \% *($ IFTE VP-p - Corrected Vp-p)/FSR

Figure 13. Measured error of IFTE arbitrafy function generator vs. frequency for pulsed de (3.5 $\left.v_{p-p}\right)$

\begin{tabular}{|c|c|c|c|c|}
\hline Corrected RMS & Error in $x$ & Freg in $\mathrm{kBz}$ & IFTE Spec $(z)$ & Mess. Uncert. (z) \\
\hline $\begin{array}{l}1.467278 \\
1.471334 \\
1.476299 \\
1.474165 \\
1.460436 \\
1.441010\end{array}$ & $\begin{array}{c}0.6095882573 \\
0.88360696292 \\
1.21695556725 \\
1.07396964467 \\
0.14399654423 \\
-1.2021822578\end{array}$ & $\begin{array}{r}0.01 \\
0.1 \\
1 \\
10 \\
100 \\
300 \\
1000\end{array}$ & $\begin{array}{l}4.42857142857 \\
4.42857142857 \\
4.42857142857 \\
4.42857142857 \\
4.42857142857 \\
4.42857142857 \\
4.42857142857\end{array}$ & $\begin{array}{l}0.4684 \\
0.3764 \\
0.3636 \\
0.3636 \\
0.6778 \\
1.3114\end{array}$ \\
\hline
\end{tabular}

IFTE Spec: Error $(Z P V)=(((0.04 * 3.5)+0.015) / 3.5) * 100$

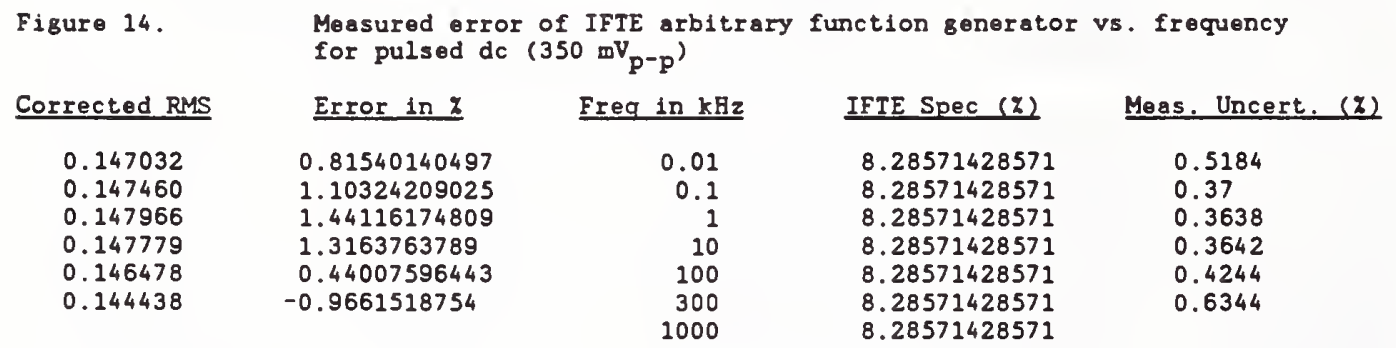

IFTE Spec: Error $(z P V)=(((0.04 * 0.35)+0.015) / 0.35) * 100$

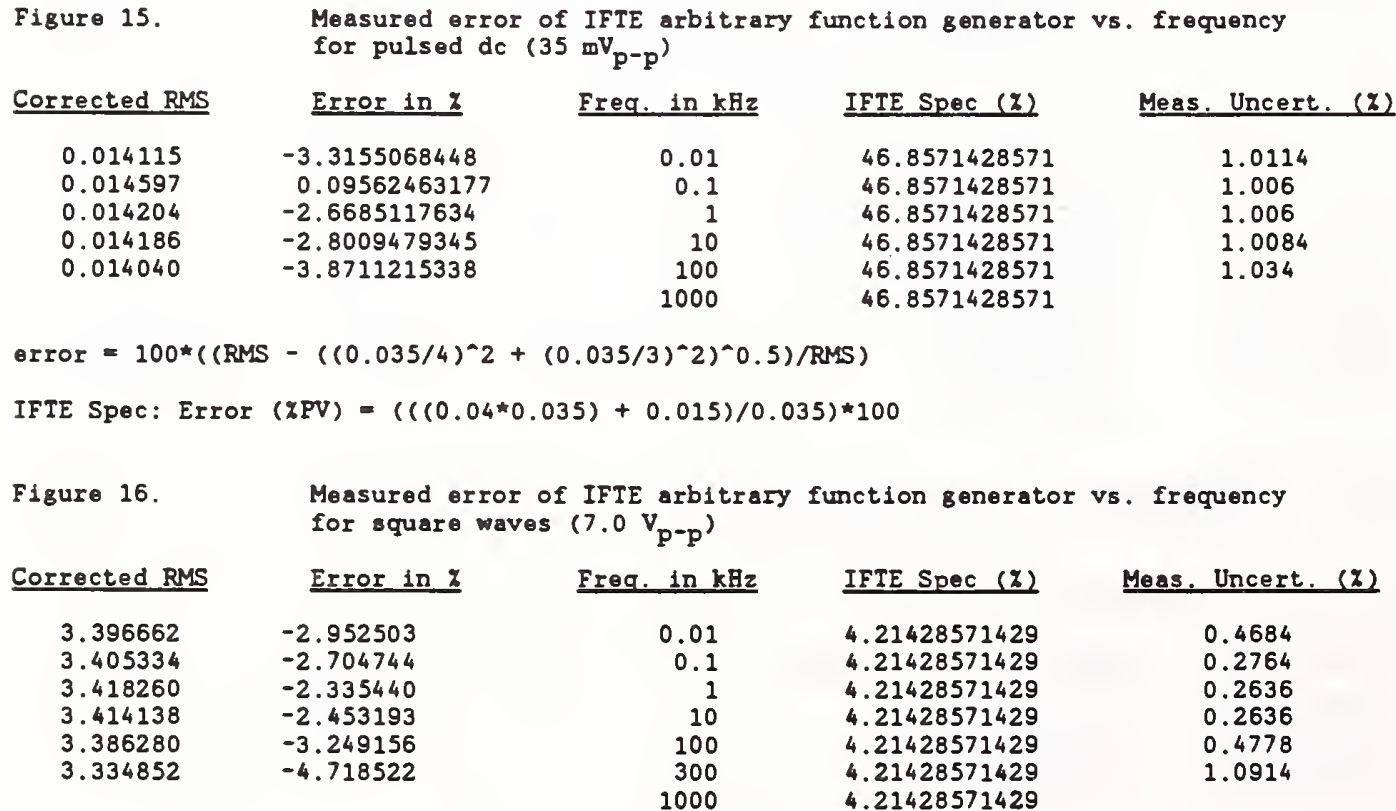




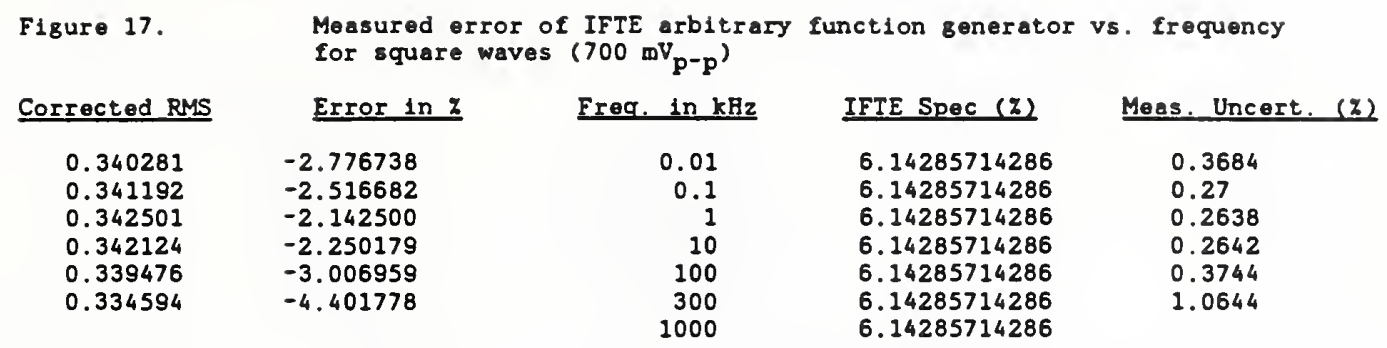

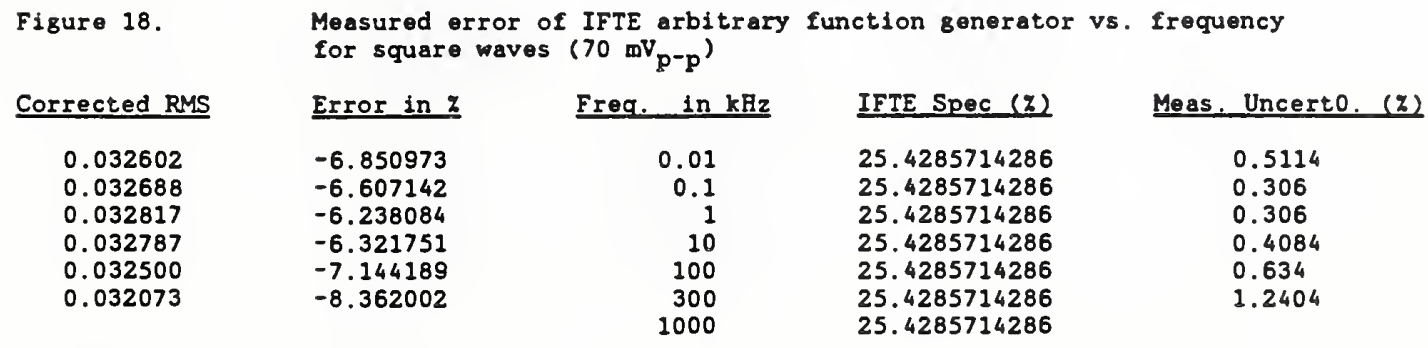

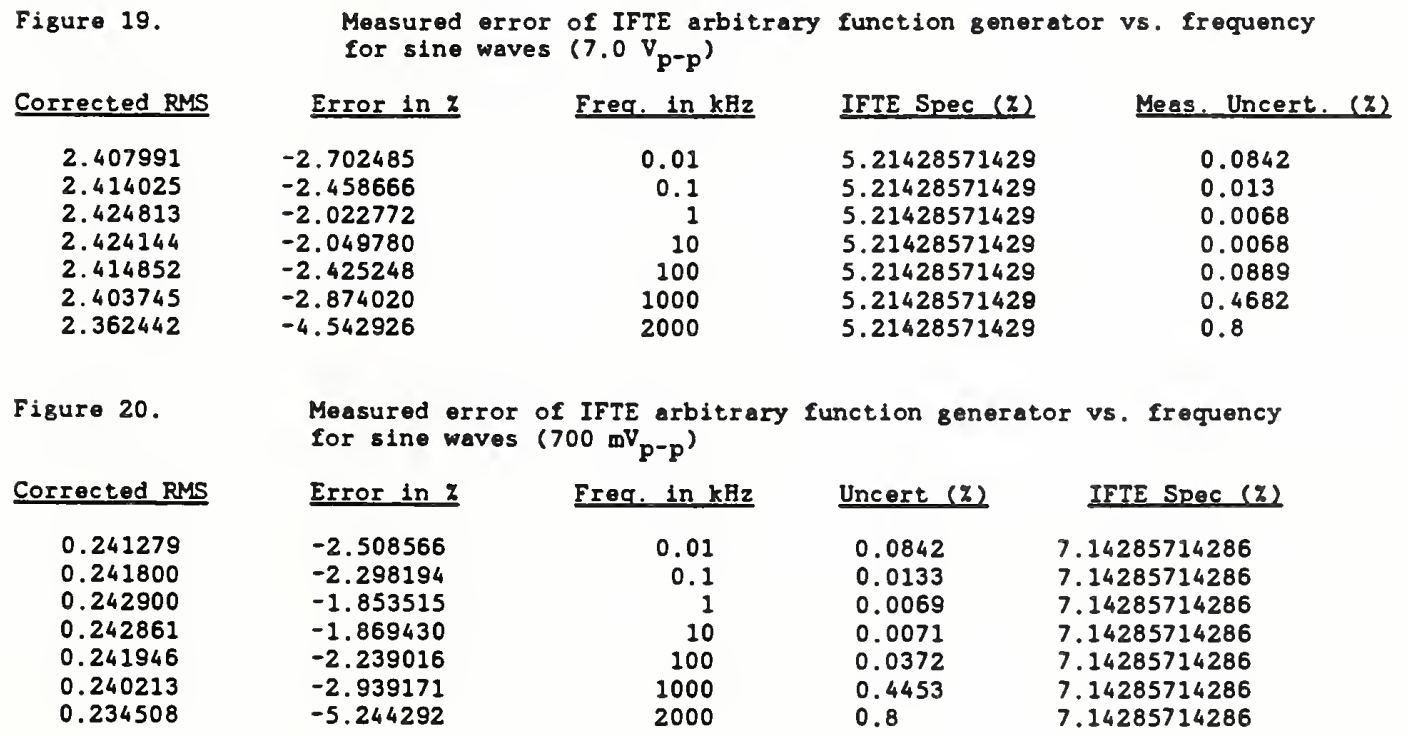

Figure 21.

\begin{tabular}{|c|c|}
\hline Corrected RMS & Error in 2 \\
\hline $\begin{array}{l}0.023105 \\
0.023160 \\
0.023265 \\
0.023271 \\
0.023178 \\
0.022475 \\
0.022290\end{array}$ & $\begin{array}{l}-6.640574 \\
-6.418411 \\
-5.994019 \\
-5.969521 \\
-6.345926 \\
-8.186765 \\
-8.932880\end{array}$ \\
\hline
\end{tabular}

Measured error of IFTE arbitrary function generator vs. frequency for sine waves $\left(70 \mathrm{mv}_{\mathrm{p}-\mathrm{p}}\right)$

Frea. in $\mathrm{kH}$

0.01
0.1
1
10
100
1000
2000

IFTE Spec ( $(z)$

26.4285714286 26.4285714286 26.4285714286 26.4285714286 26.4285714286 26.4285714286 26.4285714286
Meas. Uncert (z)

$$
\begin{aligned}
& 0.0057 \\
& 0.005 \\
& 0.003 \\
& 0.0042 \\
& 0.017 \\
& 0.4327 \\
& 0.7
\end{aligned}
$$


Figure 22.

Corrected RMS

0.197205

0.197658

0.198539

0.198499

0.197879

0.191658

Figure 23.

Corrected RMS

0.018902

0.018944

0.019030

0.019040

0.018963

0.018417
Measured error of IFTE arbitrary function generator vs. frequency for triangle waves $\left(700 \mathrm{mV}_{\mathrm{p}-\mathrm{p}}\right.$ )

Error in $\%$

Freq. in $\mathrm{kHz}$

IFTE Spec ( $($ )

Meas. Uncert. ( $(x)$

$-2.408643$

$-2.184559$

$-1.748783$

$-1.768572$

$-2.075317$

0.01
0.1
1
10
100
1000

8.14285714286

8.14285714286

8.14285714286

8.14285714286

8.14285714286

8.14285714286

0.2684

0.1266

0.1138

0.1142

0.1744

0.9906

Measured error of IFTE arbitrary function generator vs. frequency for triangle waves (70 $\mathrm{mV} p-p)$

Error in 7

$-6.460351$

$-6.251862$

$-5.823491$

$-5.778058$

$-6.157101$

$-8.861960$
Frea. in $\mathrm{kHz}$

0.01

0.1

10

100

100
1000
IFTE Spec ( $(\boldsymbol{z}$

27.4285714286

27.4285714286

27.4285714286

27.4285714286

27.4285714286

27.4285714286
Meas. Uncert. (z)
0.2114
0.21
0.206
0.2084
0.234
1.0654 
Appendix E

Specification Sheets 


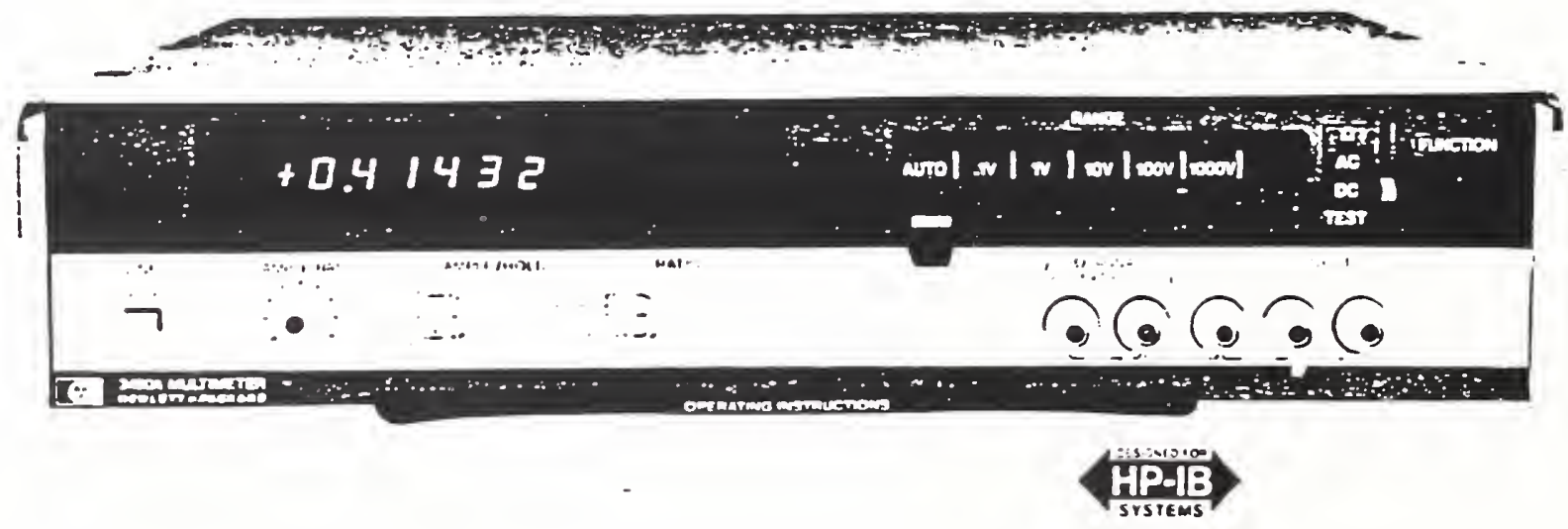

\section{Description}

Hewlett-Packard's Model $3490 \mathrm{~A}$ Multimeter is a five-digit inte. grating digital voltmeter. The basic instrument measures de voltages. ac voltages. and resistances. Additional measurement capability is achieved by the addition of low cost options.

HP's $3490 \wedge$ uses a dual slope integrating technique and is fully guarded, providing excellent noise immunity at five readings per sec. ond on all de ranges. Ranging is automatic over all ranges on all fune. tions. DC measurements can be made with I $\mathrm{V}$ resolution on the 100 $m V$ range. AC voltage measurements can be made from $20 \mathrm{~Hz} 10250$ $k \mathrm{~Hz}$ in four ranges. The I $\mathrm{V}$ range provides $10 \mu \mathrm{V}$ of ac voltage resolu. rion. Resistance measurements are made with the 4-wire conversion technique. eliminating errors caused by test lead resistances. Six ranges. including the 1002 range, are provided in the ohms functions.

\section{Self-Test}

At the flip of a switch. Hewlett-Packard's 3490^ Digital Multimeter sequences itself through 10 tests that check timing signals and autoranging circuits validate the performance of most logic-sircuit IC's and check the six-digit LED display. These tests, and six others provided by six additional front-panel switches. cut calibration costs and ensure the DMM is ready to make accurate measurements.

\section{Functions}

The standard 3490 A includes five ranges of $\mathrm{dc}$ measurement capa. bility from $100 \mathrm{mV}$ to $1000 \mathrm{~V}$. Measurements are made from the front panel at precise five readings/s, and at slower rates. using digitally controlled sampled rate selector. High input resistance. $>10^{\prime} \%$ on $100 \mathrm{mV} .1 \mathrm{~V}$. and $10 \mathrm{~V}$ range. assures accurate measurement of high impedance sources.

\section{AC Functions}

Four ranges of ac measurements are provided. The average ac value is accurately detected. and the rms value is displayed with five digits of resolution. Full autoranging. wide frequency response, and 20\% overranging are designed-in features to permit easy operation.

\section{Ohms}

Six ohms ranges are standard, and all ranges provide true four-wire ohms measurement capability. Maximum current through the unknown is approximately I mA. Over-voltage protection for ohms sensing terminals insures maximum protection against inadvertent application of a high voltage to ohms terminals. Over-voltage protection is provided to $250 \mathrm{~V}$ and fuse protection to $1000 \mathrm{~V}$.

HP's $3490 \mathrm{~A}$ has been "designed for servicability." Inside. the $3490^{\circ}$ s low parts density provides easy access for servicing. Test points and jumpers are keyed to detailed diagnusticx.

Additional diagnusitic and service aids are: Service Vidico Tape

IC Reference Baurds for use with

the HP 10529^ Logic Comparator

Spare Parts Sct
$11128 . A$

11126.1

11127,1

\section{Specifications}

\section{Voltage Ranges}

Full range display: $\pm .100000 \mathrm{v} . \pm 1.00000 \mathrm{~V}, \pm 10.0000 \mathrm{v}$. $\pm 100.000 \mathrm{v} . \pm 1000.00 \mathrm{v}$

Overrange: $20 \%$. on all panges except $1000 \mathrm{~V}$ ranfic.

Range selection: manual. automatic. or remote (optional).

DC Voltage Performance

Accuracy $\pm(x$, of reading $+\approx$ of range $)$

\begin{tabular}{|c|c|c|c|}
\hline & & O.1 VRonge & I V to 1000 V Ronge \\
\hline $\begin{array}{l}24 \text { ws } \\
30 \text { ans } \\
90 \text { dyss } \\
6 \text { monits } \\
1 \text { yed }\end{array}$ & $\begin{array}{l}\left(23^{\circ} \mathrm{C}: 1^{\circ} \mathrm{C}\right) \\
\left(23^{\circ} \mathrm{C}: 5^{\circ} \mathrm{C}\right) \\
\left(23^{\circ} \mathrm{C}: 5^{\circ} \mathrm{C}\right) \\
\left(23^{\circ} \mathrm{C} \pm 5^{\circ} \mathrm{C}\right) \\
\left(23^{\circ} \mathrm{C}=5^{\circ} \mathrm{C}\right)\end{array}$ & $\begin{array}{l}6: 28 \\
=1000 j-20011 \\
=1001-0005) \\
=1001+i 005) \\
=(0013+0005) \\
=(0015+0005)\end{array}$ & $\begin{aligned} \text { qrds } & \text { Mrng } \\
= & 10001+000 ! \\
= & 10008+0002 . \\
= & 1001+000 \% \\
= & 10013+0002 . \\
= & (0015+0002 .\end{aligned}$ \\
\hline
\end{tabular}

Notos:

1. On the $1000 \mathrm{~V}$ range, add $0.04 \mathrm{ppm} /$ volt to the $\%$ of reading specification.

2. Thermal EMFs generated external to the DVM may be compensated to achieve the \% of range accuracy specified by utilizing the rear panel zero adjust provided in the $3490 \mathrm{~A}$.

OC voltage input characteristics: fully guarded with $140 \mathrm{~dB}$ ECMR at de and $60 \mathrm{~Hz} \pm 0.1 \%$ with I $\mathrm{k} \Omega$ imbalance between guard and low.

Maximum input voltage

$0.1 \vee$ to $1000 \vee$ renges: $\pm 1500 \vee$ peak.

Guard to chasels: $\pm 500 \mathrm{~V}$ peak.

Guard to low: $\pm 200 \mathrm{~V}$ peak.

input resistance

0.1 V to $10 \vee$ ranges: $>2 \times 10^{\mathrm{m} Q} \mathrm{Q}$. (<70\% R.H.).

$100 \mathrm{~V}$ and $1000 \mathrm{~V}$ ranges: $10 \mathrm{MQ} \pm 0.15 \%$.

Maximum reading rato: $S$ readings $/ s$.

Normal mode rejection ratio: $50 \mathrm{~Hz} \pm 0.1 \%$; $60 \mathrm{~Hz} \pm 0.1 \%$; $>50$ dB.

AC Voltage Ranges

Full range display: $1.00000 \mathrm{~V} .10 .0000 \mathrm{~V} .100 .000 \mathrm{~V}, 1000.00 \mathrm{~V}$. Overrange: $20 \%$ on all ranges except $1000 \mathrm{~V}$ range.

Range selection: manual, automatic, or remote (optional). 
DIGITAL VOLTMETERS

Five-digit digital multimeter with self-test

Model 3480A (cont).

AC Voltage Pertormance

Accuracy \pm ( $\%$ of reading $+\%$ of range)

\begin{tabular}{|c|c|c|c|c|}
\hline & & $2010-5016$ & $50 \mathrm{Nz}-100 \mathrm{uth}$ & $100 \mathrm{dth}-200 \mathrm{Ut}$ \\
\hline 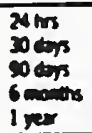 & $\begin{array}{l}\left(23^{\circ} \mathrm{C}+1^{\circ} \mathrm{C}\right) \\
\left(22^{\circ} \mathrm{C} \pm 5^{\circ} \mathrm{C}\right) \\
\left(23^{\circ} \mathrm{C} \pm 5^{\circ} \mathrm{C}\right) \\
\left(22^{\circ} \mathrm{C} \pm 5^{\circ} \mathrm{C}\right) \\
\left(23^{\circ} \mathrm{C} \pm 5^{\circ} \mathrm{C}\right)\end{array}$ & $\begin{array}{l} \pm(0.22+0.05) \\
2(0.5+0.05) \\
2(0.35+0.55) \\
=(0.0+0.05) \\
=(0.45+0.07)\end{array}$ & $\begin{array}{l} \pm(0.09+0.025) \\
\pm(0.1+0.025) \\
+(0.1+0.025) \\
\pm(0.1+0.03) \\
=(0.12+0.035)\end{array}$ & $\begin{array}{l} \pm(0.7+0.06) \\
\geq(0.75+0.06) \\
\pm(0.75+0.06) \\
=(0.75+0.07) \\
\pm(0.75+0.08)\end{array}$ \\
\hline
\end{tabular}

Notes:

1. Guard must be connected to low.

2. On the $1000 \vee$ range. add $0.01 \mathrm{ppm} /($ volt $-\mathrm{kHz})$.

3. Frequencies $>100 \mathrm{kHz}$ specified on $1 \mathrm{~V}$ and $10 \mathrm{~V}$ ranges only.

4. Specifications are for input levels above $1 / 100 t h$ of full scale.

AC Voltage Input Impedance

Without rear torminale: $2 \mathrm{M} \Omega \pm 1 \%$ shunted by $<65 \mathrm{pF}$.

With rear torminale: $2 \mathrm{M} \Omega \pm 1 \%$ shunted by $<90 \% \mathrm{pF}$.

AC voltage maximum reading rato: 1 reading/s.

AC voltage respones Uma: $<$ I s to within rated accuracy for a step

input applied coincident with encoder trigger.

AC maximum input voltago: $1000 \mathrm{~V}$ rms: $\pm 1500 \mathrm{~V}$ peak.

\section{Ohms Ranges}

Full range display: $.100000 \mathrm{k} \Omega, 1.00000 \mathrm{k} \Omega, 10.0000 \mathrm{k} \Omega, 100.000$

$\mathrm{k} \Omega, 1000.00 \mathrm{k} \Omega, 10000.0 \mathrm{k} \Omega$.

Overrange: $20 \%$ on all ranges.

Range oelectlon: manual, automatic, or remote (optional).
Remote Control, Option 022

The remote control option uses a low true logic (BCD type) code. Required voltage levels for input signal and output signal levels are listed below.

BCD and Remote Torminals

\begin{tabular}{|c|c|c|}
\hline & Hogh Lend & Leolew \\
\hline $\begin{array}{l}\text { Oni houts } \\
\text { ons Outputs }\end{array}$ & $\begin{array}{c}+39 \mathrm{~V} \pm 1.5 \mathrm{~V} . \\
100 \mathrm{Amar} \\
+3.9 \mathrm{~V} \pm 15 \mathrm{~V} . \\
400 \mathrm{Amus}\end{array}$ & $\begin{array}{l}+0.3 \geq 0.3 \mathrm{v} . \\
2 \mathrm{mi} \text { max } \\
+0.3 \mathrm{v} \pm 0.3 \mathrm{v} . \\
15 \mathrm{mi} \text { max }\end{array}$ \\
\hline
\end{tabular}

Operating temperature: $0^{\circ} \mathrm{C}$ to $50^{\circ} \mathrm{C}$.

Warm-up time: one hour warm-up required to meet all specifications on the $0.1 \mathrm{~V}$ range and the $0.1 \mathrm{k} \Omega$ range. Thirty minutes warm-up required to meet all other specifications.

Humldity range: $<95 \%$ R.H.. $0^{\circ} \mathrm{C}$ to $40^{\circ} \mathrm{C}$.

\section{Ohms Performance}

Accuracy: \pm ( $\%$ of reading $+\%$ of range)

Note: Thermal EMFs generated external to the DVM may be compensated to achieve the fi of range accuracy specified by utilizing the rear panel zero adjust provided in HP's 3490A.

\begin{tabular}{|c|c|c|c|c|c|}
\hline & & 0.160 & $10-100 \leqslant 1$ & $1000 \mathrm{EI}$ & 10,000 to \\
\hline $\begin{array}{l}24 \mathrm{~ms} \\
30 \mathrm{des} \\
90 \mathrm{ders} \\
6 \text { momens } \\
1 \text { yed }\end{array}$ & $\begin{array}{l}\left(23^{\circ} \mathrm{C}=1^{\circ} \mathrm{C}\right) \\
\left(23^{\circ} \mathrm{C}=5^{\circ} \mathrm{C}\right) \\
\left(23^{\circ} \mathrm{C}=5{ }^{\circ} \mathrm{C}\right) \\
\left(23^{\circ} \mathrm{C}=5^{\circ} \mathrm{C}\right) \\
\left(23^{\circ} \mathrm{C}=5^{\circ} \mathrm{C}\right)\end{array}$ & $\begin{array}{l}\text { wr. } \\
=(0.005+0.001) \\
=(0.012+0.005) \\
=(0.012+0.005) \\
=(0.015+0.055) \\
=(0.018+0.005)\end{array}$ & 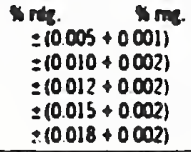 & $\begin{array}{l}\text { nis. } \\
=(0.007+0.001) \\
=(0.012+0.002) \\
=(0.015+0.002) \\
=(0.020+0.002) \\
\pm(0.025+0.002)\end{array}$ & 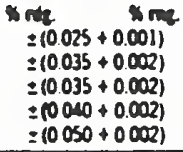 \\
\hline
\end{tabular}

Ohms Torminal Characteristics

Maximum voltage generated acrose unknown: 20 V for overtoad: $13 \mathrm{~V}$ for valid reading.

Ohms current thru unknown

- $0.1 \mathrm{~kg}$ to $10 \mathrm{kQ}$ range: $1 \mathrm{~mA}$.

$100 \mathrm{ks}$ to $1000 \mathrm{~kg}$ range: $10 \mathrm{wA}$.

$10,000 \mathrm{kn}$ range: $1 \mathrm{MA}$.

Othme overloed protectlon

Mondestruetive: $250 \mathrm{~V}$ rms.

Fuse destructive: $\pm 1000 \mathrm{~V}$ peak.

Ohme maximum reading rate

$0.1 \mathrm{kQ}$ to $100 \mathrm{k} \Omega$ rangs: 5 reading/s.

$1000 \mathrm{~kL}$ range: 4 reading/s.

$10,000 \mathrm{kd}$ rango: 2 reading/s.

\section{General}

Data Output (BCD), Option 021

Data output is 1-2-4-8 TTL output which is complible with HP SOSOB, and SOSSA Digital Recorders. Either bigh true or low arue logic code can be selected with an interasl switch.

storage temperature: $-40^{\circ} \mathrm{C}$ to $+75^{\circ} \mathrm{C}$.
Power: $100 \mathrm{~V}, 120 \mathrm{~V}, 220 \mathrm{~V}, 240 \mathrm{~V}+5 \%,-10 \%, 48 \mathrm{~Hz} 10400 \mathrm{~Hz}$ line operation $\leq 60 \mathrm{VA}$ with all options.

Sizo: $85.7 \mathrm{~mm} \mathrm{H} \times 425.4 \mathrm{~mm} W \times 466.7 \mathrm{~mm} \mathrm{D}\left(3.4^{\circ} \times 16.75^{\circ} \times\right.$ 18.4\%).

Weloht: acl, $9.38 \mathrm{~kg}$ (20.7 lb). Shipping, $11.79 \mathrm{~kg}$ (26 Jb).

Options

Price

020: BCD/remote expand, includes reas termianis in 5325

parallel

021: BCD - full parallel, 1-2-4-8 code

022: Remote - full pariltel, $1.24-8$ code

030: HP-IB remote control and data output. For cables see page 3.10.

040: Sample-and-bold"

045: Sample-and-hold (without Opt 020 or 030)

050 or 060: $50 \mathrm{~Hz}$ or $60 \mathrm{~Hz}$ operation

080. Threc-wire ratio

cos: Rack mounting kit

$\$ 1100$

5570

$\$ 700$

$\mathrm{N} / \mathrm{C}$

5245

525

3490A Digital Multimeter (includes ac, dc. \& $\$ 3100$ ohrns)

Opt 0s0: Noise Rejection for $\mathrm{SO} \mathrm{Hz}_{2}$

Opt 060: Noise Rejection for $60 \mathrm{~Hz}$

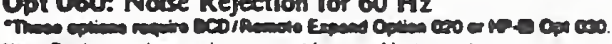

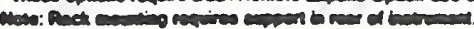

$N / C$

$N / C$ 


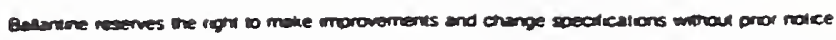

INPUT

Frequency Range: $\pm d c$. $10 \mathrm{~Hz}$ to $100 \mathrm{MHz}$; usable from under $5 \mathrm{~Hz}$ to gver $250 \mathrm{MHz}$

Voltage ranges $\leqslant d c$ and ac ms (overrange $+10 \%$, underrange $-10 \%$; $225 \mathrm{mV} \min .1100 \vee \max$.)

LOW VOLTAGE INPUT

0.25 to $0.5(10 \mathrm{~Hz}$ to $100 \mathrm{MHz})$

0.50 to $1.0(10 \mathrm{~Hz}$ to $100 \mathrm{MHz})$

$1102 \quad(10 \mathrm{~Hz}$ to $100 \mathrm{MHz})$

2 10 $4 \quad(10 \mathrm{~Hz}$ to $100 \mathrm{MHz})$

$4108 \quad(10 \mathrm{~Hz}$ 10 $30 \mathrm{MHz})$

8 to $16 \quad(10 \mathrm{~Hz}$ to $30 \mathrm{MHz})$

16 to $32 \quad(10 \mathrm{~Hz}$ to $1 \mathrm{MHz})$

Crest Fector. 100.1 of full range: $\pm 450 \mathrm{~V}$ pk max. on Low Vatage Input. $\pm 1500 \mathrm{~V}$ pk max on High Vortage input.

input overload futly protected at all frequencies to $10 \times$ range to $1100 \mathrm{~V}$ $\pm(d c+a c$ ms sinusoidal) applied continuoust). overload puts unit in standby mode, which discomnects input signal from themo-element until overload is removed.

inpert impedancer 200 OnmsNoht

Input kolation connectors may be floated $\pm 25 \mathrm{~V}$ relerenced to case ground

OPERATING MODES

Menual balances Operator manuathy null balances the transfer standard in either the normal ac input to dc outout mode or the inverse dc to ac transfer to permit setting input ac signal to a precise de level

Automatic balance: ac to de transier performed onty after inout signal ms amplitude drift is verified as less than the following: AUTO HI AOCURACY mode - 10 ppm within $10 \mathrm{~s}$ AUTO NORM mode -20 ppm within $5 \mathrm{~s}$ AUTO FAST mode - 40 pom within $5 \mathrm{~s}$

Manual transfer. balanoe is automatic in the ac input mode, but operator initiates transfer to de output based on null meter reading

Auto-Recycle repeats transfer measurement cycle approximately 15 s ater each outout READ command Auto-fecycle is an auto-zero mode, which avoids errors due to thermal dritt

DC output intemally generated dC +0.225 to $1100 \mathrm{~V}(10$ Megohms load) and everaged by external voltmeter for 10 seconds following the READ command: ripple and noise $95 \mathrm{~dB}$ below dc output amplitude or $100 \mathrm{mV}$, whichever is greater, maximum outpun current $2 \mathrm{~mA}$

READ command sent over IEEE488 bus to trigger extemal voltmeter to read transferred dc output after transfer standard dc output has settled; front panei READ light indicates command

interface bus; IEEE488-1978

Functions - SH1, AH1, T10, LEO, T5, L4, SR1, PPO, RL1, DC1, DTO, $\infty$

Bus Controls - Range (12). Balance Mode (5), Operate. Standby Recycle (3). Measure input, Measure Output

sotation - oploisolated from measuring circuits: bus digital ground connected to case

\section{TRANSFER UNCERTAINTY}

\begin{tabular}{|c|c|c|c|c|c|c|c|c|c|}
\hline \multirow[t]{2}{*}{$\begin{array}{l}\text { VOLTAGE } \\
\text { RANGE }\end{array}$} & \multirow{2}{*}{$\begin{array}{l}\text { TRANSFER ERROR } \\
\pm(\% \text { FS }+\mu V)\end{array}$} & \multicolumn{8}{|c|}{$\begin{array}{l}\text { ERROR LIMTTS AS } \pm \text { PERCENT OF DC OUTPUT } \\
\text { (with acidc correction factors applied) }\end{array}$} \\
\hline & & $\begin{array}{l}10 \mathrm{~Hz} \text { to } \\
20 \mathrm{~Hz}\end{array}$ & $\begin{array}{l}20 \mathrm{~Hz} \\
20 \mathrm{kHz}\end{array}$ & $\begin{array}{l}20 \mathrm{kHz} \text { to } \\
50 \mathrm{kHz}\end{array}$ & $\begin{array}{l}50 \mathrm{kHz} 10 \\
100 \mathrm{kHz}\end{array}$ & $\begin{array}{l}100 \mathrm{kHz} \text { to } \\
1 \mathrm{MHz}\end{array}$ & $\begin{array}{l}1 \mathrm{MHz} \text { to } \\
10 \mathrm{MHz}\end{array}$ & $\begin{array}{c}10 \mathrm{MHz} \text { to } \\
30 \mathrm{MHz}\end{array}$ & $\begin{array}{l}30 \mathrm{MHz} \text { to } \\
100 \mathrm{MHz}\end{array}$ \\
\hline $0.25-0.5$ & $.002+10 \% V$ & 0.14 & 0.003 & 0.004 & 0.008 & 0.025 & 0.2 & 0.5 & 2.8 \\
\hline $0.5-1$ & $.0017+10 \mathrm{~V}$ & 0.013 & 0.0025 & 0.0035 & 0.007 & 0.022 & 0.18 & 0.45 & 1.5 \\
\hline $1-2$ & $.0016+10 \mathrm{VV}$ & 0.013 & 0.0023 & 0.0035 & 0.007 & 0.022 & 0.18 & 0.45 & 1.5 \\
\hline $2-4$ & $.0016+10, V$ & 0.013 & 0.0023 & 0.0035 & 0.007 & 0.022 & 0.18 & 0.45 & 2.0 \\
\hline $4-8$ & $.0016+10, v$ & 0.013 & 0.002 & 0.003 & 0.007 & 0.022 & 0.18 & 0.5 & - \\
\hline $8-16$ & $.0015+15, V$ & 0.013 & 0.002 & 0.003 & 0.007 & 0.022 & 0.2 & 0.5 & - \\
\hline $16-32$ & $.0015+15 \mu v$ & 0.013 & 0.002 & 0.003 & 0.007 & 0.025 & - & 一 & - \\
\hline $32-64$ & $.0015+200 x V$ & 0.013 & 0.003 & 0.004 & 0.007 & 0.025 & - & 一 & - \\
\hline $64-125$ & $.0015+200 \mu v$ & 0.015 & 0.003 & 0.0045 & 0.01 & 0.025 & - & - & - \\
\hline $125-250$ & $.0016+200 \mu v$ & 一 & 0.003 & 0.0045 & 0.01 & - & - & - & $一$ \\
\hline $250-500$ & $.0017+200 \mu V$ & 一 & 0.004 & 0.005 & 0.01 & 一 & 一 & 一 & 一 \\
\hline $500-1000$ & $.002+3004 V$ & - & 0.005 & 0.005 & 0.015 & - & - & - & - \\
\hline
\end{tabular}

- Nil ranges are calorated retotive to $1 \mathrm{kHz}$ using Ballantine's calbotion standards, which are traceable to NBS. The de trenster outout votage is measured with a hoth resolution DVM. whose dc uncertamties are atgebraically additive as are the NBS standard uncertainties. The oc outpul is averaged lor 10 s aher the READ command over successive ac to do transter maserements. Al moasurements are mede at the center of the $16056 \mathrm{~A}$ Tee. mounted at the inpul connoctor.

ACDC difference correction tectors are upplied by Ballantine for trequencies and amplitudes

For 1 year accuracy. add the lollowng $\%$ of dc output.

$10 \mathrm{~Hz} 1020 \mathrm{kHz}-\quad \pm 0.001 \% \quad 1 \mathrm{MHz} 1010 \mathrm{MHz}-\quad \pm 0.015 \%$

$20 \mathrm{kHz} 10100 \mathrm{kHz}-\quad \pm 0.0025 \% \quad 10 \mathrm{MHz} 1030 \mathrm{MHz}- \pm 0.15 \%$

$100 \mathrm{kHz} 101 \mathrm{MHz}-\quad \pm 0.005 \% \quad 30 \mathrm{MHz} 10100 \mathrm{MHz}- \pm 0.35 \%$

Applies bor $20^{\circ} \mathrm{C} \pm 5^{\circ} \mathrm{C}, 90 \%$ R.H. De oripur readings are averaged over $10 \mathrm{~s}$. specilied at cemer of 16056A 5-pon Tee Connector. DC bo dc iranster centives the instrument lor all systematic errors by establisting diflerence between inpul and

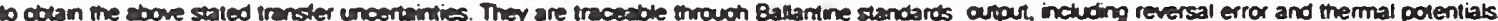
and are typicaly 3 times the above apecified addc transter scouracies. The uncertaimies of the National Standards $L$. mus be added abebrucally so obtain bsolute sccaracies.

Emironmomtat Complies with MIL-T.28800. Cass 5 tor shock, viration, transit droo, humidity to $90 \%$ R.H. nomcondensing: ternperature 0 to $+50^{\circ} \mathrm{C}$ operating $\left(+10^{\circ} \mathrm{C}\right.$ to $+40^{\circ} \mathrm{C}$ tull specifications) and $-40^{\circ} \mathrm{C}$ to $+75^{\circ} \mathrm{C}$ storage; attitude $3000 \mathrm{~m}$ operating with storage to $15,000 \mathrm{~m}$ tungus resistant: EMI protected

Pownr. 100, 120, 220 and 240 V ec, $+8 \%$ 10 $-10 \%$; 50 to $400 \mathrm{~Hz}, 80 \mathrm{VA}$ Dimentons:

Basic unit - $178 \mathrm{~mm} 77 \mathrm{H} \times 156 \mathrm{~mm}(16 \%$ ) W $\times 508 \mathrm{~mm}$ (20) D Enclasure - $203 \mathrm{~mm}$ (8) H $\times 521 \mathrm{~mm}(201 / 29 \mathrm{~W} \times 527 \mathrm{~mm}(203 / 9)$

Penel with $-483 \mathrm{~mm}$ (19)

Depth behind panet - $470 \mathrm{~mm}(18 \% \mathrm{~s})$

Welgitt $25 \mathrm{~kg}$ (56 los.); shipping weight $31.7 \mathrm{~kg}(70 \mathrm{lbs}$ )

ACCESSORIES SUPPUED.

Model 16056A Fivepon Tee Connector, AC power cable; Instruction manual

OPTION AVAILABLE:

Option 15 - rack mount with slides (bench enclosure not provided)

\section{ACCESSORIES AVAILABLE:}

Model 1620A 100 A ACDC Transconductance Amplifier Current Source

Model 1625A Active Shunt ACIDC 10 uA to 100 A

Model 6400A AC Voltage Standard

Model 120204 Type 874 to BNC fernale adapler

Model 160534 Transter Assembly

Model 16054A Maimtenance Accessony $\mathrm{KH}$

Model 16057A Sotware for computer-aided Calbration of 16058

Model $4052 \mathrm{H}$ System for entanced automated meter calbration

Model 4060H System for calbrating ac voltage calbrators

6911627-1A 16058 Spare Parts Kit - 2 years 


\section{2(D) Specifications}

\section{D Resistance Measuring System}

The limiting factors of any measurement are the accuracy. resolution and sensitivity of the measurement system. Thus, the goal of good design is to provide (1) an accuracy limited only by the state of the art, (2) resolution capable of taking full advantage of the accuracy, and (3) sensitivity sufficient to permit full use of the resolution. The graphs illustrate the performance capability of the Model 2420 Resistance Measuring System in terms of these essential design goals.

\section{Supplied with Model 242D}

- ESI Part Number 21806 Cabinet

- ESI Part Number 8306 KELVIN KLIPS ${ }^{\circ}$ Cable Set

- ESI Part Number 19125 Interconnection Kit

- ESI Part Number 19625 Instruction Manual

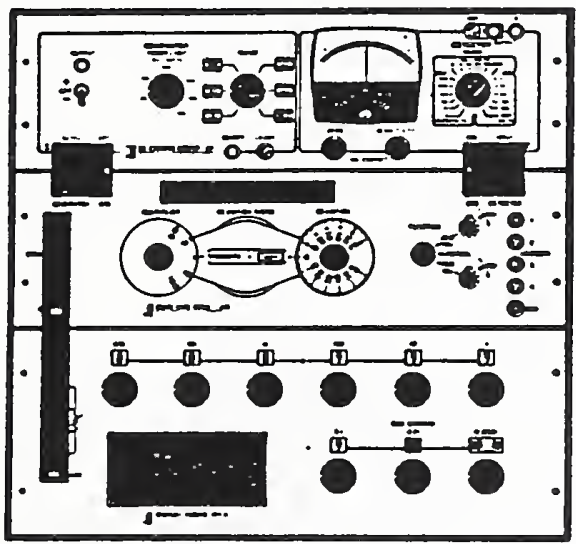

\begin{tabular}{lr} 
Dimensions: \\
\hline Width & $49.5 \mathrm{~cm}$ (19.5 inche \\
Height & $44.5 \mathrm{~cm}(17.5$ inche \\
Panel & $51.8 \mathrm{~cm}(20.4$ inche \\
Overall & $35.6 \mathrm{~cm}(14.0$ inche \\
Depth & $32 \mathrm{~kg}(70$ lb) ne \\
Weight & \\
\hline
\end{tabular}

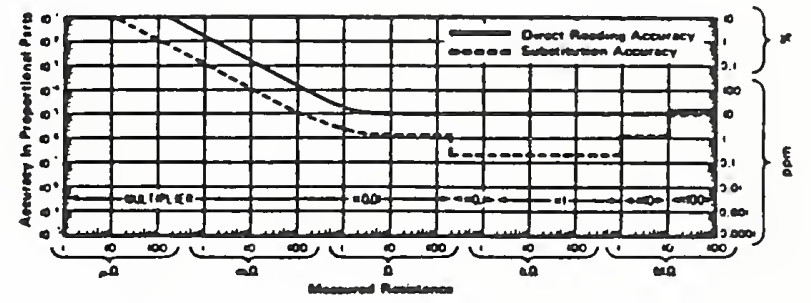

Bridge and Standard Accuracy

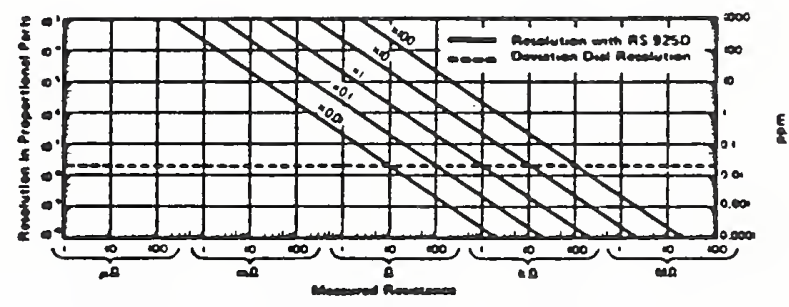

Bridge and Standard Resolution at Maximum Power

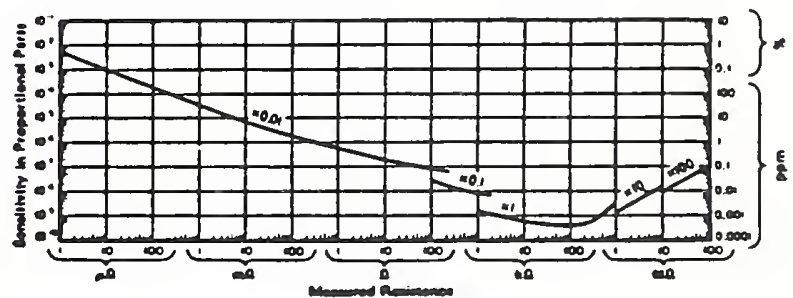

System Sensitivity 



\begin{tabular}{|c|c|c|}
\hline \multirow{4}{*}{$\begin{array}{l}\text { NIST-114A } \\
\text { (REV. 3-90) }\end{array}$} & \multirow{4}{*}{$\begin{array}{l}\text { U.S. DEPARTMENT OF COMMERCE } \\
\text { NATIONAL INSTITUTE OF STANDARDS AND TECHNOLOGY } \\
\text { BIBLIOGRAPHIC DATA SHEET }\end{array}$} & 1. PUBLCATION OR REPORT NUMBEA \\
\hline & & \begin{tabular}{|r} 
N I S T IR 4955 \\
2. PERFORMING ORGAMIZATION REPORT NUMBER
\end{tabular} \\
\hline & & \\
\hline & & 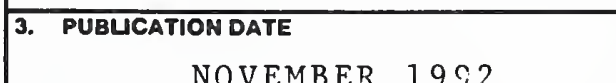 \\
\hline
\end{tabular}

Assessment of Proposed Calibration Support for the Analog Instrumentation Functions in the IFTE Test Systems

5. AUTHOR(S)

B. Bell, N. Oldham, and P. Hetrick

\begin{tabular}{|c|c|c|}
\hline 6. & PERFORMINO ORGANIZATION (IF JOINT OR OTHER THAN NIST, SEE INSTRUCTIONS) & \multirow[t]{2}{*}{ 7. CONTRACT/GRANT NUMBER } \\
\hline & \multirow{2}{*}{$\begin{array}{l}\text { U.S. DEPARTMENT OF COMMERCE } \\
\text { NATIONAL INSTITUTE OF STANDARDS AND TECHNOLOQY } \\
\text { OAITHERSBURG, MD } 20899\end{array}$} & \\
\hline & & 8. TYPE OF REPORT AND PERIOD COVERED \\
\hline
\end{tabular}

10. SUPPLEMENTARY NOTES

11. ABSTRACT (A 2OO-WORD OR LESS FACTUAL SUMMARY OF MOST SIONIFICANT INFORMATION. IF DOCUMENT INCLUDES A SIGNIFICANT BIBLOGRAPHY OA UTERATURE SURVEY, MENTION IT HERE.)

An assessment is made of the vendor's proposed calibration support for the dc and low frequency analog instrumentation functions in the Integrated Family of Test Equipment (IFTE) systems being procured by the U.S. Army. The report provides a detailed analysis of the calibration support scheme described in the vendor's proposed calibration/measurement requirements summary and related documents for the digital multimeter, counter-timer, high-speed digitizer, and arbitrary function generator instrument functions contained in the commercial equipment equivalent (CEE) version of IFTE test system. The results of onsite tests made on a CEE IFTE station (SN 017) located at Tobyhanna Army Depot

are also given in this report.

12. KEY WORDS (6 TO 12 ENTRIES; ALPHABETICAL ORDER; CAPITALZE ONLY PROPER NAMES; AND SEPARATE KEY WORDS BY SEMICOLONS) accuracy, calibration, measurement error, performance, self-alignment, software, specification, tolerance 


